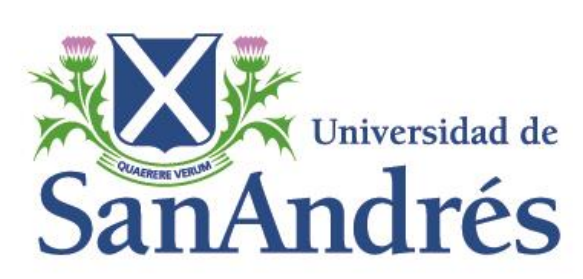

"Economic Policy Uncertainty and the Supply of Business Loans"

Por Santiago Barraza (Universidad de San Andrés) y Andrea Civelli (University of Arkansas).

D.T.: $\mathbf{N}^{\circ} 134$

Octubre 2019

Vito Dumas 284, B1644BID, Victoria, San Fernando, Buenos Aires, Argentina Teléfono 4725-7020, Fax 4725-7010

Email: economia@udesa.edu.ar 


\title{
Economic Policy Uncertainty and the Supply of Business Loans
}

\author{
Santiago Barraza and Andrea Civelli*
}

\begin{abstract}
Using a Vector Autoregressive framework of analysis, we show that banks contract their supply of business credit in response to an exogenous increase in economic policy uncertainty. This contraction takes two main, distinct forms. On the one hand, banks restrict their supply of spot funds, which we document using flows of loans and term loan originations. On the other, banks also curtail their provision of liquidity insurance, reducing the amount of new credit lines and embedding in them a pricing structure that reduces the probability of borrowers ever drawing down on the lines.
\end{abstract}

Keywords: economic policy uncertainty, bank lending, business, credit.

JEL Classification: D80, E66, G21, G28.

*Santiago Barraza: santiago.barraza@fulbrightmail.org, Universidad de San Andrés, Vito Dumas 284 (B1644BID), Victoria, Prov. Buenos Aires, Argentina. Andrea Civelli: andrea.civelli@gmail.com, University of Arkansas, Business Building 402, Fayetteville, AR 72701. URL: http://acivelli.hosted.uark.edu. We thank Fabiana Penas for invaluable discussions. We also thank Tommy Murphy, Martín Rossi, Daniel Heymann, and seminar participants at Universidad de San Andrés, Universidad de Buenos Aires, and Banco Central de la República Argentina for helpful comments and insights. We are grateful to Tim Yeager and the Arkansas Bankers Association Endowed Chair in Banking, who sponsored access to the Thomson Reuters LPC DealScan data. Lastly, we are indebted to William English at the Board of Governors of the Federal Reserve System, who kindly provided the data from the Survey of Terms of Business Lending, and to Thomas Allard, Sam Haltenhof, and Thomas Spiller for excellent technical assistance in relation to these data. Any remaining errors or omissions are our own. 


\section{Introduction}

"When confronted with uncertainty, especially Knightian uncertainty, human beings invariably attempt to disengage from medium to long-term commitments in favor of safety and liquidity."

- Alan Greenspan, Chairman of the Board of Governors ${ }^{1}$

Motivation and Research Questions. The last decade has seen a burgeoning interest in understanding the ways uncertainty affects the dynamics of the economy. As a result, the literature has identified several effects on the real and financial markets. This paper contributes to this literature by documenting a bank lending channel through which uncertainty about economic policy affects the business sector. Specifically, we show that increasing economic policy uncertainty leads to lower levels of bank lending to businesses, and this fall in lending is indeed partly driven by a contraction in the supply of credit.

"Uncertainty is an amorphous concept" (Bloom, 2014), and this has given rise to a number of related definitions and metrics over the years. Our focus here lies on economic policy uncertainty (EPU henceforth), which refers to unknown future paths of action to be taken by policy makers. In Baker, Bloom, and Davis (2016), EPU relates to decisions to be made by Congress, the White House, or the Federal Reserve, and it is primarily captured by the relative prevalence of EPU-related articles in the news media. ${ }^{2}$ In other studies, policy uncertainty can stem from specific events like the unknown outcome of gubernatorial elections, as it is the case in Jens (2017) and Falk and Shelton (2018). Almost invariably, the evidence ultimately suggests that heightened EPU leads to a fall in economic activity, which can translate into lower levels of employment, industrial production, or business investment. ${ }^{3}$

The contractionary effects that EPU has on the business sector invite questions about the role banks play in the transmission of uncertainty shocks. A first question is whether and how aggregate bank business lending responds to shocks to EPU. A second related question is whether any observed variation could be attributed to changes in the supply of credit. While answering the first question could be relatively straightforward, answering the second one is less so. On the one hand, financial theory suggests that banks would have incentives to preserve liquidity and curtail credit in response to increasing uncertainty (Caballero and Krishnamurhty, 2008). On the other, any fall in lending could be potentially attributed to a fall in the corporate demand for funds, as slowing business activity can reduce firms'

\footnotetext{
${ }^{1}$ Greenspan (2004).

${ }^{2}$ The metrics we use in this work come from Baker, Bloom, and Davis (2016). In Sections 2 and 3 we discuss this aspect at length.

${ }^{3}$ The literature has extensively documented the contractionary effects on the economy of a broader definition of uncertainty. A non-exhaustive list of works includes articles studying mainly the relation between uncertainty and economic activity, such as Bloom (2009); Bachmann, Elstner, and Sims (2013); Caldara, Fuentes-Albero, Gilchrist, and Zakrajsek (2016); Bloom, Floetotto, Jaimovich, Saporta-Eksten, and Terry (2018). Articles studying the impact of uncertainty on investment in particular, like Bernanke (1983); Leahy and Whited (1996); Bloom, Bond, and Reenen (2007); Baum, Caglayan, and Talavera (2008); Bloom (2009); Gilchrist, Sim, and Zakrajsek (2014); Bloom, Floetotto, Jaimovich, Saporta-Eksten, and Terry (2018); Smietanka, Bloom, and Mizen (2018). And works investigating the effect of uncertainty on employment, such as Bloom (2009); Caggiano, Castelnuovo, and Groshenny (2014); Leduc and Liu (2016); Schaal (2017); Bloom, Floetotto, Jaimovich, Saporta-Eksten, and Terry (2018).
} 
financial needs for different purposes, such as investment. Thus, properly identifying the role of banks in a change of credit volumes requires disentangling supply- from demand-side effects.

Empirical Strategy and Main Findings. Our empirical strategy relies on Vector Autoregressive (VAR) models and a recursive orthogonalization scheme that allow us to identify the EPU shock. Two main types of business lending data help us provide compelling answers to the preceding two questions and, at the same time, describe a rich mechanism behind the observed results. The first type of data represents flows of business loans from the Survey of Terms of Business Lending (STBL henceforth); the second type of data represents loan originations from Thomson Reuters LPC DealScan. In order to answer the first question, we study the response of the total flow of business loans disbursed by large domestic banks to EPU innovations, bearing in mind that these banks explain the bulk of total business lending. We find that, in response to an exogenous increase in EPU, aggregate business lending falls, reaching a trough after one year and taking up to four years to fully recover. Nonetheless, we note that this fall arguably reflects in part a weaker demand for funds that accompanies slowing activity and corporate investment in the wake of higher uncertainty.

Then, in order to answer the second question, we create a set of tests that jointly make evident that banks contract their supply of credit in response to an exogenous increase in EPU. In the first group of tests, we adopt the framework of analysis recently proposed by Barraza, Civelli, and Zaniboni (2019) and originally used for the identification of supply effects in bank business lending in response to monetary policy shocks. This approach focuses primarily on flows of loans and exploits the contractual differences between loans disbursed under commitment and spot loans. Under the key identifying assumption of uniform cyclical properties of the business demand for funds across bank loan types, the relative responses of loans disbursed under commitment and spot loans to EPU innovations can be used to infer changes in the supply of credit. ${ }^{4}$ This is due to the fact that, while banks can immediately adjust their supply of spot loans, they are contractually bound to provide liquidity on demand on open credit lines, regardless of their preference for liquidity at the time. The analysis reveals that, in response to a positive EPU shock, the flows of both loans extended under commitment and spot loans fall, yet the fall in the latter is about four times the fall in the former. A formal test using the ratio of loans disbursed under commitment to spot loans identifies the supply contraction that results from heightening EPU, which peaks about a year after the shock.

We corroborate the previous findings using originations of term loans in the syndicated loan market, which we obtain from DealScan. As term loans are primarily originated for immediate use, they compare well to the flows of spot loans reported in the STBL data set. DealScan offers the benefit of having a measure of loan spreads directly associated with the observed loan volumes. Thus, our attention here centers on the combined response of loan volumes and loan spreads to an EPU innovation. The results show that an exogenous increase in EPU leads to both a significant fall in term loan originations and a significant

\footnotetext{
${ }^{4}$ This identifying assumption is plausibly satisfied in the sample of large banks, which are mainly associated with large firms. Facing fewer financial constraints than small firms, large firms have fewer incentives to strategically manage their access to open credit lines. In Section 2.2, we discuss this assumption at length, including the related literature that substantiates it.
} 
increase in their spreads, clearly suggesting a new market equilibrium that entails a credit contraction. As before, the tightening effect peaks about a year after the shock.

Apart from providing spot liquidity, banks also provide liquidity insurance to firms. They do so primarily via credit lines, which grant firms access to liquidity on demand. In the last section of our analysis, we investigate banks' supply of liquidity insurance in response to EPU shocks. To this end, we use credit line originations from DealScan, focusing both on the volume of new credit lines and their associated costs. This analysis reveals two main effects of EPU on bank lending. First, in response to an exogenous increase in EPU, we observe a reduction in the volume of new credit lines accompanied by increasing costs of securing and maintaining those lines, from which we can infer banks curtail their supply of liquidity insurance. Second, the pricing structure on the new credit lines carries higher costs of drawdown with respect to the costs of securing and maintaining the lines. As Berg, Saunders, and Steffen (2016) have shown that such pricing structure is associated with lower probabilities of firms ever tapping the committed funds, our finding suggests yet another means by which banks can further slow down loan growth.

Altogether, our analysis depicts a rich mechanism through which banks respond to EPU innovations. On the one hand, they adjust immediately their supply of spot funds by contracting their supply of spot loans, which they can do without restrictions. On the other, they adjust also their supply of liquidity insurance, altering the terms of both current and future liquidity provision.

Implications. Our finding of a clear contraction in the supply of bank business lending in response to an increase in EPU is particularly relevant in light of recent research that studies the interaction between financial frictions and uncertainty, emphasizing the amplifying effects the financial system can have in the propagation of uncertainty shocks to the real economy. In the theoretical literature, Bonciani and van Roye (2015) propose a DSGE model with credit constrained entrepreneurs and frictions in the pass-through of the policy rate to the banking sector. They show that these frictions amplify the effects of uncertainty shocks on economic activity. Gilchrist, Sim, and Zakrajsek (2014) explain their empirical result of a contractionary effect of uncertainty on investment using a model that exploits the interaction between non-convex capital adjustment costs and credit market frictions, which induce credit supply contractions in response to uncertainty shocks. Arellano, Bai, and Kehoe (2016) develop a general equilibrium model with imperfect financial markets in which entrepreneurs cannot fully insure against the risk of time separation between hiring of inputs and production. In their model, higher uncertainty triggers an endogenous contraction of credit conditions. Similarly, Christiano, Motto, and Rostagno (2014) propose a model with heterogeneous probability of success for entrepreneurial activity and financial frictions due to agency problems. Changes in the dispersion of this idiosyncratic risk across firms have persistent effects on credit spreads, output, and investment. The model in Bianchi, Ilut, and Schneider (2017), instead, rely on ambiguity averse shareholders, adjustment costs, and an upward sloping marginal cost of the debt of firms to link uncertainty to the optimal capital structure of firms and shareholder payout. In their model, changes in uncertainty endogenously generate the comovement of stock prices, debt, and payout observed in the data. 
The modern empirical literature often relies on VAR models to study the effects of different types of uncertainty on macroeconomic outcomes. For instance, Baker, Bloom, and Davis (2016) use VAR models to assess the effects of shocks to their EPU measure on industrial production and employment. Gilchrist, Sim, and Zakrajsek (2014) use VAR models to gauge the effects on the economy of a financial measure of uncertainty based on firm stock returns volatility. Leduc and Liu (2016) define uncertainty shocks using the Michigan Survey of Consumers data to show, within a VAR framework of analysis, that uncertainty increases unemployment and lowers inflation. Caggiano, Castelnuovo, and Groshenny (2014) explore non-linear effects on the transmission of uncertainty in a smooth transition VAR and show that shocks to VIX, their proxy for uncertainty, have larger effects on unemployment during recessions. Bachmann, Elstner, and Sims (2013) use VAR models to compare the macroeconomic effects of uncertainty shocks based on business survey data for the U.S. and Germany, and document striking differences across countries.

Our paper shares the focus on credit markets and the provision of liquidity with the strand of literature that investigates the effects of uncertainty on financial aggregates in different empirical setups. For instance, Berger, Guedhami, Kim, and Li (2018) study the effect of EPU on bank liquidity creation. They show that higher EPU is associated with a decrease in asset-side and off-balance sheet liquidity creation. They further show that spreads on business loans increase with increases in EPU, which they interpret as a sign of a contraction in the supply of liquidity. Yet, while they provide this evidence on the intensive margin of business loans, they explicitly leave as an open question the relationship between the extensive margin on business loans and EPU. Here, we make a clear contribution in this regard, as our empirical design allows us to identify the responses of both the intensive and extensive margins of business loans to innovations in EPU. Thus, we can clearly identify the contraction in the supply of business loans in response to an exogenous increase in EPU. Moreover, our results also bring new insights on the role the pricing schedule of credit lines plays in curtailing the supply of loans beyond what is readily observable from the spread on drawn funds. Overall, our findings provide stronger support to the claim in Berger, Guedhami, Kim, and $\mathrm{Li}$ (2018) that a credit channel is at work in response to EPU shocks.

Alessandri and Bottero (2017) use loan application and rejection data from commercial banks in Italy between 2003 and 2012 to assess the effects of multiple measures of economic uncertainty on credit conditions. They find a substantial reduction in the acceptance probability of new credit applications and smaller responsiveness of banks to the short-term interest rate during periods of heightened uncertainty. This paper empirically documents the role of frictional capital markets in the transmission channel devising an identification strategy based on heterogeneous capitalization across lenders. In our work, we exploit frictions arising from contractual differences between spot loans and loans under commitment instead.

Lastly, Bordo, Duca, and Koch (2016) show that policy uncertainty is negatively related to the growth of different loan categories, including business loans; this is observable both at aggregate- and bank-level. They argue that slowing loan growth is attributable to both demand and supply factors, and in order to substantiate a role of supply they point to the significant effect bank financial constraints play in the response. Our work contributes to their early findings in a number of ways. First and foremost, we identify the causal effect of EPU on the supply of business loans, which is unfeasible in their empirical setup given the 
use of loan aggregates or stocks of loans. Loan aggregates and stocks of loans lump together the different effects of new loans, drawdowns from existing credit lines, loan repayments, and accruals of loan losses. This easily confounds the effects of demand and supply. Using flows of loans and loan originations instead, we overcome this issue. Second, by documenting the contractionary responses of loan terms to EPU shocks, we add new evidence to substantiate their claim that banks adjust their supply of credit. ${ }^{5}$

The paper proceeds as follows. Section 2 introduces an overview of our empirical VAR model, estimation methodology and identification assumptions. Section 3 summarizes the characteristics of the business lending data and the EPU measures used in the analysis. Section 4 introduces the main findings of the paper. Section 5 discusses further insights and presents an extensive robustness analysis of the main results. Finally, Section 6 concludes.

\section{Empirical Methodology}

\subsection{Framework of Analysis}

In this work, we use a Bayesian VAR framework of analysis that relies on a recursive orthogonalization scheme to identify the EPU shock. In our setting, the economy is described by a vector of endogenous variables $Y_{t}$, whose reduced-form dynamics are modeled as a $p$ thorder VAR

$$
Y_{t}=\sum_{i=1}^{p} B_{i} Y_{t-i}+\varepsilon_{t}
$$

where $B_{i}$ is a matrix of parameters and the VAR residuals $\varepsilon_{t}$ follow a distribution $\varepsilon_{t} \sim$ $\mathcal{N}\left(0, \Sigma_{\varepsilon}\right)$ such that $\mathbb{E}\left(\varepsilon_{t} \varepsilon_{t}^{\prime}\right)=\Sigma_{\varepsilon}$ and $\mathbb{E}\left(\varepsilon_{t} \varepsilon_{s}^{\prime}\right)=0 \forall t \neq s$.

In defining $Y_{t}$, we borrow from two main strands of literature. On the one hand, on the strand of literature that studies the interaction between monetary policy and the business lending sector (den Haan, Sumner, and Yamashiro, 2007; Barraza, Civelli, and Zaniboni, 2019). On the other hand, on the strand that uses VAR models to study the effects of uncertainty on the economy (Bachmann, Elstner, and Sims, 2013; Gilchrist, Sim, and Zakrajsek, 2014; Baker, Bloom, and Davis, 2016; Leduc and Liu, 2016). Thus, $Y_{t}$

\footnotetext{
${ }^{5}$ Papers that study the relationship between other macro, micro, and financial measures of uncertainty, but not economic policy uncertainty, and bank lending include Valencia (2017) and Buch, Buchholz, and Tonzer (2015). Using different types of data and methodologies, these papers find that uncertainty has detrimental effects on lending. Valencia (2017) documents higher uncertainty - measured by the dispersion of real GDP growth professional forecasts - reduces credit supply. Identification in a panel regression is achieved by exploiting variations in the capital-to-asset ratio across banks, and the effect is robust to using other uncertainty definitions. Similarly, Buch, Buchholz, and Tonzer (2015) rely on bank-level heterogeneity to identify the negative impact of uncertainty on bank lending. Their primary measure of uncertainty is the cross-sectional dispersion of shocks to bank-level variables, such as profitability and asset growth, but they also find similar results with more traditional uncertainty definitions. Following Berger, Guedhami, Kim, and Li (2018) and Bordo, Duca, and Koch (2016), our work continues the exploration of the nexus between uncertainty and bank lending focusing on economic policy uncertainty, an important type of uncertainty whose relation to bank lending has not been fully explored yet.
} 
is formed to include a block $X_{t}$ of variables that represent the real sector, a measure of economic policy uncertainty $e p u_{t}$, and a block $Z_{t}$ of monetary policy and financial variables, in that order:

$$
Y_{t}=\left[\begin{array}{c}
X_{t} \\
e p u_{t} \\
Z_{t}
\end{array}\right]
$$

More specifically, $X_{t}$ includes the log of the real gross domestic product (GDP), the $\log$ of the GDP price deflator, and the log of real gross private investment by domestic businesses; $e p u_{t}$ is the U.S. Baseline Overall EPU Index from Baker, Bloom, and Davis (2016), while the variables in $Z_{t}$ vary to address different purposes of analysis. In the first specifications, the financial block includes the $\mathrm{Wu}-\mathrm{Xia}$ shadow policy rate (Wu and Xia, 2016), the 10-year Baa-Treasury credit spread, and a measure of the flow of bank business lending from the Survey of Terms of Business Lending, alternatively considered in aggregate, separating loans extended under commitment from spot loans, or as a ratio between these two categories. ${ }^{6}$ In subsequent specifications, we replace the STBL loan data with series on term loan or credit line originations from DealScan, together with their corresponding spreads. In Section 2.2, we discuss in detail the purposes of these different models.

In order to identify the EPU shock, we follow a standard practice in the literature of monetary policy (see, for instance, Christiano, Eichenbaum, and Evans, 1999) and assume a linear relation between the reduced-form residuals $\varepsilon_{t}$ and the fundamental structural innovations of the model $u_{t}$. Thus,

$$
\varepsilon_{t}=A_{0} u_{t}
$$

where $\mathbb{E}\left(u_{t} u_{t}^{\prime}\right)=V$ is diagonal, implying that the structural shocks are orthogonal, and $V$ is normalized to represent unit-variance structural shocks. Moreover, $A_{0}$, the structural impact multiplier matrix, has a block-recursive structure and can be recovered as the lowertriangular Cholesky factor of $\Sigma_{\varepsilon}$.

It is also a well-established practice in empirical monetary VAR analysis (see, again, Christiano, Eichenbaum, and Evans, 1999) to identify monetary policy shocks by placing the monetary policy instrument between the real block $X_{t}$ and the financial block $Z_{t}$ within $Y_{t}$. This setting embodies the assumption that the Federal Reserve incorporates information on the current state of the real sector to form its policy decision, but information about the current state of the financial sector is not part of the decision process. At the same time, the financial sector is allowed to respond on impact to the policy innovation, while the real sector only responds with a lag. Our baseline identification strategy similarly pivots on the central position of $e p u_{t}$ within $Y_{t}$ and the block-recursive structure of $A_{0}$. Thus, our identification strategy boils down to assuming two main restrictions apply on the contemporaneous effects

\footnotetext{
${ }^{6} \mathrm{We}$ use the $\mathrm{Wu}$-Xia shadow rate as a measure of the true monetary policy stance. This rate is virtually the same as the Federal Funds rate throughout the sample period, except between the December 2008 and December 2015, when the Federal Funds rate remained at the zero lower bound. We leave for Section 5 a more thorough discussion of this issue.
} 
of the structural innovations in the model. First, eput is affected by the contemporaneous state of the real sector, $X_{t}$, but not by the contemporaneous state of the financial sector, $Z_{t}$. And, second, while the financial sector can respond on impact to an $e p u_{t}$ innovation, the real sector is assumed to respond with a lag. It is worth mentioning finally that, given the block-recursive structure of $A_{0}$, the impulse response functions corresponding to an EPU shock are invariant to the specific ordering of the variables within each of the blocks $X_{t}$ and $Z_{t}$.

The results we present in Section 4 correspond to $\operatorname{VAR}(2)$ models (i.e. $p=2$ ) estimated with Bayesian methods that incorporate Minnesota priors (Litterman, 1979, 1986; Doan, Litterman, and Sims, 1984). ${ }^{7}$ For this purpose, we use the econometric package developed by Dieppe, Legrand, and van Roye (2016). In Section 4 we use different specifications of $Z_{t}$, centering our attention on alternative measures of bank business lending that help us identify the transmission mechanism of economic policy uncertainty. In Section 5 we explore some further insights and run a host of robustness checks that span from the inclusion of additional variables to changes in the lag order to changes in the recursive ordering. The main estimation sample period is 1985:Q1-2017:Q1, which includes the Great Recession and the era of unconventional monetary policy that followed the 2007-2009 financial crisis. We address possible implications of this period for the transmission mechanism of EPU by adopting a shadow rate in our baseline specifications and considering alternative monetary policy rates and sample periods in Section 5. We discuss then these aspects in greater detail.

\subsection{Identification Strategy of Supply-Side Effects}

The empirical analysis of this paper investigates the response functions of bank business lending to structural innovations in EPU. Our main goal is to understand how the supply of credit responds to heightened policy uncertainty, which requires an identification strategy to disentangle supply-side from demand-side effects in the changes of the observed equilibrium of the business lending market. Our identification strategy comprises two main parts: one that relates to the supply of spot funds, and another that relates to the supply of liquidity insurance. The former is built around data both on flows of loans from the STBL data set and term loan originations from DealScan, while the latter is built entirely on data

\footnotetext{
${ }^{7}$ Bayesian estimation methods combine prior information on the distribution of the parameters of interest with the likelihood in the data to obtain posterior distributions of the parameters. These methods are particularly suitable to estimate models with a large number of parameters with respect to the amount of data available, as they help avoid overfitting of the data. In Bayesian VAR models, the two key blocks of parameters of interest are the coefficient matrix $B_{i}$ and the reduced-form error variance-covariance matrix $\Sigma_{\varepsilon}$. The Minnesota prior method assumes that $\Sigma_{\varepsilon}$ is known - in this study, it takes its value from its OLS counterpart - and that each endogenous variable has a unit root, which allows thinking the reduced-form VAR model as a multivariate random walk process. Thus, in defining the prior distribution of $B_{i}$, each endogenous variable is modeled to have a gaussian prior mean coefficient of one on its own first lag, and gaussian prior mean coefficients of zero on larger own lags and all cross-variable lags. Furthermore, the priors on the coefficient variances also reflect the belief that own lags are more informative than lagged values of the other variables in the model and that shorter lags are more informative than larger lags. As the method smoothly combines prior information with the likelihood in the data, the Minnesota prior method produces parsimonious models, characterized by analytically tractable, gaussian posterior distributions of the parameters. See Canova (2007) and Kilian and Lütkepohl (2017) for overviews of Bayesian VAR analysis.
} 
on credit line originations from DealScan. We discuss this strategy and the assumptions it relies on next.

Supply of Spot Funds. In Section 4.2, we adapt to our purposes the methodology proposed by Barraza, Civelli, and Zaniboni (2019) in a study of the transmission of monetary policy shocks through bank business lending. This part of the analysis focuses on the responses of flows of loans from the STBL data set to EPU innovations. In order to uncover supply-side effects, the approach exploits the relative differences in responses of loans disbursed under commitment and spot loans, and it relies on two key identification assumptions.

The first assumption relates to the recursive ordering to impose on the model variables to identify the structural EPU shocks. Our benchmark identification ordering reflects the underlying assumption that financial markets clear immediately after the observation of the macroeconomic conditions and any uncertainty in the policy stances, yet their feedback to the real sector and the policy-making process takes place with a lag. The rationale behind this choice parallels the one used in the monetary literature to identify monetary shocks by placing the policy instrument between the macro and the financial blocks of the model. Moreover, in choosing the baseline ordering, we also follow the intuition in Gilchrist, Sim, and Zakrajsek (2014), who present a VAR model with a real sector and a financial block which includes a credit spread and the Federal Funds rate, and place the uncertainty measure between the two blocks. Their measure of uncertainty captures common variations in volatility of daily firm stock returns, and their identification assumption hinges on the interaction between this form of uncertainty and credit spreads. By ordering the uncertainty measure before the credit spread, but after the real block, they assume that financial uncertainty is exogenous to movements in the spread, while responding on impact to the macroeconomic fundamentals.

In our baseline model, we add business loans to the credit spread and the policy rate in the financial block, and we focus on the effects of uncertainty arising from economic policy instead. However, we maintain the assumption that the policy-making process that determines policy uncertainty is endogenous to the macroeconomic block, thereby ensuring that the effects of the real sector are accounted for when we estimate the responses of the financial block to exogenous shocks to EPU. Hence, this identification scheme allows us to distinguish between unexpected innovations in policy uncertainty and news about expected future economic conditions already embedded in the contemporaneous shocks to output and inflation. Nevertheless, as noted by Baker, Bloom, and Davis (2016) and Stock and Watson (2012), identification in this context remains a difficult and open issue. Thus, while we deem our choice of the baseline recursive ordering plausible and appropriately grounded in the literature, in Section 5.2 we check the robustness of our results to the use of two alternative, opposite schemes, where we place EPU either first or last in the ordering structure.

EPU ordered first implies that uncertainty is the most exogenous variable in the model and it does not respond on impact to shocks to any other variables - neither from the real nor the financial block. At the same time, all the other variables can respond immediately to an uncertainty shock. The literature has relied on this assumption before. For instance, Leduc and Liu (2016) use this assumption in a model with a consumer uncertainty measure based on the Michigan Survey; Baker, Bloom, and Davis (2016) use it in a model with their U.S. Baseline Overall EPU Index; and Caggiano, Castelnuovo, and Groshenny (2014) employ it 
in a model where the VIX (volatility) Index from the Chicago Board Options Exchange is used as a proxy for uncertainty. ${ }^{8}$ This ordering is arguably better suited for data at monthly frequency, and it has a practical justification for survey-based consumer uncertainty measures in which the surveys run the month before new macroeconomic information is released.

These papers, however, also consider alternative Cholesky schemes in which uncertainty is placed after all the other variables in the model. In this case, movements due to past or contemporaneous shocks affecting the real or financial sectors are fully controlled for in measuring the uncertainty innovations. At the same time, the other variables in the model only respond to EPU shocks with a lag. This recursive ordering can be especially suitable in periods where the policy-making process promptly reacts to both economic and financial news. A case in point is the period comprising the Financial Crisis and the Great Recession, during which policy makers, including the monetary authority, reacted swiftly to news to prevent financial markets from freezing entirely. In such cases, the EPU measure could easily capture not only the effects of policy uncertainty, but also the effects of expected future credit market uncertainty, which in our model would be reflected by endogenous responses of business loans to future uncertainty in the financial sector. If this is the case, it becomes relevant to correctly account for these feedback elements in the identification of the structural economic policy uncertainty shock.

Once the structural EPU innovations are identified, the second key assumption of this identification approach relates more closely to the identification of the effect these shocks have on the supply of business loans. Again, following Barraza, Civelli, and Zaniboni (2019), we assume uniform cyclical properties of the business demand for funds across bank loan types. This assumption is meant to build on previous studies on the transmission mechanism of monetary policy that compare the responses of different financial aggregates to disentangle supply-side from demand-side effects in the credit markets. Some of these works include Kashyap, Stein, and Wilcox (1993), Sofianos, Melnik, and Wachtel (1990), and Morgan (1998).

The assumption allows us to exploit a key contractual difference between loans extended under commitment and spot loans reported in the STBL data set. Once a loan commitment is made, a bank is contractually bound to provide liquidity on demand on it while the agreement is in good standing, regardless of its preference for liquidity at the time. In general, this is always the case unless the borrower's conditions are such that it violates the material adverse change (MAC) clause in the contract. In contrast, at any time, a bank can freely decide whether to supply liquidity or not via new spot loans - at least, from a contractual standpoint. Then, given a change in conditions that could increase a bank's preference for liquidity, the bank could immediately adjust the origination of spot loans, but it would still have to provide liquidity on demand on open credit lines. Flows of spot loans should, therefore, more closely reflect banks' preferences for liquidity over time. Assuming that demand for both types of loans has uniform cyclical properties and comparing the relative responses of loans extended under commitment and spot loans to EPU shocks allows us to make inferences regarding the willingness of banks to supply spot funds in response to changes in uncertainty.

\footnotetext{
${ }^{8}$ All these papers consider small or mid-size VAR models, with slightly different variable choices that include both macroeconomic and financial variables, as in our model.
} 
We argue that the assumption of uniform cyclical properties of loan demand is plausibly satisfied in our setup as we limit the analysis to loans originated by large banks, which are generally associated with large firms (Berger, Miller, Petersen, Rajan, and Stein, 2005). Large firms face fewer financial constraints than smaller firms, and they can be relatively confident about their ability to secure funds in the future. Thus, if business opportunities warrant it, they can draw down on open credit lines or demand new spot loans as needed and maintain comparable demand for liquidity on both types of loans across the business cycle. Small firms, in contrast, conscious of possible frictions in securing funds in the future, might have incentives to strategically manage their access to open credit lines over the cycle. By restricting our comparison to banks within the same size category, we also follow an insight in Demiroglu, James, and Kizilaslan (2012), who show that controlling for firm characteristics is important in the identification of supply-side effects in the bank loan market. As this assumption is essential to our identification strategy of supply effects on spot funds, in Sections 4.2 and 5.2 we provide extensive evidence supporting both the assumption and the results we derive from it. And, for completeness, in Section 5.1 we also report an analysis for small banks, whose results suggest that small firms indeed display a different demand for funds.

In the first part of Section 4.2, we apply our identification approach to the STBL data to formally test the hypothesis that, as banks have motives to preserve liquidity when faced with increasing uncertainty, we should expect them to curtail the provision of spot funds in the wake of a positive EPU shock. In terms of business lending, this would translate into a slowdown in the flow of spot loans which exceeds the contraction in the corporate demand for funds. In comparison, the slowdown in the flow of loans extended under commitment should be at the same time less severe, as banks are constrained to fund open credit lines in good standing. Therefore, in order to identify the supply-side effect, we include the ratio of loans extended under commitment to spot loans in the $Z_{t}$ block of our VAR model. We interpret a positive response of this ratio, accompanied by a simultaneous increase in credit spreads, as an indication of a contraction in the supply of spot funds.

In the second part of Section 4.2 we turn our attention to originations of term loans in the syndicated loan market, which we obtain from DealScan. We use these originations to device a test whose results serve as an intuitive confirmation of the supply-side results based on the STBL data. As term loans are primarily originated for immediate use, they compare well to the flow of spot loans we observe in the STBL data set. However, the syndicated term loans in DealScan offer a clear advantage over the STBL data, as they carry an observable All-In Spread Drawn (AISD henceforth) at loan level. The AISD captures the cost of spot funds over the reference market rate, and this allows us to build consistent series of loan volumes and the associated cost of spot funds.

We then include these series in the $Z_{t}$ block of our VAR model in lieu of the STBL data and the market credit spread. The reasoning we employ here is straightforward: given an exogenous increase in EPU, a negative response of term loan originations combined with a positive response of the loan spreads indicate a new equilibrium in the loan market that must involve a prevailing contractionary supply shift. The only assumption required for this to hold is that the demand and supply functions are regularly shaped, with demand being a decreasing function of the loan spread and supply being an increasing function of it. 
Supply of Liquidity Insurance. In Section 4.3 we explore a further dimension of the banks' response to EPU innovations via business lending. Specifically, we study their provision of new liquidity insurance, which they primarily administer through credit lines. We propose and test two main hypotheses here. The first hypothesis is that, in response to an exogenous increase in EPU, banks curtail their supply of liquidity insurance, as their preference for liquidity increases and they become less willing to guarantee access to liquidity on demand.

To test this hypothesis, we consider a model in which the $Z_{t}$ block includes the volume of credit line originations in DealScan together with their average All-In Spread Undrawn (AISU henceforth) and their AISD, which respectively represent the cost of securing and maintaining a line and the cost of drawing down on a line. This model clearly parallels the one we use with syndicated term loans, with the only difference that it also includes the AISU, which constitutes a relevant cost for credit lines, but not for term loans. ${ }^{9}$ A negative response of credit line originations combined with a positive response of AISU would identify a new equilibrium resulting from a predominant contraction in the supply of new credit lines, under the same assumption of regularly shaped demand and supply schedules as for new term loans.

The second hypothesis we propose is that banks further tighten their provision of credit by imposing on new credit lines a pricing structure that reduces the probability of firms ever tapping the committed funds, therefore slowing down loan growth. This hypothesis relies on a finding in Berg, Saunders, and Steffen (2016) showing that firms securing credit lines with higher cost of drawdown with respect to the cost of securing and maintaining the lines are less likely to take down the committed funds. We first note that a necessary condition for the mechanism to be discernible in our setting would involve a positive response of AISD to higher uncertainty. We can readily check the fulfillment of this condition using the previous model, where we also control for the movements of new credit lines and AISU. We then formally test the hypothesis with a model that includes the ratio of AISD to AISU along with the volume of credit line originations in the $Z_{t}$ block. A positive response of this ratio combined with a negative response of the credit line volumes would reveal that banks exploit this additional mechanism to conduct a credit tightening.

\section{Data}

We turn now to a more detailed discussion of our data. We distinguish four main groups of data: data that relate specifically to the measurement of economic policy uncertainty, data on flows of business loans from the Survey of Terms of Business Lending, data on loan originations from Thomson Reuters DealScan, and, lastly, the macroeconomic data that are standard in this strand of literature. We discuss them in that order.

EPU data. Our benchmark measure of economic policy uncertainty is the U.S. Baseline Overall EPU Index from Baker, Bloom, and Davis (2016) and in a robustness test we use the U.S. News-Based Policy Uncertainty Index, which is the main component of the former

\footnotetext{
${ }^{9}$ AISU and AISD spreads are discussed in greater detail in Section 3.
} 
index. In what follows, we use the term EPU to refer to the former and the term EPU News to refer to the latter. ${ }^{10} \mathrm{EPU}$ is the weighted-average of four measures, with EPU News accounting for half the weight of EPU. The remaining three components of EPU are the Tax Expiration Index, the CPI Forecast Disagreement Measure, and the Federal/State/Local Purchases Disagreement Measure, which are all equally-weighted. While we refer the reader to Baker, Bloom, and Davis (2016) for a thorough discussion on the methodological aspects behind the construction of these measures, we summarize here key aspects that are essential to our identification strategy and the interpretation of our results.

EPU News compiles search results among news articles published in ten major newspapers in the U.S. ${ }^{11}$ This metric is designed to reflect the relative prevalence of articles that are indicative of economic policy uncertainty. A given article is deemed to signal economic policy uncertainty if it contains at least one term from each one of the following three sets of terms: (i) "uncertainty" or "uncertain"; (ii) "economic" or "economy"; (iii) "Congress", "legislation", "White House", "regulation", "Federal Reserve", or "deficit". The Tax Expiration Index compiles every year temporary federal tax code provisions from the Congressional Budget Office and reflects provision expirations that can create uncertainty in the business environment. The CPI Forecast Disagreement and the Federal/State/Local Purchases Disagreement measures rely on data from the Survey of Professional Forecasters run by the Federal Reserve Bank of Philadelphia. Both measures reflect, at a quarterly frequency, the dispersion of forecasts among professional forecasters, which is indicative of uncertainty about the future state of the economy. In so doing, these metrics follow a well-established practice in the literature that uses forecast disagreements as proxies for uncertainty - see Bloom (2014) for a discussion and Bachmann, Elstner, and Sims (2013) for an example. As can be expected from the weights used in its construction, EPU News is the true driver of EPU, and this is readily apparent from the plot of both series we report in Figure 1.

STBL data. Our data on flows of bank loans to businesses come from the Survey of Terms of Business Lending. Between 1977 and 2017 the Board of Governors of the Federal Reserve System ran this quarterly survey among roughly 350 banks. The survey responses are reweighted and aggregated to represent the population of banks and the Board publishes the main results through the E.2 Release. The most recent portion of the historical data is publicly available through the Board's website. In this work, nonetheless, we also use the earlier part of the data kindly made available to us by the Board upon request. We are particularly interested in the series of business loans that partition the amounts of loans disbursed by large and small domestic banks via two different types of contractual agreements, namely loans disbursed under commitment and spot loans - which are not part of commitments. ${ }^{12,13}$ These series represent "gross loan extensions made during the first full week in

\footnotetext{
${ }^{10}$ In Section 5.2 we also use two variations of the EPU News index meant capture monetary policy uncertainty and fiscal policy uncertainty. We defer to that section the corresponding discussion.

${ }^{11}$ The newspapers are the Boston Globe, the Chicago Tribune, the Dallas Morning News, the Houston Chronicle, the Los Angeles Times, the Miami Herald, the San Francisco Chronicle, USA Today, the Wall Street Journal, and the Washington Post.

${ }^{12}$ Throughout the paper, we use the term business loans to refer to commercial and industrial loans.

${ }^{13}$ To give a sense of what the distinction between large and small bank entails, the E.2 Release of April 2017 - which publishes results for the February 2017 survey - states that "As of December 31, 2016, assets
} 


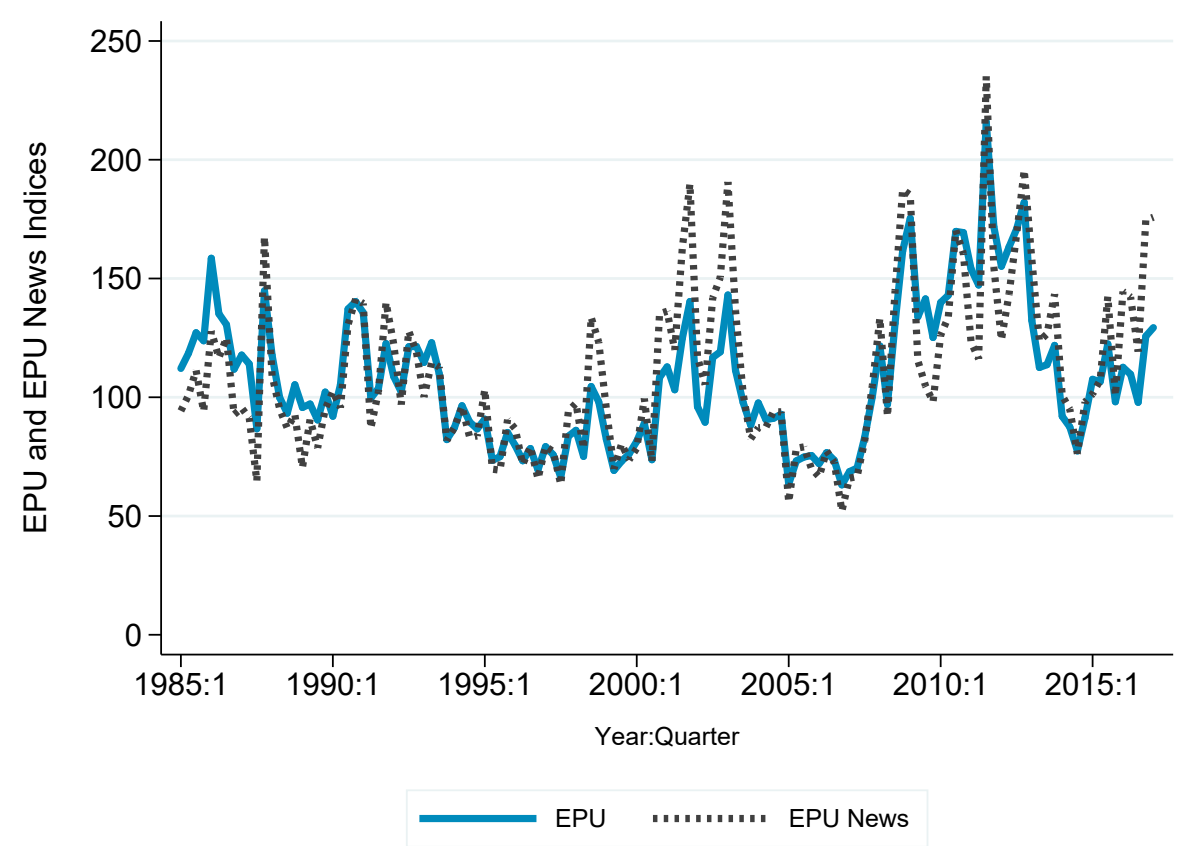

Figure 1: EPU and EPU News, from Baker, Bloom, and Davis (2016).

the middle month of each quarter" (Board of Governors of the Federal Reserve System, 2017) and, thus, constitute outstanding sources of information in what regards flows of bank credit to businesses. In different specifications of our models we use the separate series of loans disbursed under commitment and spot loans, their sum, or the ratio of loans disbursed under commitment to spot loans. The data show that commitments are a widely used contractual agreement, as they historically represent roughly $80 \%$ of the flows of loans. As discussed in Section 2.2, we focus our analysis on lending by large banks, which largely dominate the business loan market and drive the aggregate dynamics. This is clearly illustrated by Figure 2. Our STBL data set runs from 1982:Q3 through 2017:Q1, yet in their use we are generally constrained by the earliest available data on EPU, which starts in 1985:Q1.

DealScan data. We also use data on loan volumes and spreads on originations recorded in Thomson Reuters LPC DealScan. DealScan tracks loan originations in the syndicated loan market, where large banks originate a significant portion of their business loans (Ivashina, 2009). ${ }^{14}$ In this market, banks finance portions of loans originated to mid-size and large borrowers, which allows them to efficiently diversify their lending portfolios. In a typical syndicated loan transaction, a borrower appoints a lead arranger, or a group of them, and extends a mandate to arrange a credit transaction. This mandate generally includes a term

of the large banks were at least \$5.5 billion. Median total assets for all insured banks were roughly \$202 million. Assets at all U.S. branches and agencies averaged $\$ 10.5$ billion" (Board of Governors of the Federal Reserve System, 2017).

${ }^{14}$ The E.2 Release of April 2017 is informative also on this point. The release reports that loans made under participation or syndication represent $61.5 \%$ of the loans extended by large domestic banks, $27.7 \%$ of loans made by small domestic banks, and $59.7 \%$ of those made by all domestic banks. 


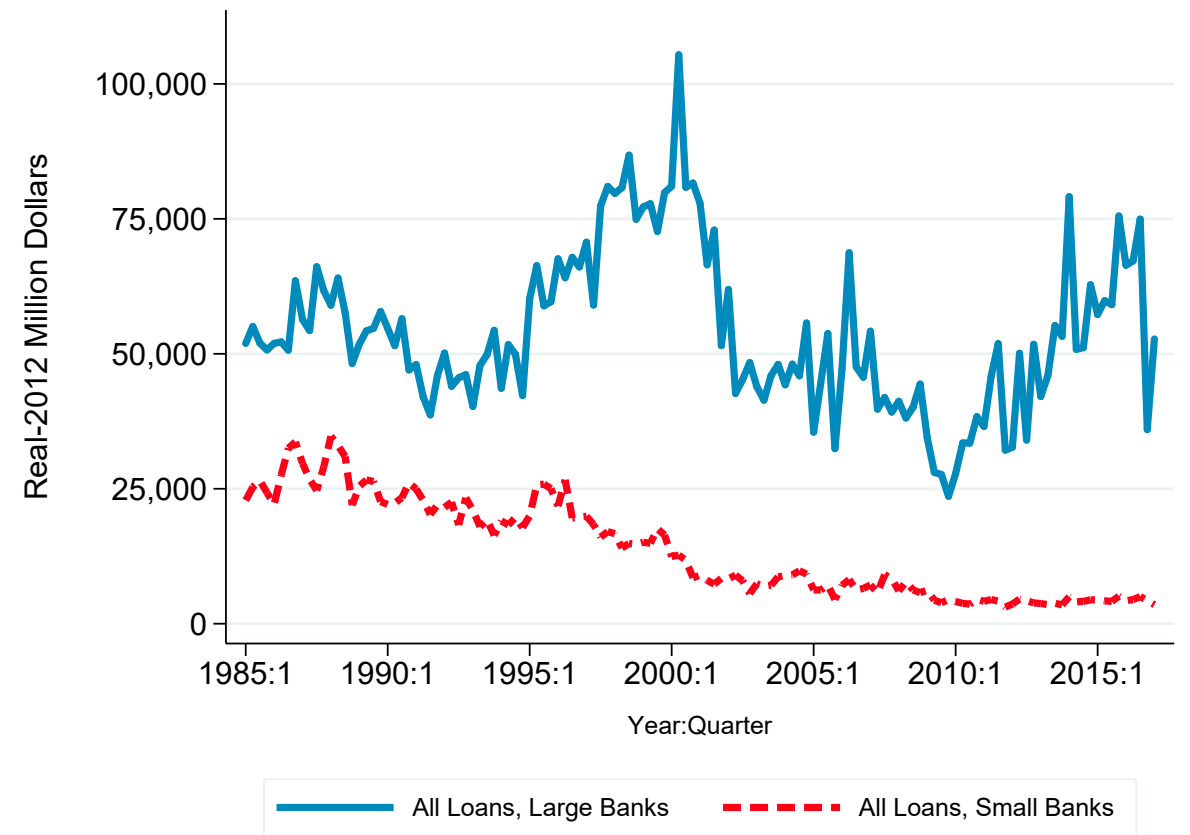

Figure 2: Total Loans issued by Large and Small Banks in the STBL Data Set, in Real Terms, Seasonally Adjusted.

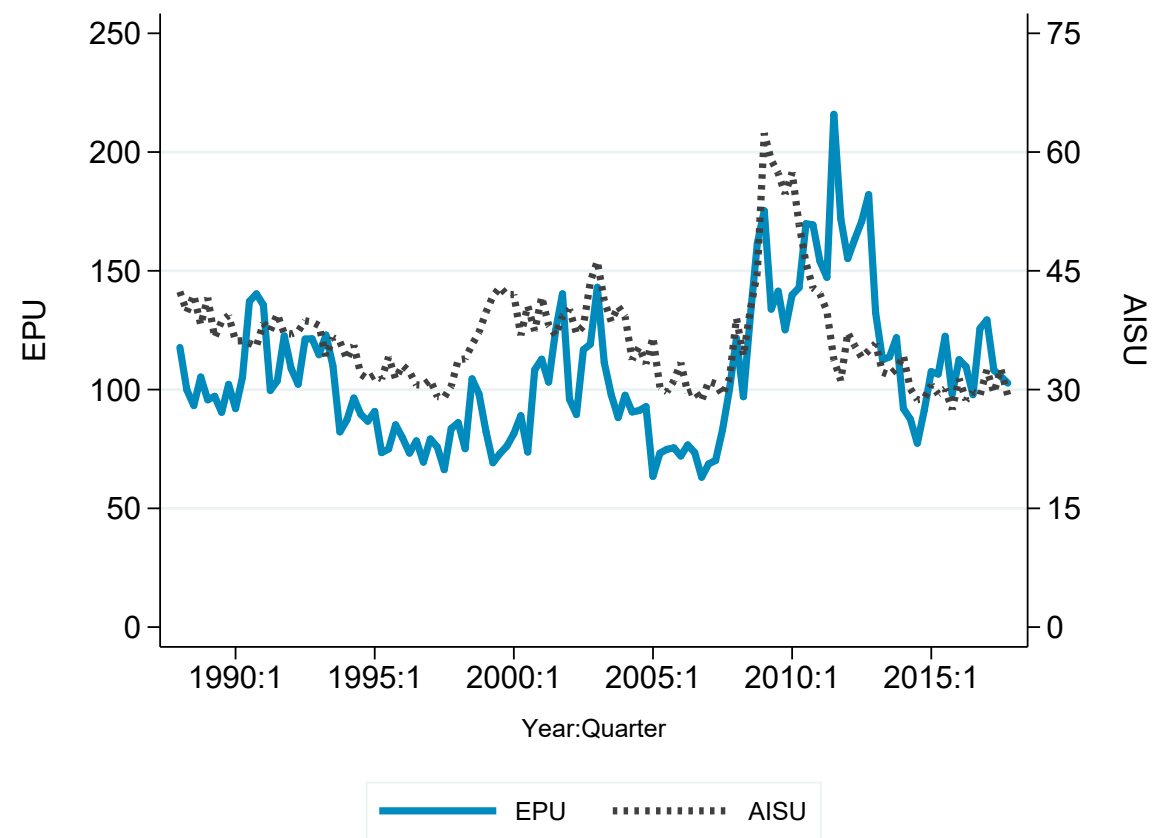

Figure 3: EPU and All-In Spread Undrawn on Credit Lines from DealScan. 


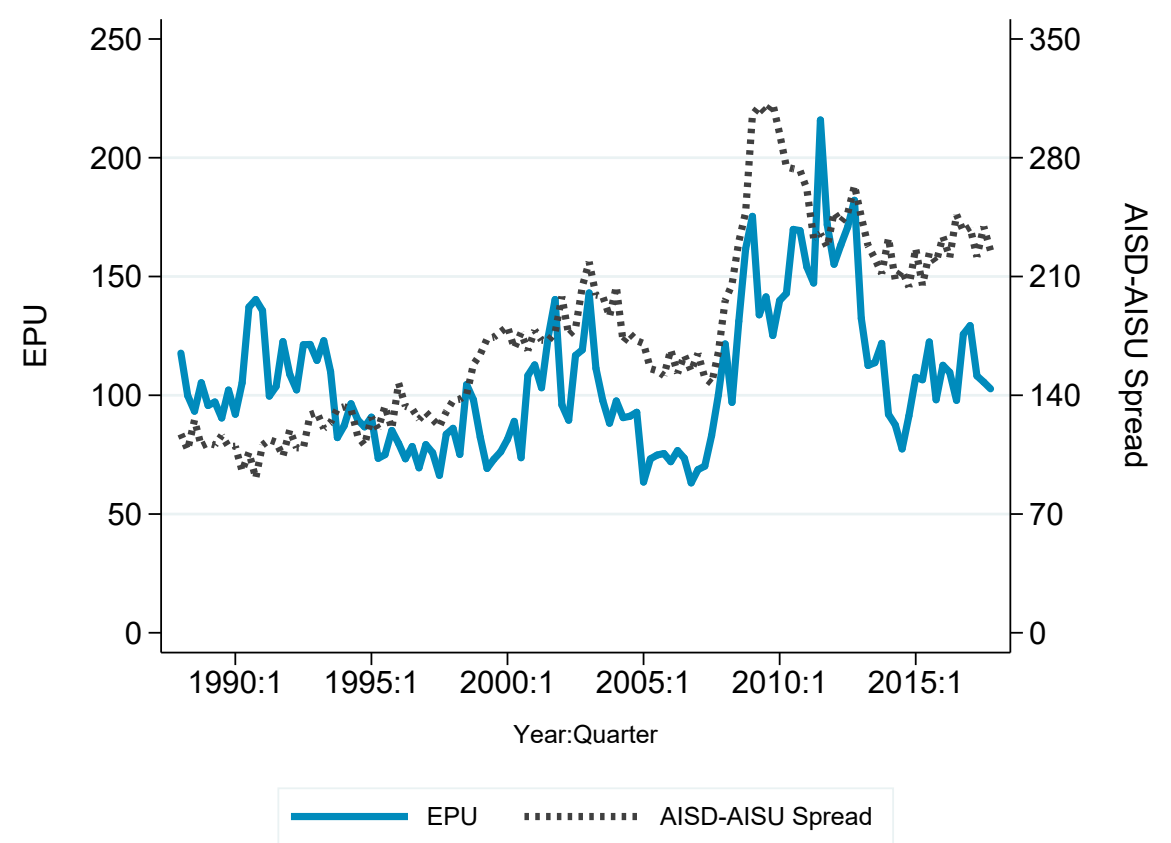

Figure 4: EPU and the Spread between All-In Spread Drawn and All-In Spread Undrawn on Credit Lines from DealScan.

sheet setting the basis of the credit conditions sought. Upon a negotiation and bidding process, other financial institutions will join the syndicate and the final terms of the arrangement will be defined. A single arrangement can include more than one facility in a single package, and each facility usually represents one of two main types of loans: term loans or revolver loans. ${ }^{15}$ The data series we use in our analysis are based on two subsets of the 123,295 facilities originated in U.S. dollars, to non-financial U.S. firms, and syndicated in the U.S. market between 1988 and 2017. ${ }^{16}$

In Section 4.2 we study term loan originations and their associated costs of liquidity. ${ }^{17}$ A term loan gives the borrower a short availability period to borrow up to a maximum amount agreed on the package. Generally, after drawdown, the loan is due for repayment either following an amortizing schedule or as a bullet payment at maturity, when repayment in full is due. Term loans are primarily priced using a base market rate and a spread and fees to be added to it. The most frequently used base rate is LIBOR, and DealScan reports the All-In-Spread-Drawn, or AISD, defined as the sum of the spread over LIBOR plus the facility fee (see Berg, Saunders, and Steffen, 2016). Thus, AISD is a good measure of the cost of spot liquidity after accounting for the cost of interbank lending. Moreover, given that

\footnotetext{
${ }^{15}$ See Sufi (2007) for a more comprehensive description of this market. And see Strahan (2010) for an excellent discussion of the workings and key economic rationales in this market.

${ }^{16}$ Non-financial firms are defined as those with (non-missing) Standard Industrial Classification (SIC) code less than 6000 or more than 6999 .

${ }^{17}$ These loans are defined as those whose loan type is "Term Loan" or "Term Loan A" through "Term Loan K", and they represent 41,041 loans, or $33 \%$ of the qualifying facilities. In what follows, we refer to these loans as spot loans or term loans interchangeably.
} 
term loans are originated for prompt disbursement and use, they are closely comparable to spot loans from the STBL data set.

In Section 4.3 we study the origination of revolvers. Revolvers are lines of credit whereby banks offer businesses liquidity on demand. ${ }^{18}$ Under a revolver agreement, a borrower is typically entitled to draw down on and repay the line on one or multiple occasions for a pre-specified period of time. Since this contract essentially offers the borrower an option to access liquidity on demand, banks charge this service via a commitment fee, which is a fee on the unused amount on the line. Banks can also charge borrowers an annual facility fee, which is independent of the use of funds, yet in credit lines commitment fees appear twice as frequently as facility fees and seldom does a single contract carry both commitment and facility fees at once (Berg, Saunders, and Steffen, 2016). The sum of commitment fee and facility fee is referred to as the All-In-Spread-Undrawn, or AISU, in DealScan. Naturally, banks also charge clients for the actual use of funds. Thus, should a borrower draw down on a line, she will be charged for the use of funds a cost equal to the base rate plus a spread. In DealScan, this spread is reflected in the AISD.

It is evident, then, that AISU and AISD represent costs associated with two distinctly different services. On the one hand, AISU represents the cost of an insurance granting access to liquidity on demand - an access that might or might not materialize - or the price of an option to access liquidity on demand. On the other hand, AISD represents the actual cost of tapping the funds. In Section 4.3 we elaborate further on this option view of credit lines and posit that, in response to increasing EPU, banks become wary of giving up liquidity and write more expensive options of liquidity on demand, which also carry a higher cost to access liquidity with respect to the cost of securing the option. In Figure 3 we plot AISU on credit lines together with EPU, and this figure suggests that the cost of securing and maintaining a credit line varies with EPU. Figure 4 illustrates the spread between AISD and AISU on credit lines together with EPU, and it makes apparent not only that this spread changes over time, but also that it widens as policy uncertainty increases. This suggests that the cost of outright liquidity increases with respect to the cost of the liquidity option as policy uncertainty heightens.

Macroeconomic data. The main source of our macroeconomic data is FRED, the online repository maintained by the Federal Reserve Bank of St. Louis. We obtain from FRED the real GDP, the GDP deflator, gross business investment, the Federal Funds rate, and the 10-year Baa-Treasury credit spread. ${ }^{19}$ Additionally, we also use two alternative shadow rates that proxy for the effective monetary policy stance during the period in which the Federal Funds rate reached the zero lower bound, between December 2008 and December 2015. These measures come from Wu and Xia (2016) and Krippner (2013, 2015), and we obtain them from the websites of the Federal Reserve Bank of Atlanta and the Reserve Bank of New

\footnotetext{
${ }^{18}$ Credit lines are defined as facilities whose loan type is "Revolver/Line $<1$ Yr.", "Revolver/Line $\geq 1$ Yr.", or "Revolver/Term Loan", and they represent 62,925 facilities, or $51 \%$ of all qualifying facilities. Notice that we use the terms revolvers, commitments, and credit lines interchangeably, as for all intents and purposes in this work, they represent sufficiently close agreement types.

${ }^{19}$ The corresponding series ids are as follows. Real GDP: gdpc1; GDP deflator: gdpdef; Gross Business Investment: w987rc1q027sbea; Federal Funds rate: fedfunds; 10-Year Baa-Treasury Constant Maturity: baa10ym.
} 
Zealand, respectively. To conclude this section, we shall add that dollar-denominated series are expressed in real terms and series are seasonally adjusted following standard practices in the literature. ${ }^{20}$

\section{Main Results}

In this section, we present the main results of our analysis. Sections 4.1 and 4.2 present results for the analysis mostly based on STBL data on flows of business loans extended by large domestic banks in the U.S. By association, this analysis primarily refers to the dynamics of business lending to large firms (Berger, Miller, Petersen, Rajan, and Stein, 2005). ${ }^{21}$ The last part of Section 4.2 and Section 4.3 present, respectively, results for the analysis based on spot loan and credit line originations in the syndicated loan market, from DealScan. As before, also these loans are closely associated to relatively large firms.

The first result of the analysis shows that the total flow of business lending falls in response to an exogenous increase in EPU (Section 4.1). Part of this fall can be plausibly attributed to a contraction in loan demand accompanying the slowdown in economic activity and the fall in investment resulting from the shock. Signs of this contraction in loan demand are apparent from the moderate use firms make of existing credit lines, which is shown in subsequent analysis. The second result of the analysis, however, shows that the negative response of total lending also reflects a contraction in the supply of spot loans (Section 4.2). This is observable in the sharp decline of funds extended as spot loans, which far exceeds the slowdown in the pace at which borrowers draw down funds on their credit lines, and coincides with a sudden increase in credit spreads.

The third result relies on loans originated in the syndicated loan market and shows that the decline in spot loans is also associated with an increase in the spread of these loans (Section 4.2), thus corroborating the conclusion of a loan supply contraction drawn in the second result. The fourth and fifth results show that the credit supply contraction also extends to the provision of liquidity insurance (Section 4.3). On the one hand, in response to increasing EPU, banks originate fewer credit lines at higher costs to secure and maintain the lines. On the other hand, those new credit lines also carry higher costs to access the committed funds, and represent a pricing structure that disincentivizes borrowers from drawing down on the lines. Overall, the combined evidence convincingly supports the existence of a bank lending channel in the transmission of EPU shocks to the rest of the economy.

\subsection{Total Business Lending}

We first document that aggregate business lending falls in response to an exogenous increase in EPU. This is illustrated in Figure 5, where we report the response functions of

\footnotetext{
${ }^{20}$ That is, all series are seasonally adjusted, except for measures of interest rate or spread, the EPU and EPU News indexes, and the S\&P 500 index.

${ }^{21}$ In Section 5, we will extend this analysis to all banks combined and small banks separately. As we discuss in detail then, the results from all banks considered as a single group resemble those presented in this section, as large banks drive the aggregate dynamics of the business loan market. The results for small banks, in contrast, exhibit meaningful differences which we discuss in time.
} 
the variables of our model to a one-standard-deviation innovation to the EPU index, which roughly corresponds to an increase in the uncertainty index of 22 points. The size of this innovation is relatively moderate. As a reference, consider that the EPU index was about 60-70 points during the first part of 2007, before the financial crisis unraveled, and reached 190 points in October 2008, at the apex of the crisis. In this figure, and all the following ones, the solid lines correspond to the median response of a variable to the shock, whereas the dashed lines represent the 14/86th percentile bands of the posterior distribution of the responses. $^{22}$ The estimation sample is 1985:Q1-2017:Q1 and the $\mathrm{x}$-axis represents years from the shock.

The variables included in this first model are GDP, the GDP deflator, gross business investment, the EPU index, the $\mathrm{Wu}$-Xia shadow rate, the credit spread, and the amount of all C\&I loans originated by large banks. This ordering of variables defines the baseline identification scheme of the structural innovations as well. Observing variables at the same point in time within the quarter is important for an accurate application of the contemporaneous restrictions imposed by the Cholesky scheme. As explained in Section 3, STBL variables are observed during the second month of a quarter. For this reason, and given our focus on the response of lending to EPU innovations, whenever we use the STBL data and whenever possible, we align the observation of other variables in the model to the timing of the STBL data. Hence, we use the observation corresponding to the second month within each quarter for the EPU index, the shadow rate, and the credit spread. ${ }^{23}$

The last panel in Figure 5 illustrates the response of the total flow of loans. The response is null on impact, but it rapidly turns negative for the next four years. The response is inversely hump-shaped and significant for up to two years, with the EPU shock foreshadowing a maximum fall of roughly $2 \%$ in total loans after one year. This result is robust to a number of unreported robustness checks. The responses of the other variables of the model are in line with what has been typically found in the VAR literature on the effects of uncertainty on macroeconomic outcomes. Noticeably, GDP, business investment, and the policy rate fall as well. The effects are smaller in order of magnitude than those observed for the loan aggregate, but the responses are similarly hump-shaped and relatively persistent. Output displays a decline in the first year and a half, dropping about one tenth of a percentage point at its trough. It then gradually recovers within sixteen to twenty quarters after the impulse. This result is consistent with previous findings documenting falls in the level of activity, such as the fall in industrial production in Baker, Bloom, and Davis (2016).

Business investment also experiences a contraction, falling close to half a percentage point six to seven quarters after the EPU shock. This decline is sizable when compared to that of GDP and underscores the sensitivity of corporate investment to EPU. This fall is also in line with what both the theoretical and the empirical literature have documented regarding the effects of uncertainty on corporate investment (e.g. Bernanke, 1983; Leahy and Whited, 1996; Bloom, Bond, and Reenen, 2007; Baum, Caglayan, and Talavera, 2008; Jens, 2017; Smietanka, Bloom, and Mizen, 2018; Falk and Shelton, 2018). Moreover, as our main

\footnotetext{
${ }^{22}$ This choice of bands is well-established in the literature of Bayesian VAR models (see, for instance, Sims and Zha, 1998).

${ }^{23}$ The macro variables are necessarily measured over the quarter instead, and are observed at the end of the period only. In the baseline identification scheme, however, they are assumed to respond to the EPU shock with one lag, which in part mitigates the concerns about the observation timing issue.
} 

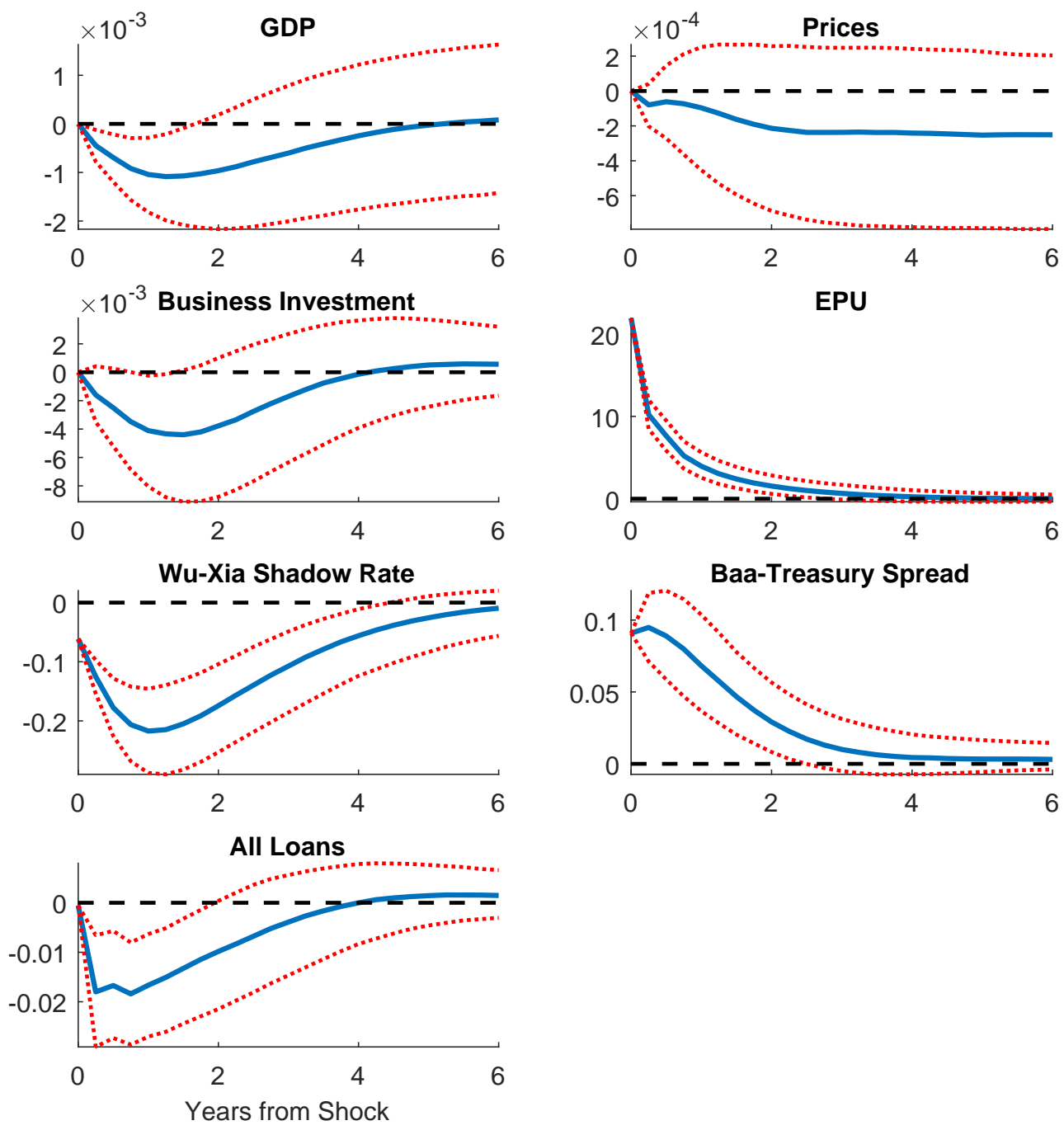

Figure 5: EPU and the Response of All Loans Extended by Large Banks from STBL, 1985:Q1-2017:Q1. Orthogonalized responses to a one-standard-deviation structural innovation of EPU. The model includes the log of real GDP, the log of the GDP deflator, the log of real gross business investment, the baseline overall EPU index, the Wu-Xia shadow rate, the 10-year Baa-Treasury credit spread, and the amount of all loans originated by large domestic banks. $\operatorname{VAR}(2)$. Years from the shock on the $\mathrm{x}$-axis.

interest lies in studying the response of loan supply to EPU shocks, this response makes evident that controlling for corporate investment in our model plays an important role, as falling investment could naturally result in weaker demand for funds, and this is an element to control for.

The credit spread, on the other hand, rises sharply in response to the EPU innovation. This increase is economically and statistically significant. At the peak of the response, two quarters from the shock, the credit spread rises about 10 basis points. It takes three to four years for the response to die out. The effect we find is in line with the impulse response 
function reported by Gilchrist, Sim, and Zakrajsek (2014) for an uncertainty measure of financial nature, and it is interpreted as an implicit outcome of a supply side contraction in the financial markets. We regard this response, jointly with the response of loans, as a first indication of the potential importance that the financial channel might have in the propagation of uncertainty shocks to the real economy. We further investigate this point in the next subsection.

In concluding this section, we note that the response of the spread could raise questions as to whether the EPU shock could confound the effects of other forms of uncertainty, such as those stemming from the financial sector. In Section 5, we investigate this possibility explicitly by considering different orderings in the Cholesky scheme and by adding a stock price index to the financial block.

\subsection{Supply of Spot Funds}

Evidence from STBL. We now turn to specifications in which the total flow of loans from STBL is replaced by alternative combinations of its components: the flow of loans disbursed under commitment and the flow of spot loans. The main purpose of this exercise is to identify a supply-side effect in the transmission mechanism of EPU shocks. In order to do so, we exploit a key contractual difference between commitments and spot loans, which is that banks can immediately alter their supply of spot loans but they are contractually bound to provide liquidity on demand on pre-existing commitments. We begin the analysis by estimating a model in which loans disbursed under commitment and spot loans are included separately to replace total loans. Figure 6 illustrates the response functions of this model.

The first point worth mentioning is that this modification in the specification leaves the responses of the non-loan variables fundamentally unchanged. We find, however, crucial differences between the responses of the two types of loans. Loans extended under commitment exhibit a mildly negative, but not significant, response from the second quarter on, with a fall in the order $1 \%$ at its trough. This response presents two aspects of interest. First, it shows that the slowdown in loans extended under commitment is noticeably smaller than the one displayed by total loans in Figure 5. Second, in terms of timing, this response is comparable to that of business investment, which lends support to the conjecture that loans extended under commitment plausibly reflect the changing financial needs firms face in the wake of an EPU shock.

In contrast, the EPU shock foreshadows a much larger and significantly negative response of spot loans, which fall by almost $4 \%$ at the trough, five to six quarters from the shock. That is, the magnitude of the maximum fall in spot loans, which banks can adjust immediately, is about four times as large as that of loans extended under commitment, which banks are contractually bound to serve upon demand. Furthermore, these differing responses in the flows of loans are coupled with the significant, concomitant increase in credit spreads, all of which points to a loan supply contraction.

We can test more formally the hypothesis that the EPU shock foreshadows a contraction in the supply of business loans. To this end, we use the ratio of loans extended under commitment to spot loans to synthesize the relative response of the two types of loans. We stress that, in the face of increasing uncertainty, banks have incentives to accumulate liquidity (Caballero and Krishnamurhty, 2008), and that curtailing lending offers a means to do 

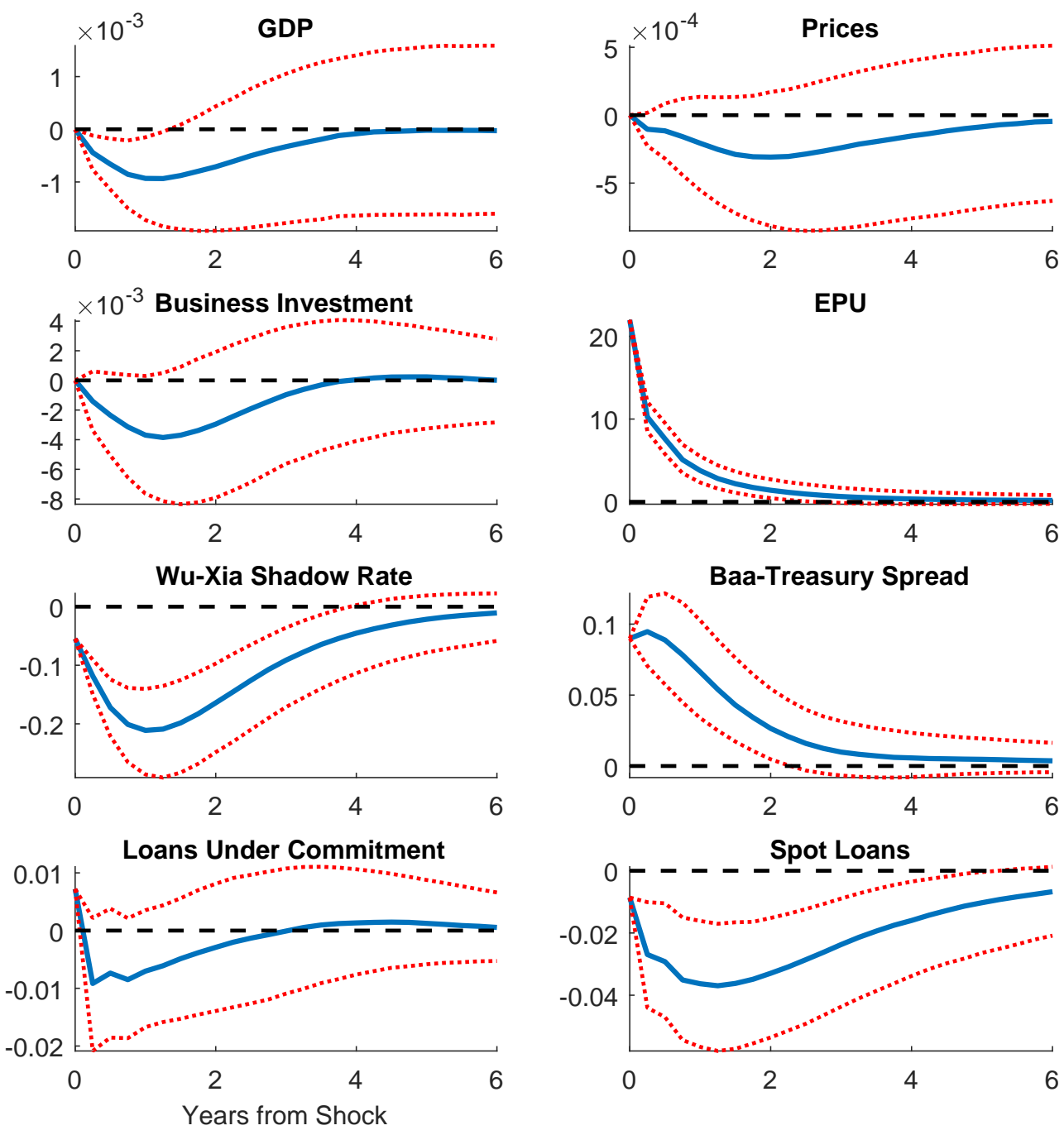

Figure 6: EPU and the Response of Loans Extended under Commitment and Spot Loans Extended by Large Banks from STBL, 1985:Q1-2017:Q1. Orthogonalized responses to a one-standard-deviation structural innovation of EPU. The model includes the log of real GDP, the $\log$ of the GDP deflator, the log of real gross business investment, the baseline overall EPU index, the Wu-Xia shadow rate, the 10-year Baa-Treasury credit spread, and the amounts of loans extended under commitment and spot loans originated by large domestic banks. $\operatorname{VAR}(2)$. Years from the shock on the $\mathrm{x}$-axis. 
so. Still, as they are contractually bound to serve pre-existing commitments, they are only able to constrain flows of lending immediately on spot loans. We expect this ratio to have a positive response to an exogenous increase in EPU, meaning that firms cannot secure new spot loans at the same pace they can draw down funds from their credit lines.

As discussed in Section 2.2, this identification strategy relies on the assumption that loan demand has uniform cyclical properties across the two types of contracts. There are reasons to believe this assumption is plausibly satisfied in our setup. The main reason is that we limit the analysis to large banks and, by association, mainly large firms. Large firms typically face fewer financial constraints than small firms, and can tap alternative sources of financing, if needed. In particular, this makes them less likely to refrain from using their open credit lines than small firms if they need the funds. After controlling for any change in credit spreads, this should result in comparable demands across the two types of loans.

Smaller firms, in contrast, are more likely to be financially constrained and have incentives to strategically manage open credit lines in response to different types of shocks, making our identifying assumption untenable for this type of firm. Then, the exclusion of small banks from our sample becomes important. Indeed, Figure 13a illustrates that the response of loans disbursed under commitment by small banks is significantly different from the response of loans disbursed under commitment by large banks, which suggests that the two types of banks face different loan demands after an uncertainty shock. We discuss this point in detail in Section 5.1.

The goal of this exercise is, then, to provide statistical support to the hypothesis of a supply-side contraction in the provision of liquid funds to businesses in response to higher uncertainty EPU. The literature has dedicated significant attention to study the role financial frictions play in the transmission of uncertainty shocks to the real economy, especially to business investment. For instance, in the theoretical models of Christiano, Motto, and Rostagno (2014) and Arellano, Bai, and Kehoe (2016) financial frictions interact with uncertainty shocks determining credit supply restrictions, ultimately amplifying the impact that uncertainty has on the economy, beyond the "wait and see" effect usually observed at firm level. Thus, finding evidence in support of this channel is certainly of great economic interest.

Figure 7 introduces the results of this new model where the ratio of loans disbursed under commitment to spot loans replaces their separate series used in Figure 6. The response of the loan ratio to an EPU innovation in Figure 7 is positive from impact onwards. It is hump-shaped, persistent, with a peak between the fifth and sixth quarters, and it is statistically significant up to six years from the shock. Comparing these results to those in Figure 6 for the separate series of loans, we note that the loan ratio response is driven by the fall in spot loans. This evidence, combined with the spike in credit spreads, corroborates the signs of a contraction in the supply of liquid funds. Quantitatively, this impulse response suggests a loan supply contraction of roughly 14-15 basis points at peak for each unit increase of EPU. This corresponds, for instance, to a fall in loan supply of about 17-18\% between 2007 and 2008 when EPU rose by some $120-130$ points during the financial crisis. The responses of the other variables in the model are very much unaffected, and all results presented here hold up well to an extensive set of robustness checks that we present later in Section 5.2.

We assess next the relevance of EPU innovations in explaining variations in the loan variables. We resort to the analysis of the forecast error variance decomposition (FEVD 

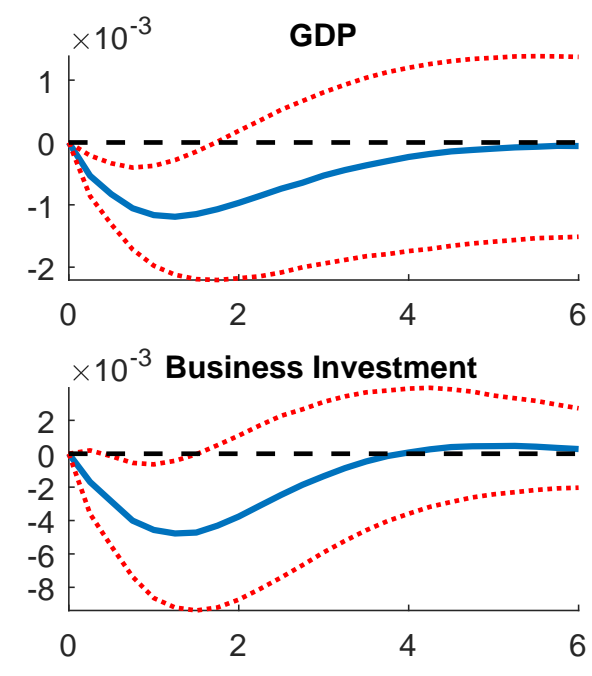

Wu-Xia Shadow Rate
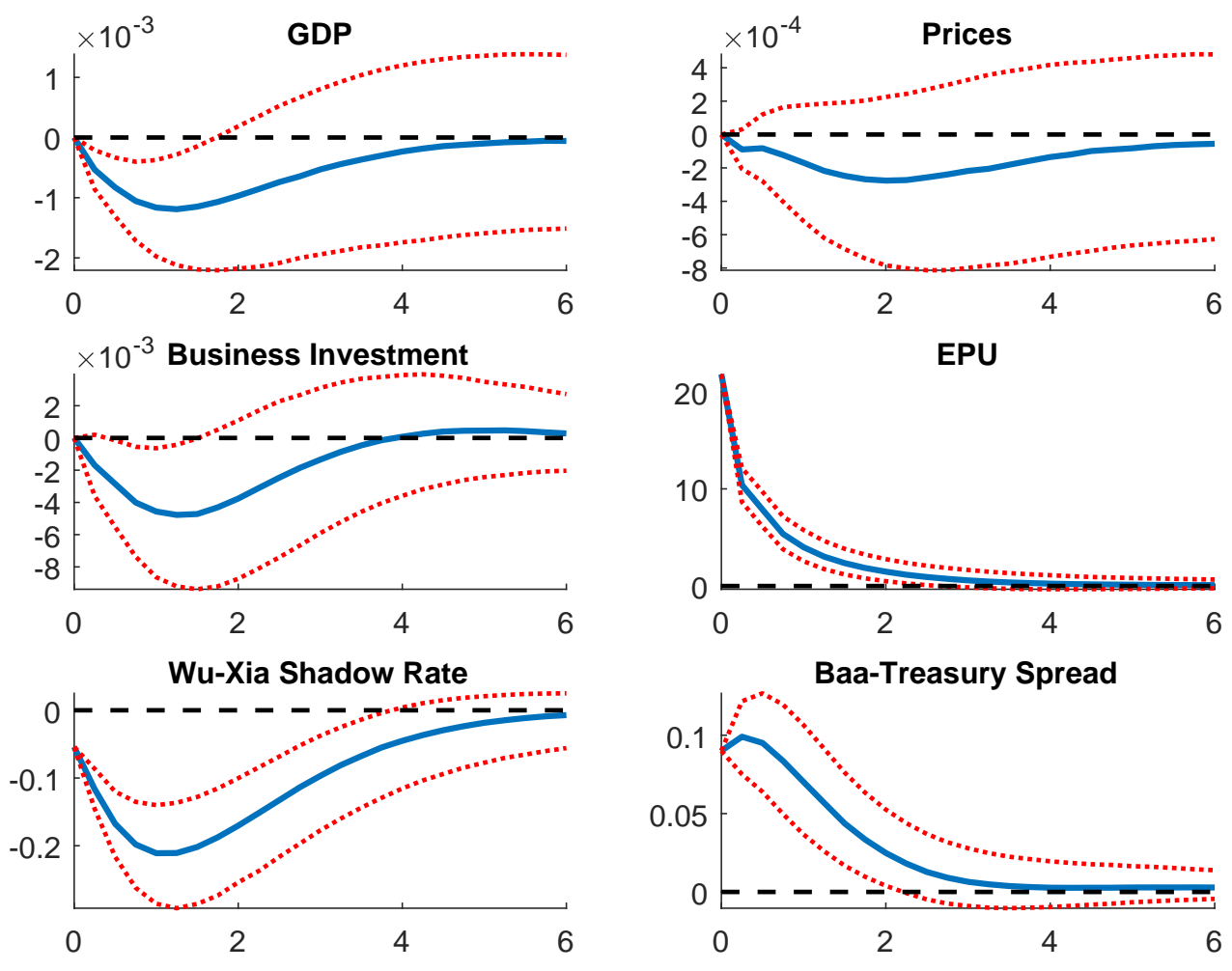

Figure 7: EPU and the Response of the Ratio of Loans Extended under Commitment to Spot Loans Extended by Large Banks from STBL, 1985:Q1-2017:Q1. Orthogonalized responses to a one-standard-deviation structural innovation of EPU. The model includes the log of real GDP, the log of the GDP deflator, the log of real gross business investment, the baseline overall EPU index, the Wu-Xia shadow rate, the 10-year Baa-Treasury credit spread, and the ratio of loans extended under commitment to spot loans originated by large domestic banks. $\operatorname{VAR}(2)$. Years from the shock on the x-axis. 
henceforth), which summarizes the relative importance of each structural innovation in explaining the deviations of a variable from its forecast at different horizons.

We have said that, in response to an exogenous increase in EPU, banks would only be able to immediately adjust the amount of spot loans they provide, as they are contractually bound to serve on demand pre-existing credit lines. By the symmetry of the linear VAR models we use here, we could similarly argue that in the wake of an exogenous decrease in EPU, banks could rapidly augment their supply of credit by loosening the conditions on new spot loans beyond the (now relatively tight) conditions on pre-existing credit lines. An implication of this argument is that spot loans should be more responsive to EPU innovations than credit lines are. Figure 8 illustrates the FEVD of loans extended under commitment and spot loans from the model reported in Figure 6 and the FEVD of the loan ratio from our benchmark model reported in Figure 7. Figure 8 substantiates our point, as it shows that EPU innovations explain $7.1 \%$ and $6.3 \%$ of the six-year forecast errors of spot loans and the loan ratio, respectively, but they only explain $2.3 \%$ of the forecast errors of loans extended under commitment.

Evidence from DealScan. To conclude this section, we provide additional evidence in support of the identification strategy used in Figure 7 and the finding of a loan supply contraction in response to an EPU shock; we do so by estimating a model based on data on syndicated loan originations from DealScan. In interpreting the results from Figure 7 we have argued that, in response to a positive EPU shock, banks implement a credit contraction through a reduction in their supply of spot loans. Using DealScan data, we are able to estimate a new model where the volume of new term loans - which are conceptually comparable to flows of spot loans - and their corresponding AISD replace the flows of loans from the STBL and the credit spread. ${ }^{24}$

The fact that the DealScan data set allows us to create series of both loan volumes and their corresponding spreads represents an advantage with respect to the STBL data, which lacking this link we have complemented with market credit spreads. Notice that, as the DealScan series are constructed as quarterly summations and averages from the individual facilities, we must now align the observation of the other variables in the models using DealScan data to this form of time aggregation. Consequently, we use quarterly averages for the EPU index and the shadow rate as well. We illustrate the responses of the term loan volume and AISD spread in Figure 9, while Figure A1 in the Appendix presents the full set of impulse response functions for the model.

If an overall supply contraction dominates the spot loan market equilibrium after a shock that heightens EPU, the fall in spot loans must be accompanied by an increase in the price firms pay to obtain the new loans. Figure 9 exactly illustrates this point. Spot loans drop by an amount similar to that of the baseline specifications (compare to Figure 6, for instance), with a sharp decline in the short-run after the shock, reaching a trough about a year from the shock, and slowly recovering in the longer term. The response of the AISD, at the same time, is positive on impact and continues with a dynamic that mirrors the response

\footnotetext{
${ }^{24}$ The use of loan spreads in this model has a parallel in Berger, Guedhami, Kim, and Li (2018), who ultimately posit that increasing spreads are indicative of banks hoarding liquidity when faced with increasing economic policy uncertainty. The results we present here lend support to their claim.
} 
of loan volumes. We regard this exercise as an empirical validation of our identification strategy. Lastly, it is worth mentioning that it is reassuring to find that using in this model the flows of spot loans from STBL in lieu of the volume of term loan originations from DealScan would yield very similar results. This is so because, as mentioned in Section 3, term loans recorded in DealScan are generally meant for prompt disbursement and are thus closely comparable to the flow of spot loans reported in the STBL data set.

\subsection{Supply of Liquidity Insurance}

A key function of the banking system is the provision of liquidity on demand (Kashyap, Rajan, and Stein, 2002; Gatev and Strahan, 2006; Gatev, Schuermann, and Strahan, 2009; Strahan, 2010). In relation to the business sector, this function is fundamentally implemented via commitments, which offer firms a form of liquidity insurance. In this section, we document two main facts that relate to this primary function of banks and innovations in EPU. The first fact is that, in response to an exogenous increase in EPU, banks contract their supply of liquidity insurance. That is, they raise the cost of originating and maintaining new credit lines, and reduce the amount of funds they commit through them.

The second fact we document is that the new credit lines that banks originate carry steeper costs of effective access to liquidity on demand with respect to the cost of securing and maintaining the lines. By means of this strategy, banks reduce the probability of drawdown on commitments, ultimately slowing down loan growth and further contracting loan supply. From an option theory standpoint, this is equivalent to writing liquidity options carrying steeper striking prices with respect to the option price. Ceteris paribus, higher striking prices should translate into lower probabilities of the option ever being in the money, thus reducing the probability of exercise - i.e. drawdown in our case. This notion is rooted in the intuition developed in previous work that sees credit lines as options, including Thakor, Hong, and Greenbaum (1981), Shockley and Thakor (1997), and Berg, Saunders, and Steffen (2016). ${ }^{25}$ Yet more specifically, it builds on the finding in Berg, Saunders, and Steffen (2016) showing that borrowers paying higher costs associated with drawing down on their credit lines with respect to the costs of securing and maintaining those lines are significantly less likely to draw down the committed funds. ${ }^{26}$

\footnotetext{
${ }^{25}$ In Thakor, Hong, and Greenbaum (1981) a commitment is described as a put option whereby a customer is entitled to sell the bank a debt claim at a predetermined (exercise) price. The bank sells this option to the customer for a fee. The customer shall choose to exercise the option whenever the market price of the debt claim is lower than the price the bank is contractually bound to pay for it, which will occur when market spot rates are higher than the committed rate. Berg, Saunders, and Steffen (2016) call this option the drawdown option on credit lines. Shockley and Thakor (1997) emphasize that this put option on the customer's debt claim is isomorphic to a call option on interest rate markups, as the total rate on funds drawn on commitments is typically set as a fixed spread or markup over a variable market rate (such as LIBOR). The customer will exercise the option to draw down on the line whenever the total committed rate is below the market spot rate on a comparable loan. Our discussion in this section of a credit line as an option is along the lines of this second interpretation.

${ }^{26}$ The narrative in Berg, Saunders, and Steffen (2016) is constructed using the equivalent assertion that borrowers paying lower costs for securing and maintaining their credit lines with respect to the costs associated with drawing down on the lines are significantly less likely to draw down the committed funds. Our choice of wording to describe this relationship is simply meant to facilitate the exposition here.
} 


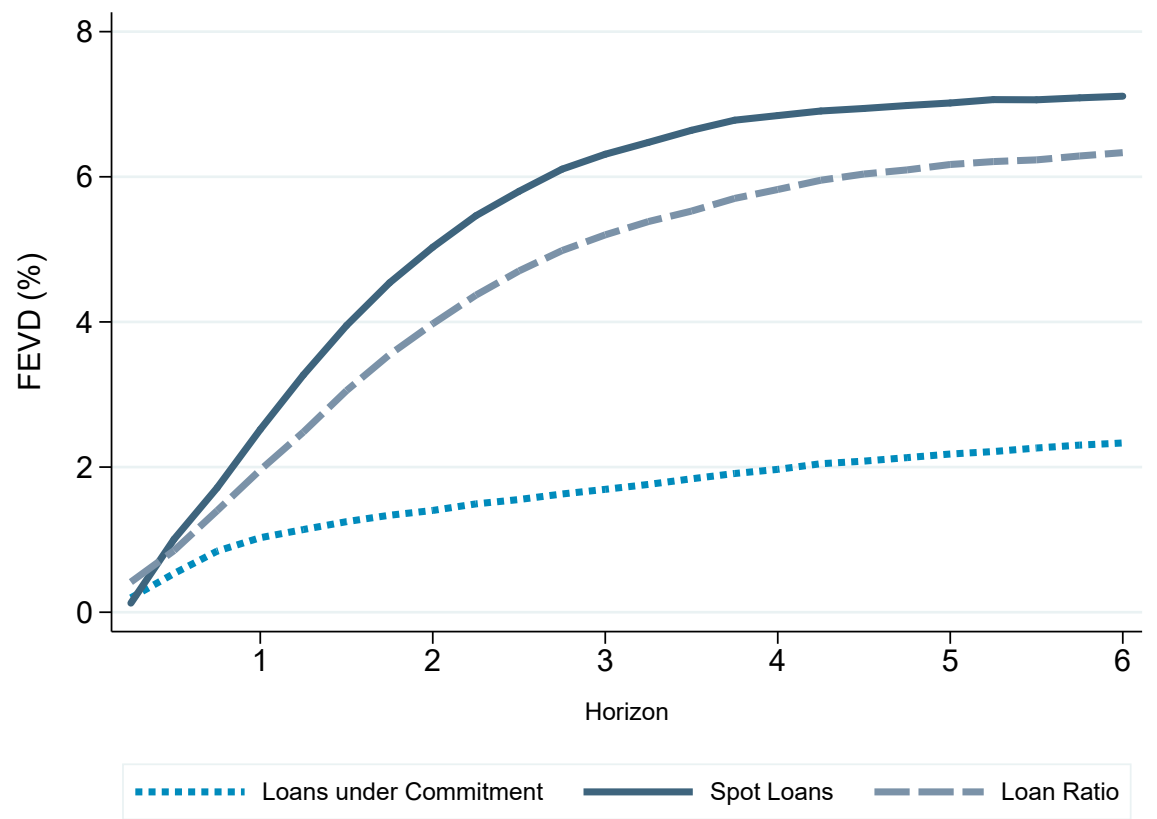

Figure 8: Forecast Error Variance Decomposition for Loans Extended under Commitment, Spot Loans, and the Loan Ratio. Horizon in years on the x-axis.
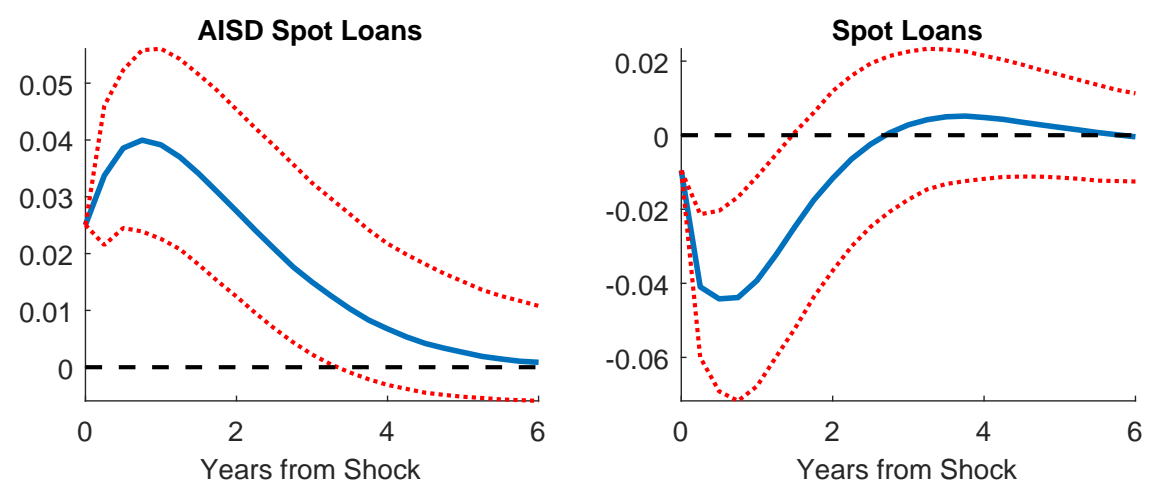

Figure 9: EPU and the Response of the All-In Spread Drawn on New Term Loans and the Volume of Term Loan Originations from DealScan, 1988:Q1-2017:Q1. Orthogonalized responses to a one-standard-deviation structural innovation of EPU. The model includes the $\log$ of real GDP, the log of the GDP deflator, the log of real gross business investment, the baseline overall EPU index, the Wu-Xia shadow rate, the AISD on new term loans, and the volume of term loan originations from DealScan. VAR(2). Years from the shock on the $\mathrm{x}$-axis. 

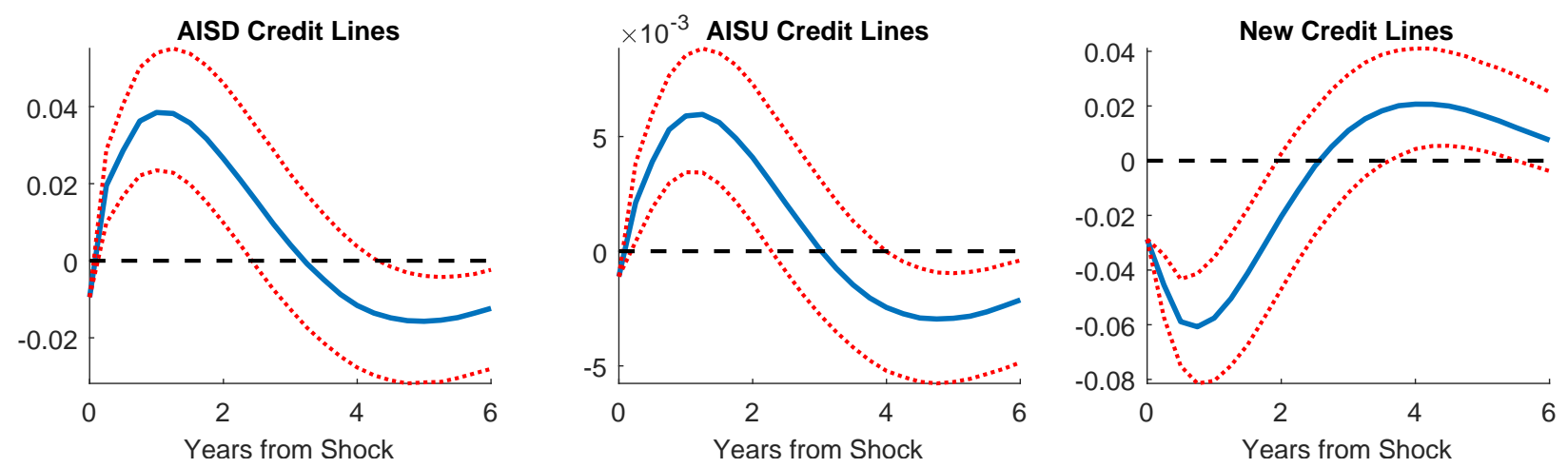

Figure 10: EPU and the Response of the All-In Spread Drawn, All-In Spread Undrawn, and Volume of New Credit Line Originations from DealScan, 1988:Q1-2017:Q1. Orthogonalized responses to a one-standard-deviation structural innovation of EPU. The model includes the $\log$ of real GDP, the log of the GDP deflator, the log of real gross business investment, the baseline overall EPU index, the Wu-Xia shadow rate, the AISD and AISU on new credit lines, and the volume of new credit line originations from DealScan. VAR(2). Years from the shock on the $\mathrm{x}$-axis.

Credit lines in DealScan offer virtually ideal pieces of information to help us substantiate the preceding two points. On the one hand, the AISU approximates well the notion of the cost of purchasing an option of liquidity on demand, which gives the borrower a liquidity insurance. On the other, AISD represents the cost of tapping the committed funds and can be thought of as the exercise price on the option. ${ }^{27}$ The customer will exercise this option when the locked-in AISD is below the market spread on comparable spot loans.

Figure 3, which plots EPU and the AISU on new credit lines from DealScan, suggests that the cost of liquidity insurance rises with EPU, and suggests an intuition consistent with first point above. Additionally, Figure 4 plots EPU and the spread between AISD and AISU on new credit lines, and it reveals that the exercise price on the liquidity option does rise with respect to the cost of the option as policy uncertainty rises. Thus, this latter figure suggests an intuition consistent with the second point above.

In order to formally document that banks contract their supply of liquidity insurance in response to a positive EPU shock, we estimate a model that includes in its $Z_{t}$ block the originations of new credit lines on DealScan together with the series of AISD and AISU on those credit lines. This model is molded on that reported in Figure 9, with the difference that credit lines are priced using two relevant spreads, instead of just one. Figure 10 reports the new key results, and Figure A2 in the Appendix presents the entire set of impulse response functions. The combination of a significantly positive response of AISU and a significantly negative response of new credit lines offers a clear sign of a predominant contraction in the supply of liquidity insurance, under the weak assumption of regularly sloped demand and supply curves. This contraction is immediate and peaks between four and six quarters after the shock, with the origination of credit lines falling up to $6 \%$. Moreover, the effect is long

\footnotetext{
${ }^{27}$ More precisely, the cost of tapping the committed funds would be the sum of a base rate (e.g. LIBOR) plus the AISD. Similarly, the cost of alternatively securing funds on the spot loan market would be determined as the sum of a base rate plus the prevailing spread on the spot market.
} 
lasting, taking roughly three years to fade out.

Next, we formally substantiate our assertion that, in response to an exogenous increase in EPU, banks issue new credit lines bearing a pricing structure that reduces the probability of borrowers tapping the lines. The first element of evidence in this respect comes again from Figure 10. The significantly positive response of AISD accompanying the fall in the volume of new credit lines makes evident that the contraction in the supply of liquidity is also observable in the new lines. This evidence parallels that presented on Figure 9 for new term loans and is entirely expected. In the limit, a credit line could be originated and used immediately, in which case it would be a close substitute for a term loan. Should the cost of liquidity differ meaningfully across contract types, firms would have incentives to arbitrage away the difference and bring the cost of liquidity to an equilibrium across contract types.

The second piece of evidence comes from a new VAR model that includes the ratio of AISD to AISU for credit lines, so as to emphasize that an exogenous increase in EPU foreshadows a relative increase in the cost of accessing liquidity with respect to the cost of securing the liquidity option. ${ }^{28}$ We report the key results in Figure 11, which substantiates our point. The AISD/AISU ratio displays a positive response on impact and rises quickly to peak about a year from the shock. Concurrently, new credit line originations fall, providing evidence of credit tightening.

A number of reasons could help explain why a bank could sometimes choose to implement a credit contraction by increasing the cost of drawdowns with respect to the cost of the credit lines instead of declining credit altogether. First, a perceived higher credit risk could make it desirable for the bank to delay drawdowns as much as possible, thus maintaining the option to reassess the convenience of lending in the future. Should the borrower's creditworthiness deteriorate, the bank could resort to the non-compliance of the MAC clause and decline funding the line or, as it is often the case, reduce the amount of it to fund (Shockley and Thakor, 1997). Second, reducing the volume of drawdowns could allow the bank serving more clients than it otherwise could. This would allow the bank not only to preserve its banking relationships, but also to nurture them. As banks develop relationships in expectation of capturing future rents from their customers (Sharpe, 1990; Rajan, 1992), declining credit during a period of heightened uncertainty could harm these relationships and prove excessively costly in the long-run. Finally, yet still importantly, writing credit lines would allow the bank to safeguard its sources of current and future income, even despite effectively providing less liquidity. Altogether, these empirical results lend themselves to an interpretation grounded on sound economic principles.

\section{$5 \quad$ Further Insights and Robustness Checks}

In this section, we present some new insights and run a host of robustness checks on our main results. In the first part of Section 5.1, we show that the loan ratio results presented in Section 4.2 are not driven by the Financial Crisis of 2007-2009 or the ensuing Great Recession and unconventional monetary policy regime. Next, we present an analysis of lending by small banks in response to an EPU shock to document a contrast with large

\footnotetext{
${ }^{28}$ This is the inverse of the ratio Berg, Saunders, and Steffen (2016) use to test their Hypothesis 5.
} 

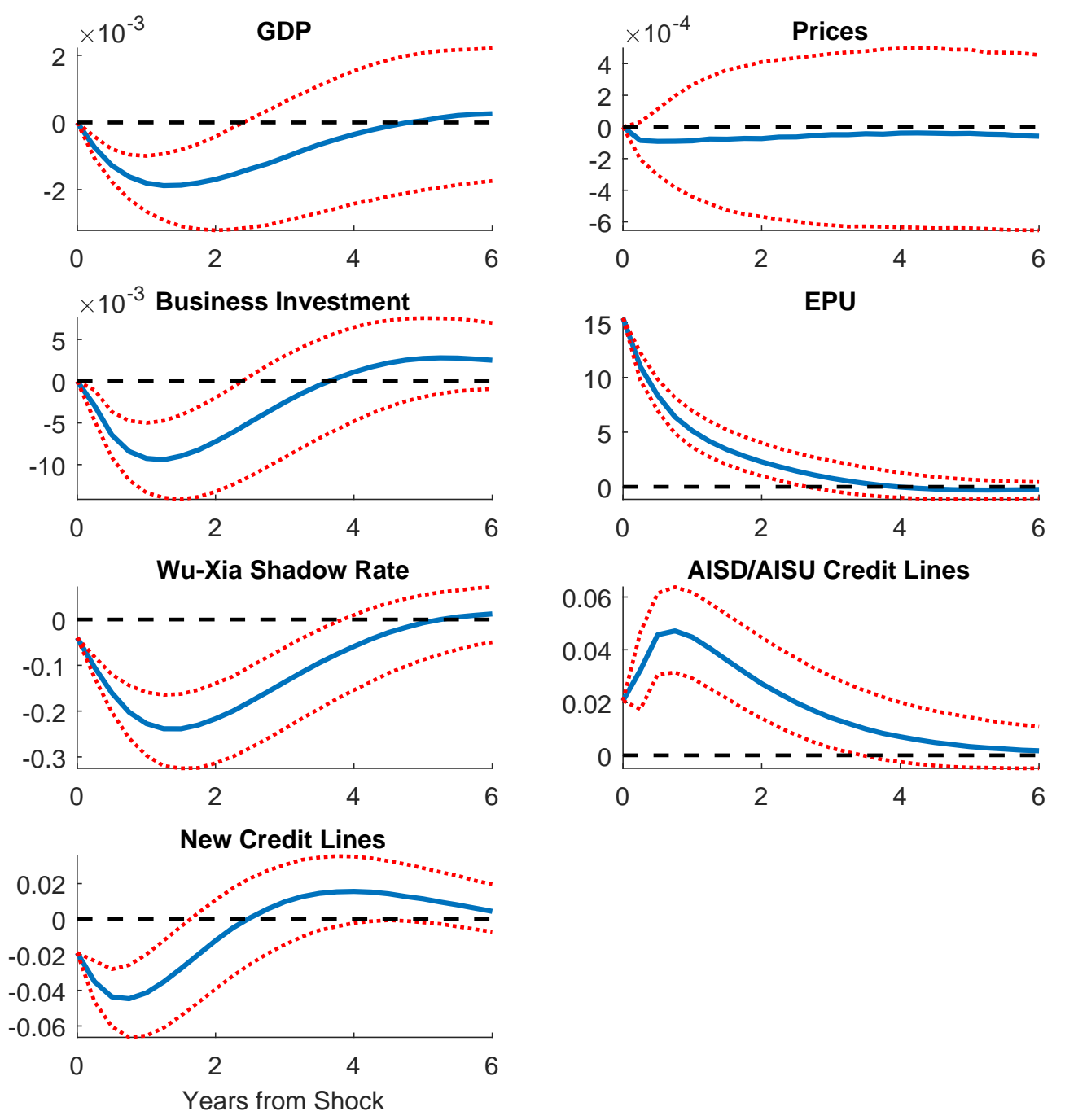

Figure 11: EPU and the Response of the AISD/AISU Ratio on New Credit Lines and the Volume of New Credit Line Originations from DealScan, 1988:Q1-2017:Q1. Orthogonalized responses to a one-standard-deviation structural innovation of EPU. The model includes the log of real GDP, the log of the GDP deflator, the log of real gross business investment, the baseline overall EPU index, the Wu-Xia shadow rate, the ratio of All-In Spread Drawn (AISD) to All-In Spread Undrawn (AISU) on new credit lines, and the volume of new credit line originations from DealScan. VAR(2). Years from the shock on the x-axis. 
banks. In Section 5.2, we thoroughly check the robustness of the loan ratio results by adopting a variety of alternative model specifications. For reading convenience, we report in the Appendix the full sets of responses that accompany the responses of the lending variables presented here.

An overarching message emerges clearly from these tests. Irrespective of the specification and data we consider, our analysis suggests that an exogenous increase in EPU foreshadows a contraction in the supply of business loans at large banks.

\subsection{Further Insights}

The Financial Crisis, the Great Recession, and the Unconventional Monetary Policy Regime. The sample we use in our benchmark model includes the Financial Crisis, the Great Recession, and the post-recession period characterized by an unconventional monetary policy regime. This period not only entails persistently high levels of EPU, but also includes a documented acute contraction in the supply of credit (see, for instance, Ivashina and Scharfstein, 2010; Cornett, McNutt, Strahan, and Tehranian, 2011; Santos, 2011; Adrian, Colla, and Shin, 2013; Chodorow-Reich, 2014). It is then important to assess whether the result of a supply-side contraction from the benchmark model is driven by this period of unusually high levels of uncertainty and pronounced contraction in the supply of loans, and whether the benchmark result also holds excluding this more extreme regime. Caldara, Fuentes-Albero, Gilchrist, and Zakrajsek (2016) express a similar concern about their baseline results based on the 1973:M1-2015:M3 sample period, and they replicate their analysis using only the pre-crisis period. We follow here their approach and estimate our benchmark model using the 1985:Q1-2007:Q2 sample.

Figure 12 illustrates the response of the loan ratio to a positive one-standard deviation uncertainty shock on this shorter sample. The hump-shaped behavior of the response is fully preserved, with a peak that arrives roughly two years after the shock. This peak is delayed by about one year with respect to the benchmark response in Figure 7, indicating a more conservative adjustment process of loan supply in the pre-crisis period. Similarly, the magnitude of the response decreases by about $1.5 \%$ at the peak with respect to the benchmark model, and after four years from the shock the response is not significant anymore. It is worth noting that the smaller response of the loan ratio is only partially explained by the smaller standard deviation of the EPU shocks in the pre-crisis period. Once this is accounted for, the measured supply contraction corresponds to about 9-10 basis points per unit increase of EPU. Even though these elements show, altogether, that excluding the Financial Crisis, Great Recession, and unconventional monetary policy regime period leads to a smaller effect of uncertainty on loan supply, we can safely conclude that the transmission mechanism we describe in Section 4 is a feature of the interaction between uncertainty and banking system that applies during more standard economic and policy conditions as well.

We report the full set of impulse response functions for the pre-crisis sample in Figure A3 of the Appendix. All the other responses in the model closely resemble those in the benchmark model, especially the variables from the real block.

The Role of Bank Size. The consolidation process of the banking industry (Berger, Demsetz, and Strahan, 1999; DeYoung, 2014) has given birth to larger banks, which have 


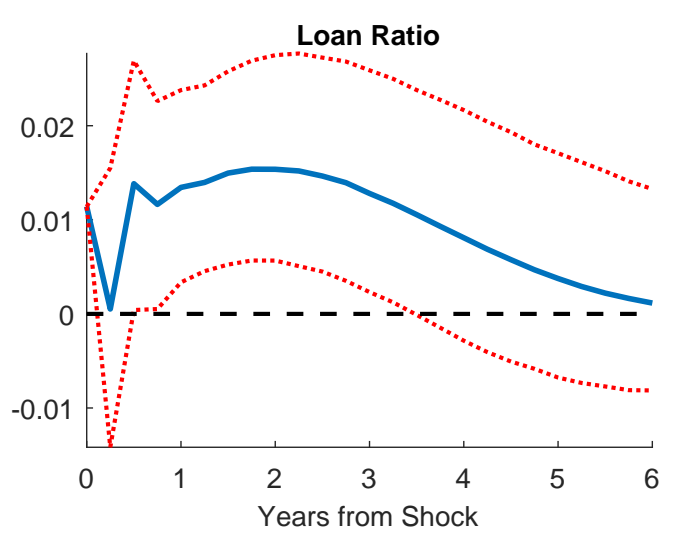

Figure 12: EPU and the Response of the Ratio of Loans Extended under Commitment to Spot Loans Extended by Large Banks, 1985:Q1-2007:Q2. Orthogonalized responses to a one-standard-deviation structural innovation of EPU. The model includes the log of real GDP, the log of the GDP deflator, the log of real gross business investment, the baseline overall EPU index, the Wu-Xia shadow rate, the 10-year Baa-Treasury credit spread, and the ratio of loans extended under commitment to spot loans originated by large domestic banks. $\operatorname{VAR}(2)$. Years from the shock on the x-axis.

become increasingly more important players in the origination of business credit, as can be seen in Figure 2. While large banks originated about two thirds of the business loans before 1995, they currently originate well over $90 \%$ of them in our sample. Large and small banks embrace different business models and serve different clienteles - while large banks tend to serve larger firms, small banks specialize in serving smaller ones (Berger, Miller, Petersen, Rajan, and Stein, 2005). Smaller firms tend to be informationally more opaque and, partially as a result of this, more credit constrained. This naturally creates incentives for small firms to strategically administer their use of available liquidity, such as the one on open credit lines. Thus, in the face of increasing uncertainty, they could have pressing incentives to slow draw downs and preserve access to open credit lines. This response would differ from that of larger, less constrained firms, with access to alternative sources of funds.

Figure 13 illustrates the responses to uncertainty shocks from two models in which small bank loans replace the large bank loans we have used thus far. Figure 13a is for a model in which loans extender under commitment and spot loans are considered separately, paralleling Figure 6, while Figure 13b considers the loan ratio for small banks, as in our main specification in Figure 7 for large banks. ${ }^{29}$

In the analysis of large banks-large firms we have seen that both loans extended under commitment and spot loans display negative responses soon after exogenous increases in EPU. However, while the response of loans extended under commitment is relatively mild over time, the response of spot loans builds up to become three to four times the size of the former. This leads to a positive and significant response of the loan ratio, which peaks about a year from the shock. In clear contrast, in the analysis of small banks-small firms we

\footnotetext{
${ }^{29}$ The full set of impulse response functions for these two models can be respectively found in Figures A4 and $\mathrm{A} 5$ of the Appendix.
} 

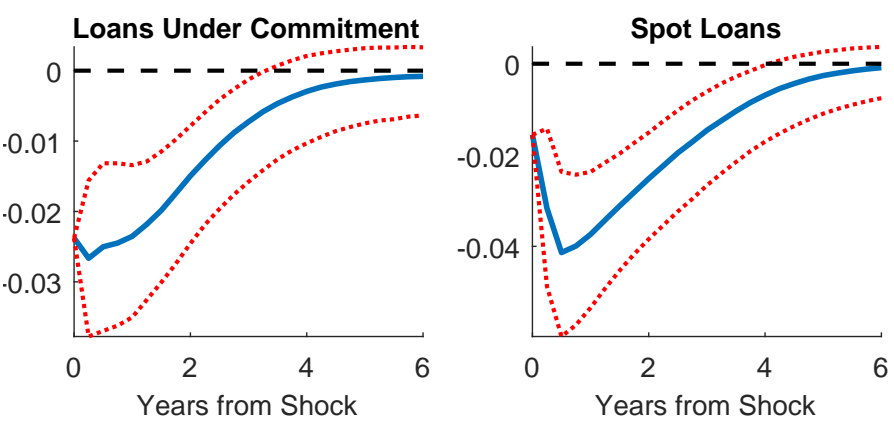

(a) Small Banks - Loans Separately

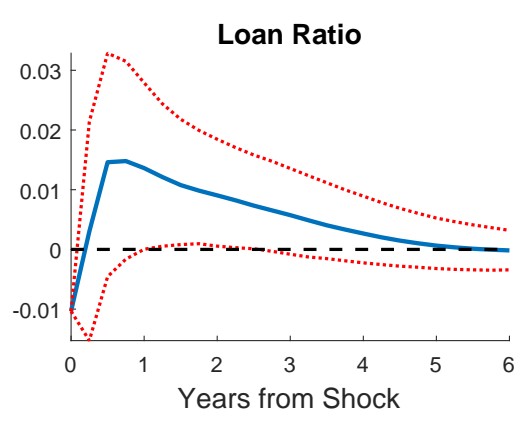

(b) Small Banks - Loan Ratio

Figure 13: EPU and the Response of the Ratio of Loans Extended under Commitment to Spot Loans Extended by Small Banks, 1985:Q1-2017:Q1. Orthogonalized responses to a one-standard-deviation structural innovation of EPU. The model includes the log of real GDP, the log of the GDP deflator, the log of real gross business investment, the baseline overall EPU index, the Wu-Xia shadow rate, the 10-year Baa-Treasury credit spread, and either the amount of loans extended under commitment (a) and spot loans or the ratio of loans extended under commitment to spot loans (b) originated by small domestic banks. $\operatorname{VAR}(2)$. Years from the shock on the x-axis.

observe in Figure 13a a sharp decline in loans extended under commitment in the short- and medium-run, which is comparable in size to the fall of spot loans during most of the horizon.

These individual responses lead to a much smaller and largely non-significant response of the loan ratio, as we observe in Figure 13b. The immediate fall in loans extended under commitment among small banks seems to suggest that small firms manage their access to liquidity more cautiously than larger firms would do in response to heightening EPU, slowing down their drawdowns on credit lines so as to preserve the liquidity insurance they offer. Mainly for this reason, we deem appropriate to consider large banks and small banks separately in our baseline analysis. It is worth mentioning at this point that an analysis of loans extended by large and small banks combined yields very similar results to those from the analysis of large banks. This is hardly surprising, as large banks originate most of the aggregate business loans, thus driving the aggregate dynamics. For completeness, we report the impulse response functions of this model in Figure A6 of the Appendix.

\subsection{Robustness Checks}

VAR Order Selection. The choice of lag order two in the benchmark model was guided by the standard criteria of comparing the posterior probabilities of models - to this end, we considered lag orders between one and four. In the first robustness check of the benchmark loan ratio model reported in Figure 7, we use a lag order of four instead. This lag order is frequently used in the monetary policy literature for analyses based on quarterly data. Figure 14a shows that the response of the loan ratio under this alternative specification is consistent with the response in our benchmark model. The full set of responses is reported in Figure A7. In the unreported tests of models using lag order one or three, we find similar 
results.

Structural Identification Ordering. The benchmark identification strategy reflects the belief that, while credit markets clear immediately in response to an uncertainty shock, the real economy adjusts with a delay of a lag. We check the robustness of the results to the following two alternative identification schemes.

First, as in Baker, Bloom, and Davis (2016), we assume that EPU is the most exogenous variable in the system and both the real economy and the financial markets adjust immediately to an uncertainty shock. In the block-recursive identification model we adopt, this is achieved by placing EPU first in the vector of endogenous variables. The response of the ratio of loans extended under commitment to spot loans for this model is reported in Figure 14b, and it shows that this causal ordering of the variables does not affect our results. Figure A8 in the Appendix illustrates the full set of responses.

Second, we place EPU last in the identification ordering. In doing so, both past and contemporaneous shocks that affect the real economy, the financial sector, and even the monetary policy stance are controlled for in the uncertainty innovations. This ordering resembles the second identification scheme in Gilchrist, Sim, and Zakrajsek (2014), for instance. This ordering choice could be plausible in cases where it becomes important to assess the impact of EPU innovations on other variables conditional on the information on both the real and financial sectors of the economy. Figure 14c shows that, while the magnitude of the loan ratio response for this model is slightly reduced, the shape of the response clearly follows that of the benchmark result. Figure A9 presents the full set of responses.

Alternative Measures of Monetary Policy Stance. We now assess the possible implications of two alternative measures of monetary policy stance for our results. In the benchmark specification we use the $\mathrm{Wu}$-Xia shadow rate to capture the monetary policy stance during the period of unconventional monetary policy that followed the 2007-2009 financial crisis, when the Federal Reserve resorted to large-scale asset purchases and forward guidance to further ease the monetary conditions and the federal funds rate reached the zero lower bound.$^{30}$ As a first check, then, Figure 14d illustrates the response of the loan ratio when the actual federal funds rate replaces the $\mathrm{Wu}$-Xia shadow rate. A policy rate stuck at the zero lower bound during a significant part of the sample could, in principle, affect the identification of the policy uncertainty shocks in the model. However, the response of the loan ratio remains relatively unaltered also in this case, with a significantly positive response from impact until roughly the third year after the shock. Figure A10 displays the full set of responses.

In the second check, the Krippner shadow rate Krippner $(2013,2015)$ replaces the WuXia rate. While conceptually similar, these two measures of the shadow rate bear differences in the modeling and estimation procedures, which could have an impact on the identification of the EPU shock as well. ${ }^{31}$ Moreover, recent literature on monetary policy (see, for instance

\footnotetext{
${ }^{30}$ See Bernanke (2012) for a description of these policies.

${ }^{31}$ Both methodologies build on the shadow rate term structure model introduced by Black (1995) to find more suitable measures of the underlying policy stance. Wu and Xia (2016) propose an analytical approximation to the shadow rate term structure model that is easily tractable and can be applied directly
} 


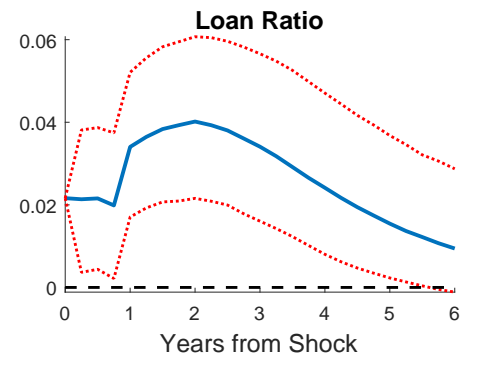

(a) $\operatorname{VAR}(4)$

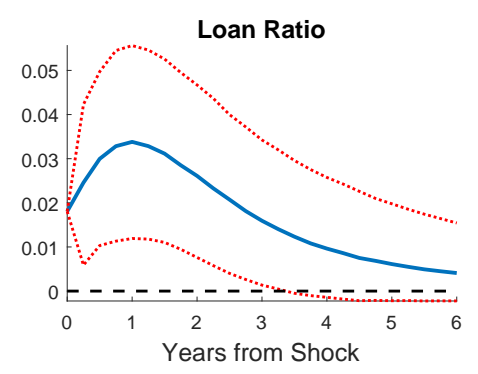

(d) Federal Funds Rate

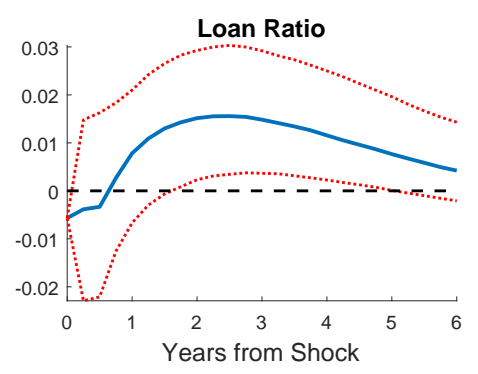

(g) MPU

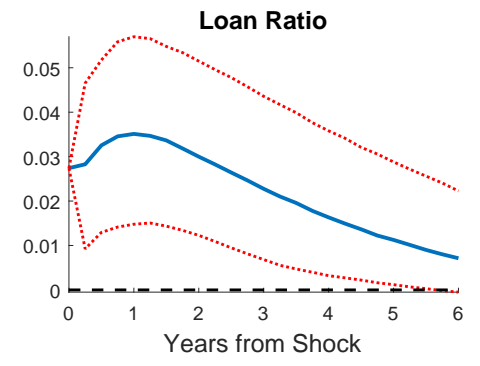

(b) EPU first in the identification ordering

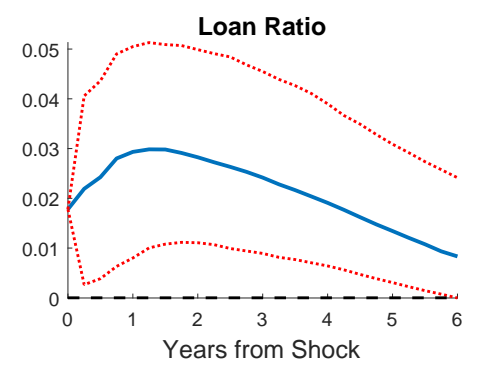

(e) S\&P Index

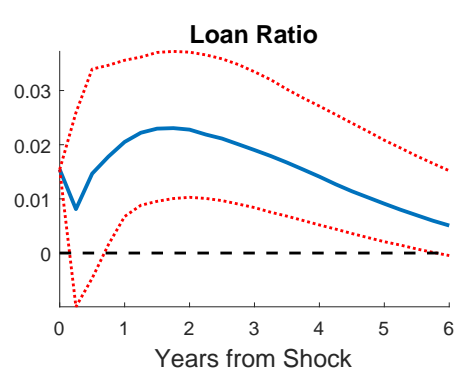

(h) FPU

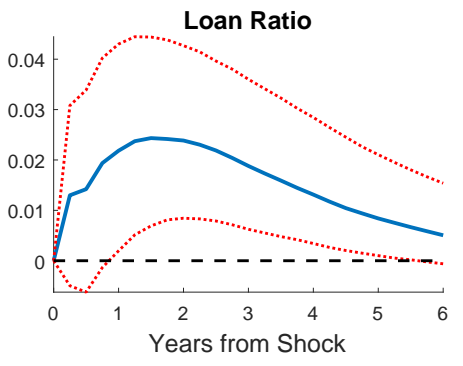

(c) EPU last in the identification ordering

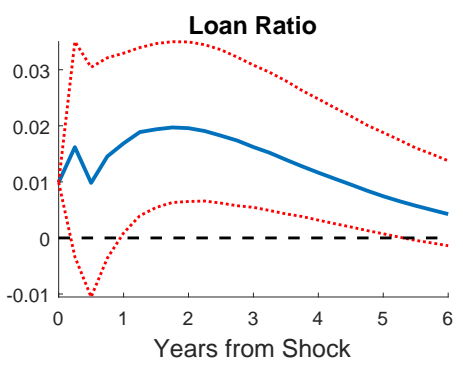

(f) EPU News

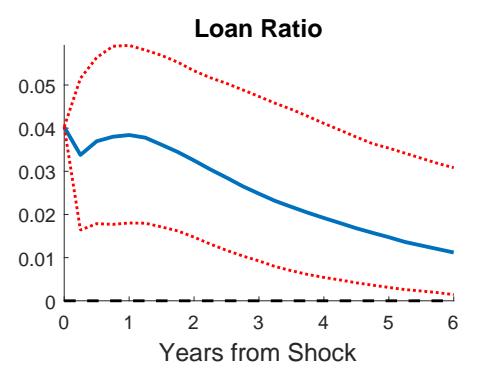

(i) BBD Sample

Figure 14: Robustness Checks: Response of the Ratio of Loans Extended under Commitment to Spot Loans Extended by Large Banks. Sample period is 1985:Q1-2017:Q1 in all cases, except BBD Sample, which is 1985:Q1-2014:Q4. Response to a one-standard-deviation structural innovation in EPU. The benchmark model is modified in each robustness exercise as described in the panels. Years from the shock on the x-axis. 
Wu and Xia, 2016; Krippner, 2019) has pointed out that these subtle differences somewhat matter in the VAR framework of monetary policy analysis. This new response of the loan ratio is very similar to the benchmark one as well; we hence leave the illustration of this result for Figure A12 in the Appendix. Overall, we conclude that our results are robust to alternative measures of the monetary policy stance.

Changes in the Financial Block. We can introduce two changes in the financial block of the model to adjust the characterization of the financial sector. As a first change, we add the log of the S\&P 500 stock market index to the $Z_{t}$ block as in Baker, Bloom, and Davis (2016), and report the response of the loan ratio in Figure 14e - Figure A13 displays the full set of responses in the Appendix. Business decisions are typically forward looking. Firms respond to expected economic conditions and their willingness to take credit reflects their expectations regarding future profitability of investment opportunities. Policy uncertainty is an important determinant of these expectations, but more in general different types of news would also affect them. Since stock market prices embed information from multiple sources, they provide a suitable control to help us disentangle specific policy uncertainty shocks from the effects of other sources of relevant news. Moreover, explicitly including a measure of market performance in the VAR could also improve the empirical modeling of elements of latent demand and supply of credit, as stock markets are, in turn, sensitive to policy uncertainty (Pastor and Veronesi, 2013; Caldara, Fuentes-Albero, Gilchrist, and Zakrajsek, 2016; Kelly, Pastor, and Veronesi, 2016). As before, the ratio of loans extended under commitment to spot loans remains virtually unchanged.

The second change is obtained by replacing the ten-year Baa-Treasury Credit Spread of the benchmark specification with the ten-year Aaa-Treasury Credit Spread. We have mentioned that choosing the sample of large banks allows the analysis to be primarily centered around large firms. There is also a well-established positive relation between firm size and creditworthiness. Thus, an alternative, plausible choice of credit spread would be Moody's Seasoned Aaa Corporate Bond Yield Relative to Yield on Ten-Year Treasury Constant Maturity. The results for this model, reported in Figure A14 of the Appendix, show that the response of the loan ratio to an EPU innovation is robust to this modification.

EPU News. As discussed in Section 3, EPU News is the main component of the EPU index, accounting for half the weight in its construction. EPU News is built to gauge economic policy uncertainty through the relative prevalence of newspaper articles that suggest such uncertainty in the media. From Figure 1, it is apparent that while EPU News drives the EPU index, it is also sensibly more volatile. We assess, next, the robustness of our benchmark loan ratio result to the use of EPU News instead of the EPU index and report the result in Figure 14f. The response of the loan ratio is slightly smaller, but besides this difference the overall interpretation of the response once again remains the same. Figure A15, in the Appendix, illustrates the full set of responses.

to discrete-time data using an extended Kalman Filter. Krippner $(2013,2015)$ proposes a framework that relies on a continuous-time Gaussian affine term structure model where the estimation is performed using the iterated extended Kalman Filter. Accordingly, they also yield slightly different shadow rates, which is apparent in Figure A11 in the Appendix. 
Monetary and Fiscal Policy Uncertainty. Using solely news data, Baker, Bloom, and Davis (2016) also build sub-indexes that gauge different dimensions of policy uncertainty. Two such sub-indexes of interest here are the Monetary Policy Uncertainty index (MPU henceforth) and the Fiscal Policy Uncertainty index (FPU henceforth). ${ }^{32}$ Given the direct link of monetary policy with the cost of bank funding, heightened MPU could discourage banks from lending. Figure $14 \mathrm{~g}$ shows evidence in this sense. Upon an MPU shock, the response of the ratio of loans extended under commitment to spot loans is positive from the third quarter on, with a peak around two and a half years from the shock. This result is consistent with recent findings in Husted, Rogers, and Sun (Forthcoming). Increasing FPU could also discourage banks from lending. For instance, FPU could hinder output, which would result in deteriorating business conditions and creditworthiness, making it sensible for banks to curtail loan supply. Figure $14 \mathrm{~h}$ presents evidence consistent with this outcome. Again, the loan ratio presents a hamp-shaped response that peaks around the second year and remains significantly different from zero for the most part of the horizon. Figures A16 and A17 in the Appendix display the full sets of responses for the MPU and FPU models.

Other Robustness Checks. We conclude this section with a few more simple specification checks. These, once again, confirm the baseline loan ratio response. First, we restrict the estimation sample to the period between 1985:Q1 and 2014:Q4 in order to mimic the period of analysis in Baker, Bloom, and Davis (2016). The response of the loan ratio from this model is reported in Figure 14i. As before, the response is the same as in the benchmark result. Figure A18 in the Appendix displays the full set of responses. Second, we add, alternatively, the amount of loans extended under commitment or the amount of spot loans to our benchmark specification. The full sets of responses are respectively illustrated in Figures A19 and A20 in the Appendix. The responses of the loan ratio remain unchanged, and the separate responses of loans extended under commitment and spot loans closely follow their responses previously reported in Figure 6.

\section{Conclusion}

In this work, we investigate the effect of economic policy uncertainty on bank business lending. Our results show that an exogenous increase in EPU causes a fall in bank business lending, partly due to softening demand for funds, but also as the result of a contraction in the supply of credit. This contraction in the supply of credit takes two main, distinct forms.

The first form of credit contraction entails a straight reduction in the availability of spot funds. In our analysis, this is evident in two different tests. The first test documents a sharp fall in the flow of spot loans with respect to that of loans extended under commitments in response to the EPU shock, all while the credit spreads rise. The second test shows a fall in the origination of new term loans in the syndicated loan market together with an increase in the loan spreads in response to the same shock.

The second form of credit contraction relates to the provision of liquidity insurance, a key function of the banking system. This effect entails banks tightening their supply of

\footnotetext{
${ }^{32}$ We refer the reader to Appendix B of Baker, Bloom, and Davis (2016) for further details on the constructions of these measures.
} 
liquidity insurance in response to heightening EPU, which they do in two ways. First, they curtail the origination of new credit lines, which reduces the amount of insured liquidity. Second, they embed in the new credit lines a pricing structure that reduces the probability of borrowers drawing down the committed funds. This can further restrain loan growth in time.

Our findings highlight the role that banks play in the transmission of EPU shocks to the rest of the economy via the supply of loans to the business sector. These findings are particularly relevant in light of the theoretical literature showing that financial frictions amplify the contractionary effects on the economy that result from heightened EPU. Thus, our results convey a simple, yet clearly relevant policy implication: predictability in policymaking can prove a powerful policy in itself. 


\section{References}

Adrian, T., P. Colla, and H. S. Shin (2013): "Which Financial Frictions? Parsing the Evidence from the Financial Crisis of 2007 to 2009," in NBER Macroeconomics Annual, ed. by D. Acemoglu, J. Parker, and M. Woodford, vol. 27, pp. 159-214. University of Chicago Press.

Alessandri, P., And M. Bottero (2017): "Bank Lending in Uncertain Times," Mimeo.

Arellano, C., Y. Bai, And P. J. Kehoe (2016): "Financial Frictions and Fluctuations in Volatility," NBER Working Paper No. 22990.

Bachmann, R., S. Elstner, and E. R. Sims (2013): "Uncertainty and Economic Activity: Evidence from Business Survey Data," American Economic Journal: Macroeconomics, $5(2), 217-249$.

Baker, S. R., N. Bloom, and S. J. Davis (2016): "Measuring Economic Policy Uncertainty," Quarterly Journal of Economics, 131(4), 1593-1636.

Barraza, S., A. Civelli, and A. Zaniboni (2019): "Business Loans and the Transmission of Monetary Policy," Journal of Financial and Quantitative Analysis, 54(2), 925-965.

Baum, C. F., M. Caglayan, and O. Talavera (2008): "Uncertainty Determinants of Firm Investment," Economic Letters, 98, 282-287.

Berg, T., A. Saunders, and S. Steffen (2016): "The Total Cost of Corporate Borrowing in the Loan Market: Don't Ignore the Fees," Journal of Finance, 71(3), 1357-1392.

Berger, A. N., R. S. Demsetz, and P. E. Strahan (1999): "The Consolidation of the Financial Services Industry: Causes, Consequences, and Implications for the Future," Journal of Banking and Finance, 23, 135-194.

Berger, A. N., O. Guedhami, H. H. Kim, and X. Li (2018): "Economic Policy Uncertainty and Bank Liquidity Creation," Mimeo.

Berger, A. N., N. H. Miller, M. A. Petersen, R. G. Rajan, and J. C. Stein (2005): "Does Function Follow Organizational Form? Evidence from the Lending Practices of Large and Small Banks," Journal of Financial Economics, 76, 237-269.

Bernanke, B. S. (1983): "Irreversibility, Uncertainty, and Cyclical Investment," Quarterly Journal of Economics, 98(1), 85-106.

(2012): "Monetary Policy since the Onset of the Crisis," Remarks at the Federal Reserve Bank of Kansas City Economic Symposium, Jackson Hole, Wyoming, August 31.

Bianchi, F., C. L. Ilut, and M. Schneider (2017): "Uncertainty Shocks, Asset Supply and Pricing over the Business Cycle," The Review of Economic Studies, 85(2), 810-854.

BlaCK, F. (1995): "Interest Rates as Options," Journal of Finance, 50(7), 1371-1376. 
Bloom, N. (2009): "The Impact of Uncertainty Shocks," Econometrica, 77(3), 623-685. $153-176$.

Bloom, N., S. Bond, and J. V. ReEnen (2007): "Uncertainty and Investment Dynamics," Review of Economic Studies, 74, 391-415.

Bloom, N., M. Floetotto, N. Jaimovich, I. Saporta-Eksten, and S. J. Terry (2018): "Really Uncertain Business Cycle," Econometrica, 86(3), 1031-1065.

Board of Governors of the Federal Reserve System (2017): "Survey of Terms of Business Lending," E.2 Release, May.

Bonciani, and van Roye (2015): "Uncertainty Shocks, Banking Frictions and Economic Activity," European Central Bank, Working Paper Series, No. 1825.

Bordo, M. D., J. V. DucA, And C. Koch (2016): "Economic Policy Uncertainty and the Credit Channel: Aggregate and Bank Level U.S. Evidence over Several Decades," Journal of Financial Stability, 26, 90-106.

Buch, C. M., M. Buchholz, and L. Tonzer (2015): "Uncertainty, Bank Lending, and Bank-Level Heterogeneity," IMF Economic Review, 63(4), 919-954.

Caballero, R. J., and A. Krishnamurhty (2008): "Collective Risk Management in a Flight to Quality Episode," Journal of Finance, 63(5), 2195-2230.

Caggiano, G., E. Castelnuovo, and N. Groshenny (2014): "Uncertainty Shocks and Unemployment Dynamics in U.S. Recessions," Journal of Monetary Economics, 67, 78-92.

Caldara, D., C. Fuentes-Albero, S. Gilchrist, and E. Zakrajsek (2016): "The Macroeconomic Impact of Financial and Uncertainty Shocks," European Economic Review, 88, 185-207.

Canova, F. (2007): Methods for Applied Macroeconomic Research. Princeton University Press.

Chodorow-Reich, G. (2014): "The Employment Effects of Credit Market Disruptions: Firm-Level Evidence from the 2008-9 Financial Crisis," Quarterly Journal of Economics, 129(1), 1-59.

Christiano, L. J., M. Eichenbaum, and C. L. Evans (1999): "Monetary Policy Shocks: What Have We Learned and to What End?," in Handbook of Macroeconomics, ed. by J. Taylor, and M. Woodford. North-Holland, Amsterdam.

Christiano, L. J., R. Motto, and M. Rostagno (2014): "Risk Shocks," American Economic Review, 104(1), 27-65. 
Cornett, M. M., J. J. McNutt, P. E. Strahan, and H. Tehranian (2011): "Liquidity Risk Management and Credit Supply in the Financial Crisis," Journal of Financial Economics, 101, 297-312.

Demiroglu, C., C. James, and A. Kizilaslan (2012): "Bank Lending Standards and Access to Lines of Credit," Journal of Money, Credit, and Banking, 44(6), 1065-1089.

den Haan, W. J., S. W. Sumner, and G. M. Yamashiro (2007): "Bank Loan Portfolios and the Monetary Transmission Mechanism," Journal of Monetary Economics, 54(3), 904924.

DeYoung, R. (2014): "Banking in the United States," in The Oxford Handbook of Banking, ed. by A. N. Berger, P. Molyneux, and J. O. S. Wilson. Oxford University Press, Oxford.

Dieppe, A., R. Legrand, and B. van Roye (2016): "The BEAR Toolbox," European Central Bank, Working Paper Series, Nro. 1934.

Doan, T., R. Litterman, and C. Sims (1984): "Forecasting and Conditional Projection Using Realistic Prior Distributions," Econometric Reviews, 3, 1-100.

Falk, N., And C. A. Shelton (2018): "Fleeing a Lame Duck: Policy Uncertainty and Manufacturing Investment in US States," American Economic Journal: Economic Policy, 10(4), 135-152.

Gatev, E., T. Schuermann, and P. E. Strahan (2009): "Managing Bank Liquidity Risk: How Deposit-Loan Synergies Vary with Market Conditions," Review of Financial Studies, 22(3), 995-1020.

Gatev, E., and P. E. Strahan (2006): "Banks Advantage in Hedging Liquidity Risk: Theory and Evidence from the Commercial Paper Market," Journal of Finance, 61(2), 867-892.

Gilchrist, S., J. W. Sim, and E. ZakrajSeK (2014): "Uncertainty, Financial Frictions, and Investment Dynamics," NBER Working Paper No. 20038.

Greenspan, A. (2004): "Risk and Uncertainty in Monetary Policy," Remarks at the Meetings of the American Economic Association, San Diego, January 03.

Husted, L., J. Rogers, And B. Sun (Forthcoming): "Monetary Policy Uncertainty," Journal of Monetary Economics.

IvashinA, V. (2009): "Asymmetric Information Effects on Loan Spreads," Journal of Financial Economics, 92, 300-319.

Ivashina, V., And D. Scharfstein (2010): "Bank Lending during the Financial Crisis of 2008," Journal of Financial Economics, 97(3), 319-338.

Jens, C. E. (2017): "Political Uncertainty and Investment: Causal Evidence from U.S. Gubernatorial Elections," Journal of Financial Economics, 124, 563-579. 
Kashyap, A. K., R. G. Rajan, and J. C. Stein (2002): "Banks as Liquidity Providers: An Explanation for the Coexistence of Lending and Deposit-Taking," Journal of Finance, 57(1), 33-73.

Kashyap, A. K., J. C. Stein, and D. W. Wilcox (1993): "Monetary policy and credit conditions: evidence from the composition of external finance," American Economic Review, 83(1), 78-98.

Kelly, B., L. Pastor, and P. Veronesi (2016): "The Price of Political Uncertainty: Theory and Evidence from the Option Market," Journal of Finance, 71(5), 2417-2480.

Kilian, L., And H. LÜtkepohl (2017): Structural Vector Autoregressive Analysis. Cambridge University Press.

Krippner, L. (2013): "Measuring the Stance of Monetary Policy in Zero Lower Bound Environments," Economic Letters, 118(1), 135-138.

(2015): Zero Lower Bound Term Structure Modeling: A Practitioner's Guide. Palgrave-Macmillan.

_ (2019): "A Note of Caution on Shadow Rate Estimates," Journal of Money, Credit and Banking, In Press.

Leahy, J. V., And T. M. Whited (1996): "The Effects of Uncertainty on Investment: Some Stylized Facts," Journal of Money, Credit and Banking, 28(1), 64-83.

Leduc, S., And Z. Liu (2016): "Uncertainty Shocks Are Aggregate Demand Shocks," Journal of Monetary Economics, 82, 20-35.

Litterman, R. (1979): "Techniques of Forecasting Using Vector Autoregressions," Federal Reserve Bank of Minneapolis, Working Paper 115.

- (1986): "Forecasting with Bayesian Vector Autoregressions: Five Years of Experience," Journal of Busines \&3 Economics Statistics, 4(1), 25-38.

Morgan, D. P. (1998): "The Credit Effects of Monetary Policy: Evidence Using Loan Commitments," Journal of Money, Credit, and Banking, 30(1), 102-118.

Pastor, L., and P. Veronesi (2013): "Political Uncertainty and Risk Premia," Journal of Financial Economics, 110, 520-545.

RaJAn, R. G. (1992): "Insiders and Outsiders: The Choice between Informed and Arm'sLength Debt," Journal of Finance, 47(4), 1367-1400.

Santos, J. A. (2011): "Bank Corporate Loan Pricing Following the Subprime Crisis," Review of Financial Studies, 24(6), 1916-1943.

SchaAl, E. (2017): "Uncertainty and Unemployment," Econometrica, 85(6), 1675-1721. 
ShARPe (1990): "Asymmetric Information, Bank Lending, and Implicit Contracts: A Stylized Model of Customer Relationships," Journal of Finance, 45(4), 1069-1087.

Shockley, R. L., And A. V. Thakor (1997): "Bank Loan Commitment Contracts: Data, Theory, and Tests," Journal of Money, Credit, and Banking, 29(4), 517-534.

Sims, C. A., And T. Zha (1998): "Bayesian Methods for Dynamic Multivariate Models," International Economic Review, 39(4), 949-968.

Smietanka, P., N. Bloom, and P. Mizen (2018): "Business Investment, Cash Holding and Uncertainty Since the Great Financial Crisis," Bank of England, Staff Working Paper No. 753 .

Sofianos, G., A. Melnik, and P. Wachtel (1990): "Loan Commitments and Monetary Policy," Journal of Banking and Finance, 14, 677-689.

Stock, J., And M. Watson (2012): "Disentangling the Channels of the 2007-2009 Recession," Brookings Panel on Economic Activity, Spring, 81-135.

Strahan, P. E. (2010): "Liquidity Production in Twenty-First-Century Banking," in The Oxford Handbook of Banking, ed. by A. N. Berger, P. Molyneux, and J. O. Wilson. Oxford University Press, Oxford.

Sufi, A. (2007): "Information Asymmetry and Financing Arrangements: Evidence from Syndicated Loans," Journal of Finance, 62(2), 629-668.

Thakor, A. V., H. Hong, and S. I. Greenbaum (1981): "Bank Loan Commitments and Interest Rate Volatility," Journal of Banking and Finance, 5, 497-510.

VAlencia, F. (2017): "Aggregate Uncertainty and the Supply of Credit," Journal of Banking and Finance, 81, 150-165.

Wu, J. C., And F. D. XiA (2016): "Measuring the Macroeconomic Impact of Monetary Policy at the Zero Lower Bound," Journal of Money, Credit, and Banking, 48(2-3), 253291. 


\section{Appendix}

In this appendix, we present additional figures to accompany those presented in the main text of "Economic Policy Uncertainty and the Supply of Business Loans," including the full sets of orthogonalized impulse-response functions for results presented in Sections $4.2,4.3$, and 5 . 

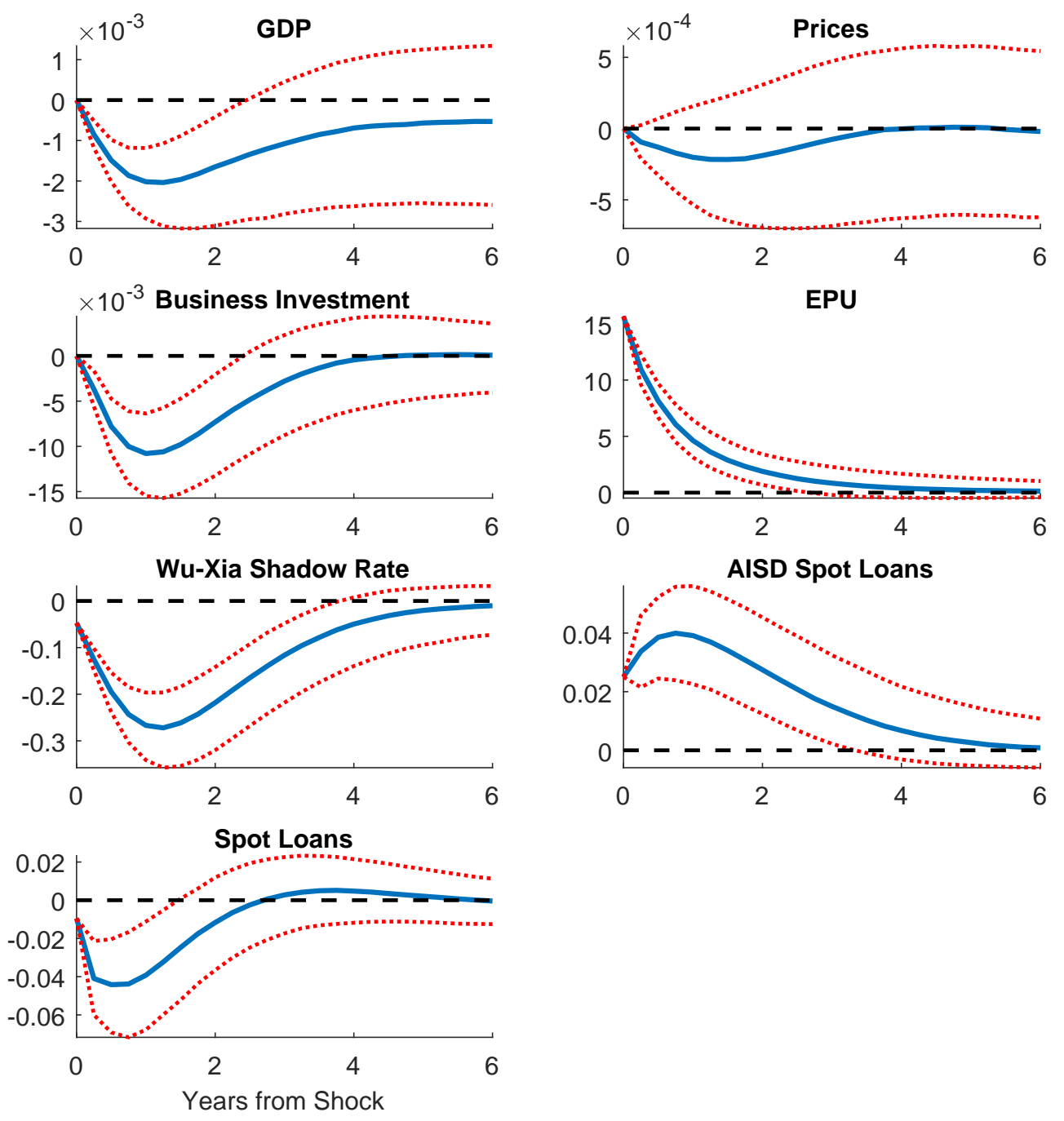

Figure A1: EPU and the Response of the All-In Spread Drawn on New Term Loans and the Volume of Term Loan Originations from DealScan, 1988:Q1-2017:Q1. Orthogonalized responses to a one-standard-deviation structural innovation of EPU. The model includes the $\log$ of real GDP, the log of the GDP deflator, the log of real gross business investment, the baseline overall EPU index, the Wu-Xia shadow rate, the AISD on new term loans, and the volume of term loan originations from DealScan. VAR(2). Years from the shock on the $\mathrm{x}$-axis. 

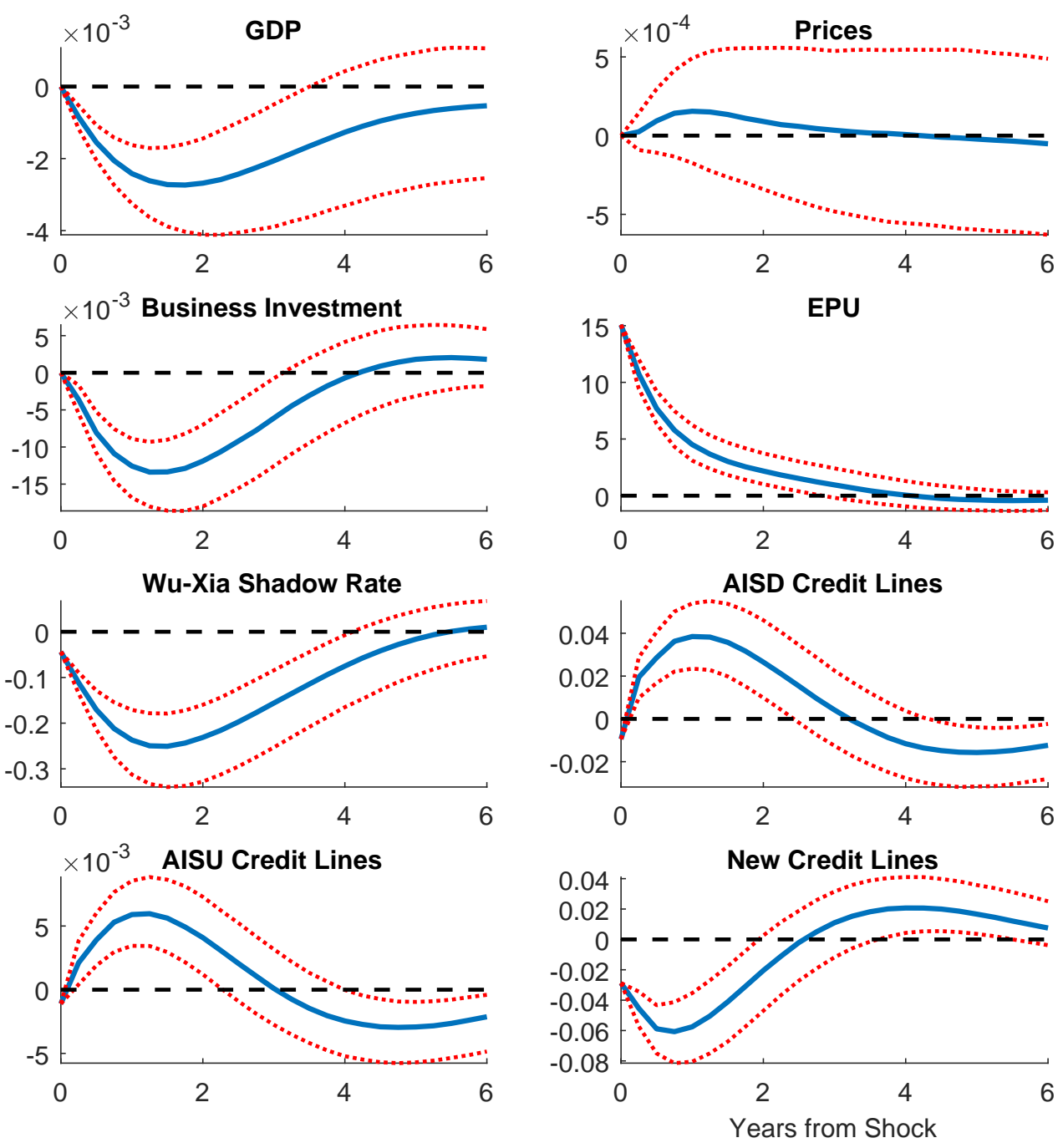

Figure A2: EPU and the Response of the All-In Spread Drawn, All-In Spread Undrawn, and Volume of New Credit Line Originations from DealScan, 1988:Q1-2017:Q1. Orthogonalized responses to a one-standard-deviation structural innovation of EPU. The model includes the $\log$ of real GDP, the log of the GDP deflator, the log of real gross business investment, the baseline overall EPU index, the Wu-Xia shadow rate, the AISD and AISU on new credit lines, and the volume of new credit line originations from DealScan. VAR(2). Years from the shock on the $\mathrm{x}$-axis. 

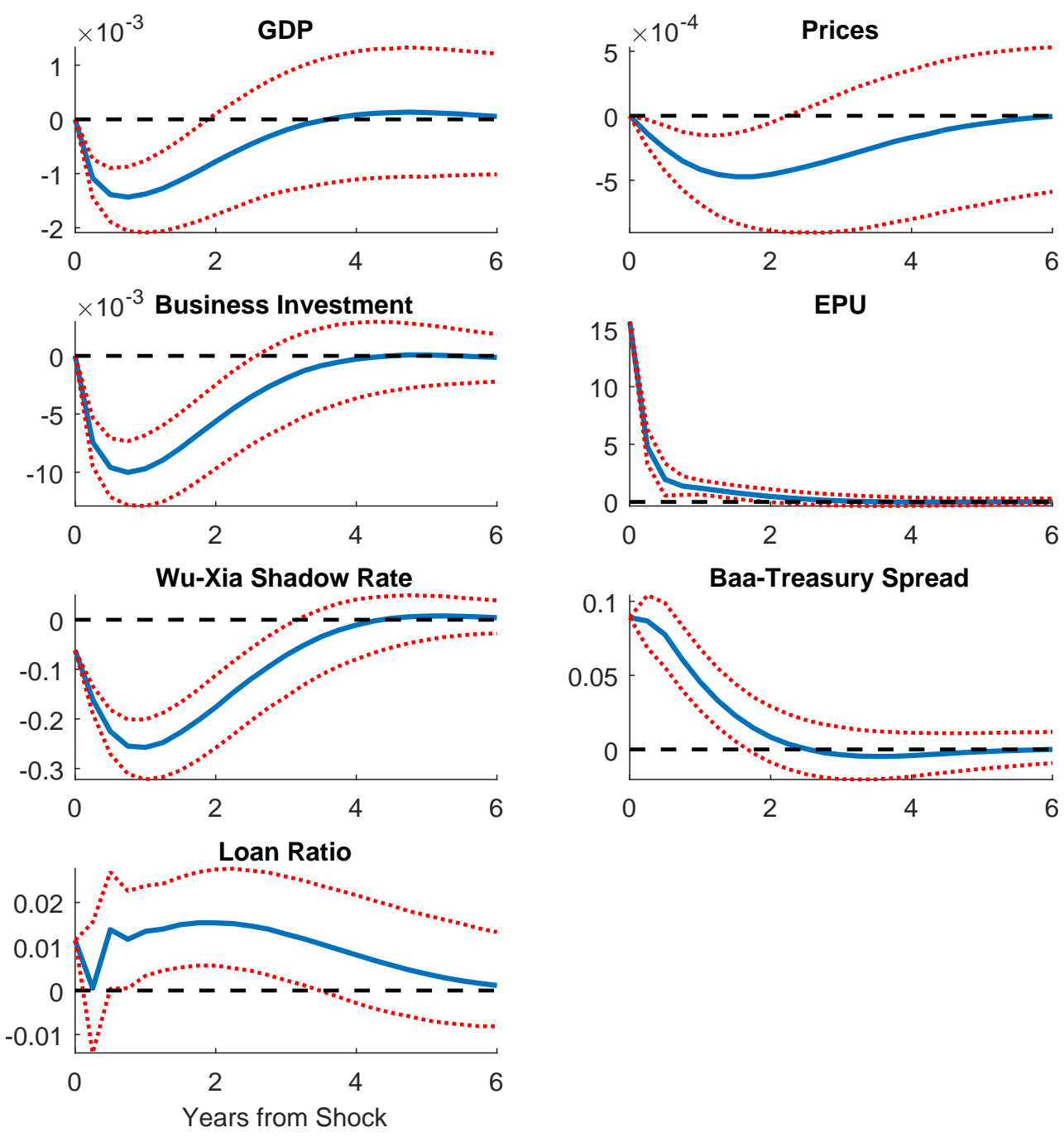

Figure A3: EPU and the Response of the Ratio of Loans Extended under Commitment to Spot Loans Extended by Large Banks from STBL, Excluding the Unconventional Monetary Policy Regime Period, 1985:Q1-200\%:Q2. Orthogonalized responses to a one-standarddeviation structural innovation of EPU. The model includes the log of real GDP, the log of the GDP deflator, the log of real gross business investment, the baseline overall EPU index, the $\mathrm{Wu}$-Xia shadow rate, the 10-year Baa-Treasury credit spread, and the ratio of loans extended under commitment to spot loans. VAR(2). Years from the shock on the x-axis. 

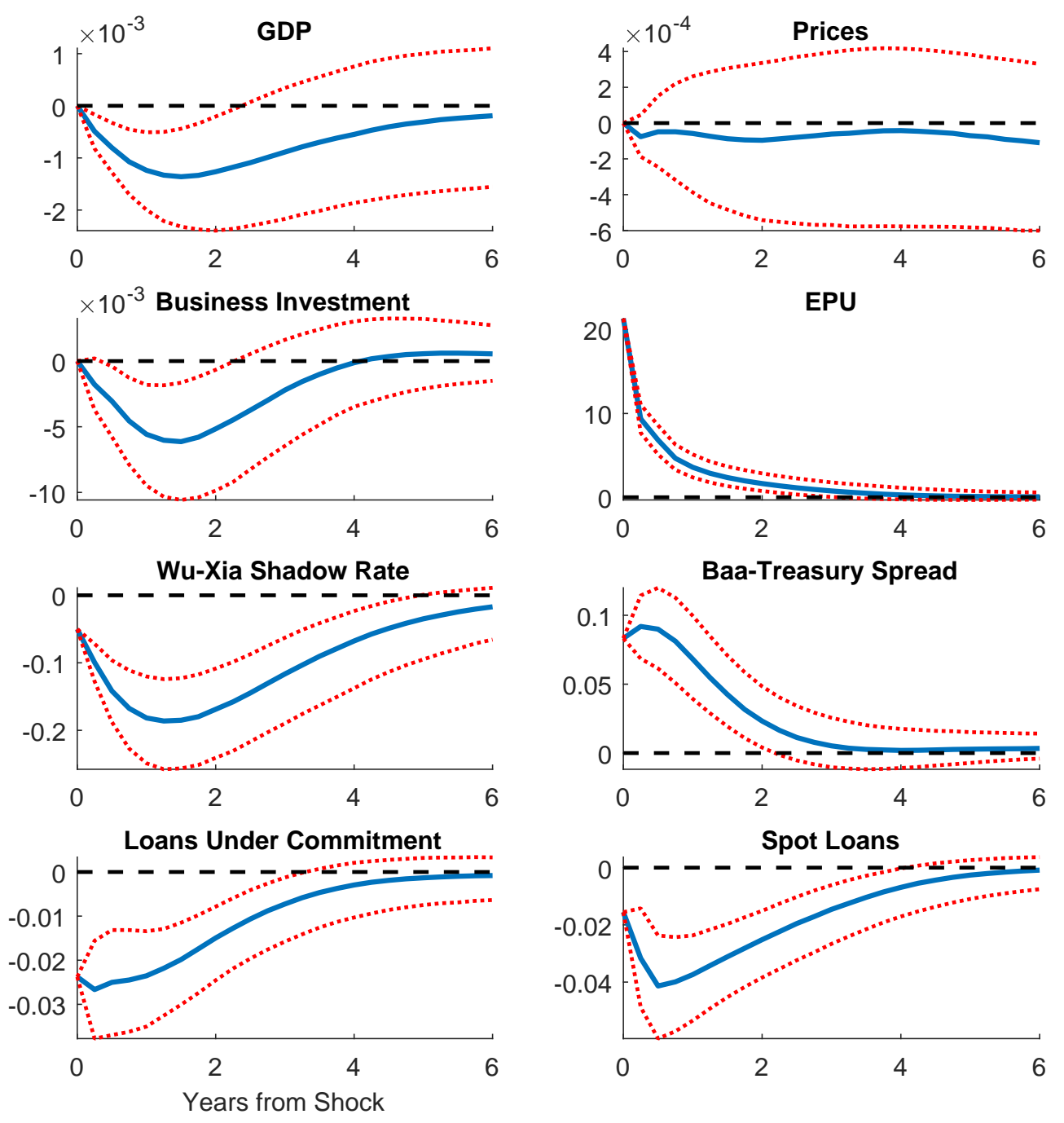

Figure A4: EPU and the Response of Loans Extended under Commitment and Spot Loans Extended by Small Banks, 1985:Q1-2017:Q1. Orthogonalized responses to a one-standarddeviation structural innovation of EPU. The model includes the log of real GDP, the log of the GDP deflator, the log of real gross business investment, the baseline overall EPU index, the $\mathrm{Wu}$-Xia shadow rate, the 10-year Baa-Treasury credit spread, and the amounts of loans extended under commitment and spot loans originated by small banks. VAR(2). Years from the shock on the x-axis. 

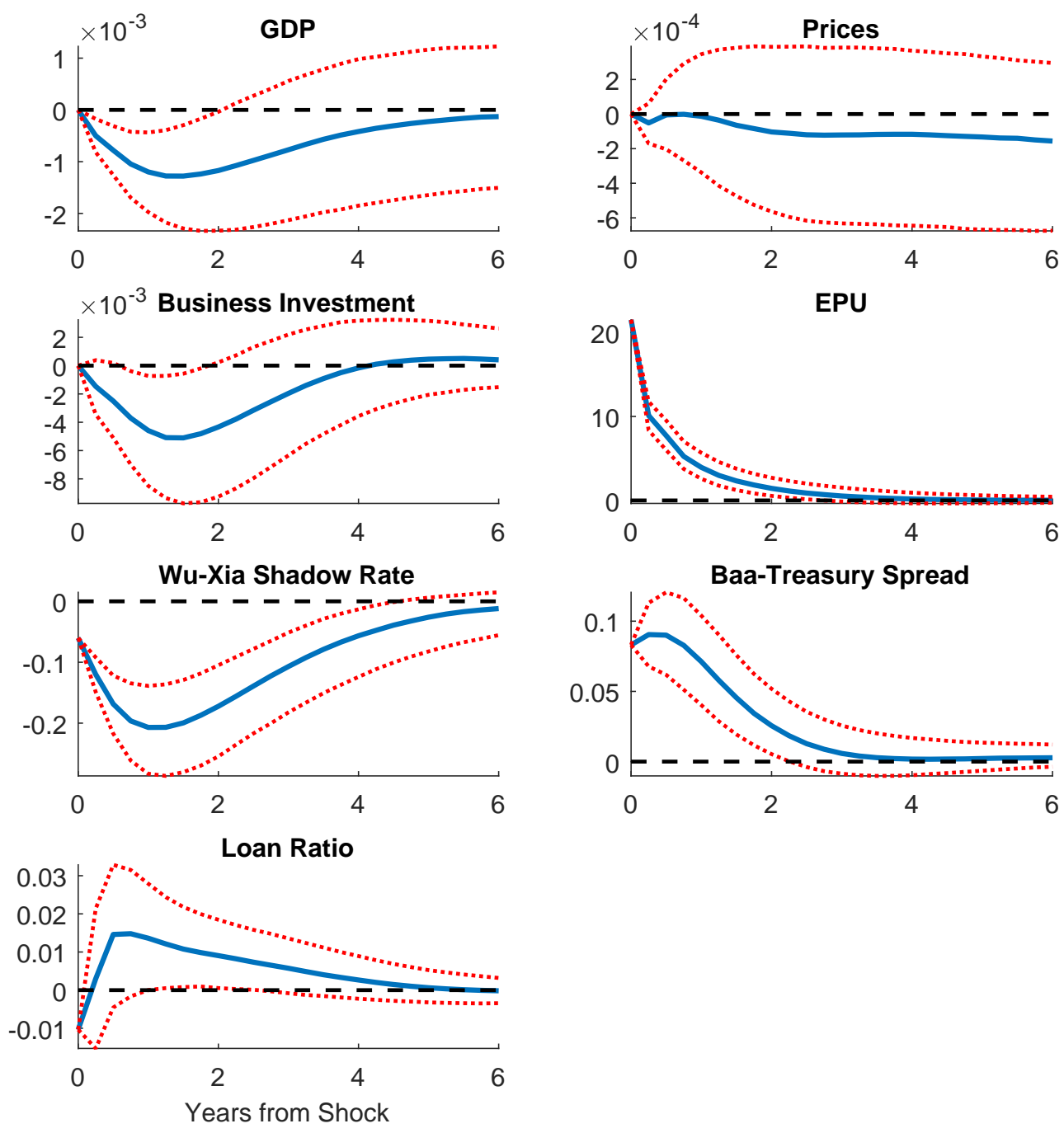

Figure A5: EPU and the Response of the Ratio of Loans Extended under Commitment to Spot Loans Extended by Small Banks from STBL, 1985:Q1-2017:Q1. Orthogonalized responses to a one-standard-deviation structural innovation of EPU. The model includes the log of real GDP, the log of the GDP deflator, the log of real gross business investment, the baseline overall EPU index, the Wu-Xia shadow rate, the 10-year Baa-Treasury credit spread, and the ratio of loans extended under commitment to spot loans extended by small domestic banks. $\operatorname{VAR}(2)$. Years from the shock on the x-axis. 

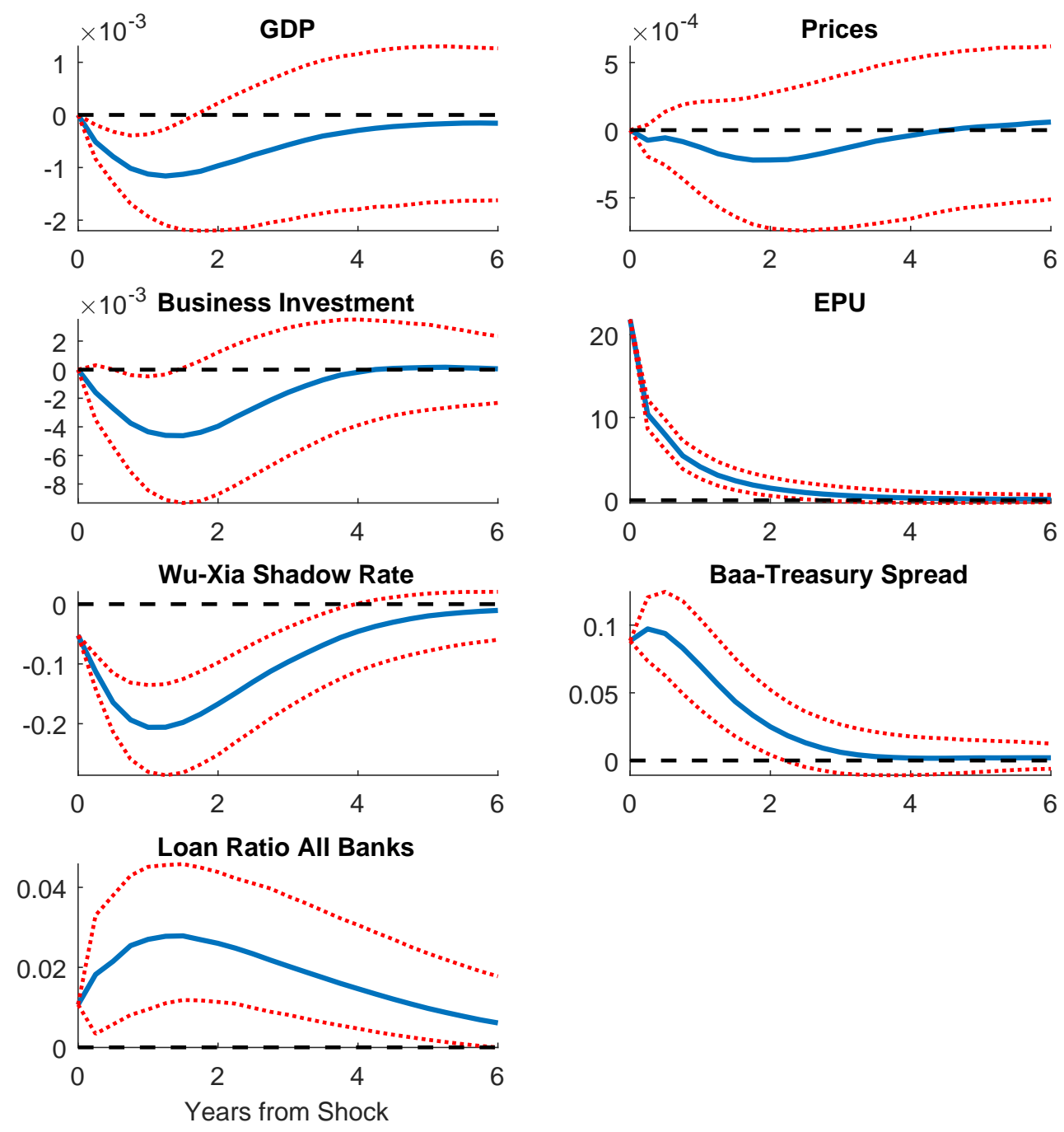

Figure A6: EPU and the Response of the Ratio of Loans Extended under Commitment to Spot Loans Extended by All Banks from STBL, 1985:Q1-2017:Q1. Orthogonalized responses to a one-standard-deviation structural innovation of EPU. The model includes the log of real GDP, the log of the GDP deflator, the log of real gross business investment, the baseline overall EPU index, the Wu-Xia shadow rate, the 10-year Baa-Treasury credit spread, and the ratio of loans extended under commitment to spot loans extended by all domestic banks. $\operatorname{VAR}(2)$. Years from the shock on the $\mathrm{x}$-axis. 

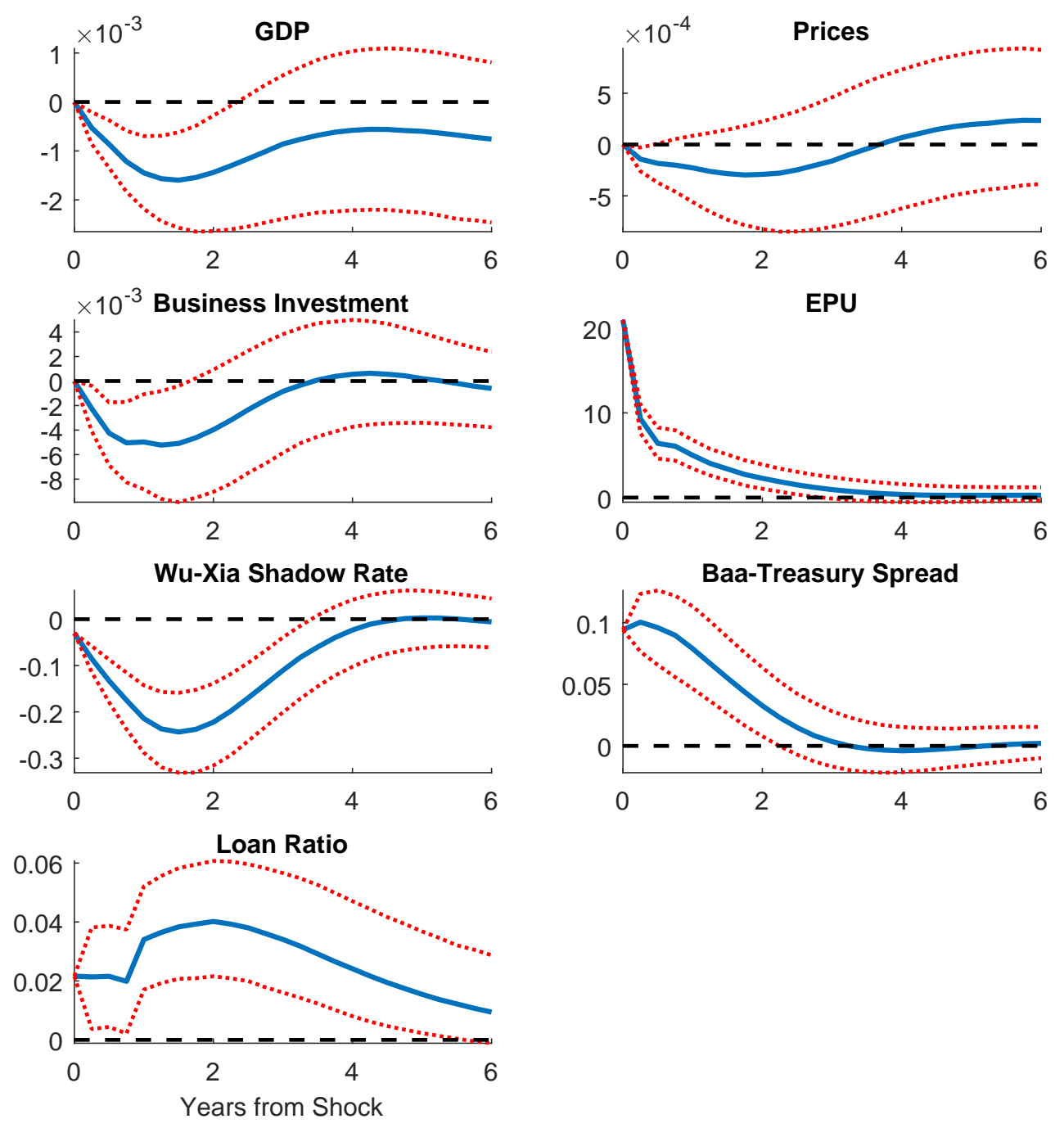

Figure A7: EPU and the Response of the Ratio of Loans Extended under Commitment to Spot Loans Extended by Large Banks from STBL, 1985:Q1-2017:Q1. Orthogonalized responses to a one-standard-deviation structural innovation of EPU. The model includes the $\log$ of real GDP, the log of the GDP deflator, the log of real gross business investment, the baseline overall EPU index, the federal funds rate, the 10-year Baa-Treasury credit spread, and the ratio of loans extended under commitment to spot loans extended by large domestic banks. $V A R(4)$. Years from the shock on the $\mathrm{x}$-axis. 

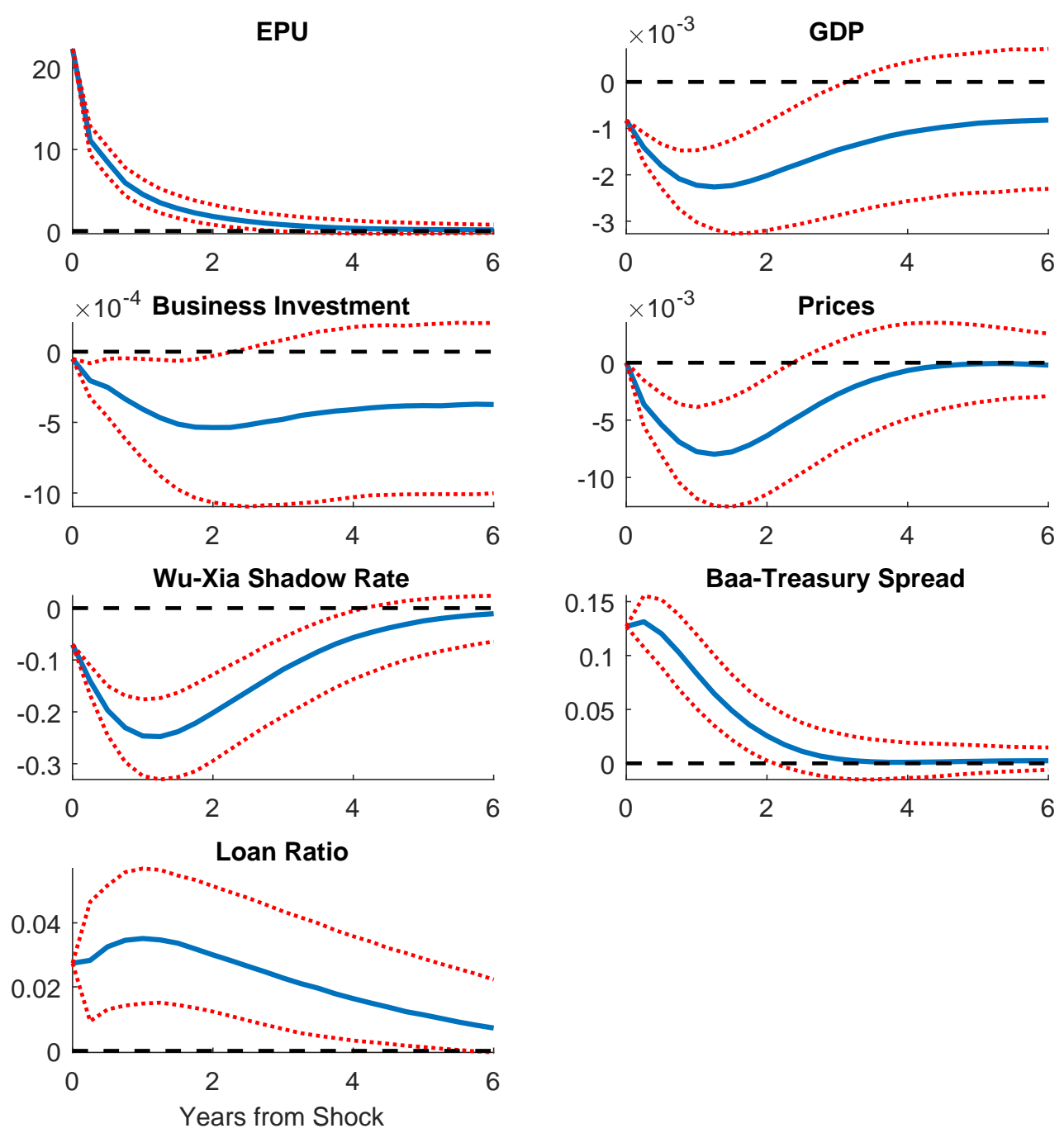

Figure A8: EPU and the Response of the Ratio of Loans Extended under Commitment to Spot Loans Extended by Large Banks from STBL, EPU First in the Recursive Ordering, 1985:Q1-2017:Q1. Orthogonalized responses to a one-standard-deviation structural innovation of EPU. The model includes the baseline overall EPU index, the log of real GDP, the log of the GDP deflator, the log of real gross business investment, the Wu-Xia shadow rate, the 10-year Baa-Treasury credit spread, and the ratio of loans extended under commitment to spot loans extended by large domestic banks. VAR(2). Years from the shock on the x-axis. 

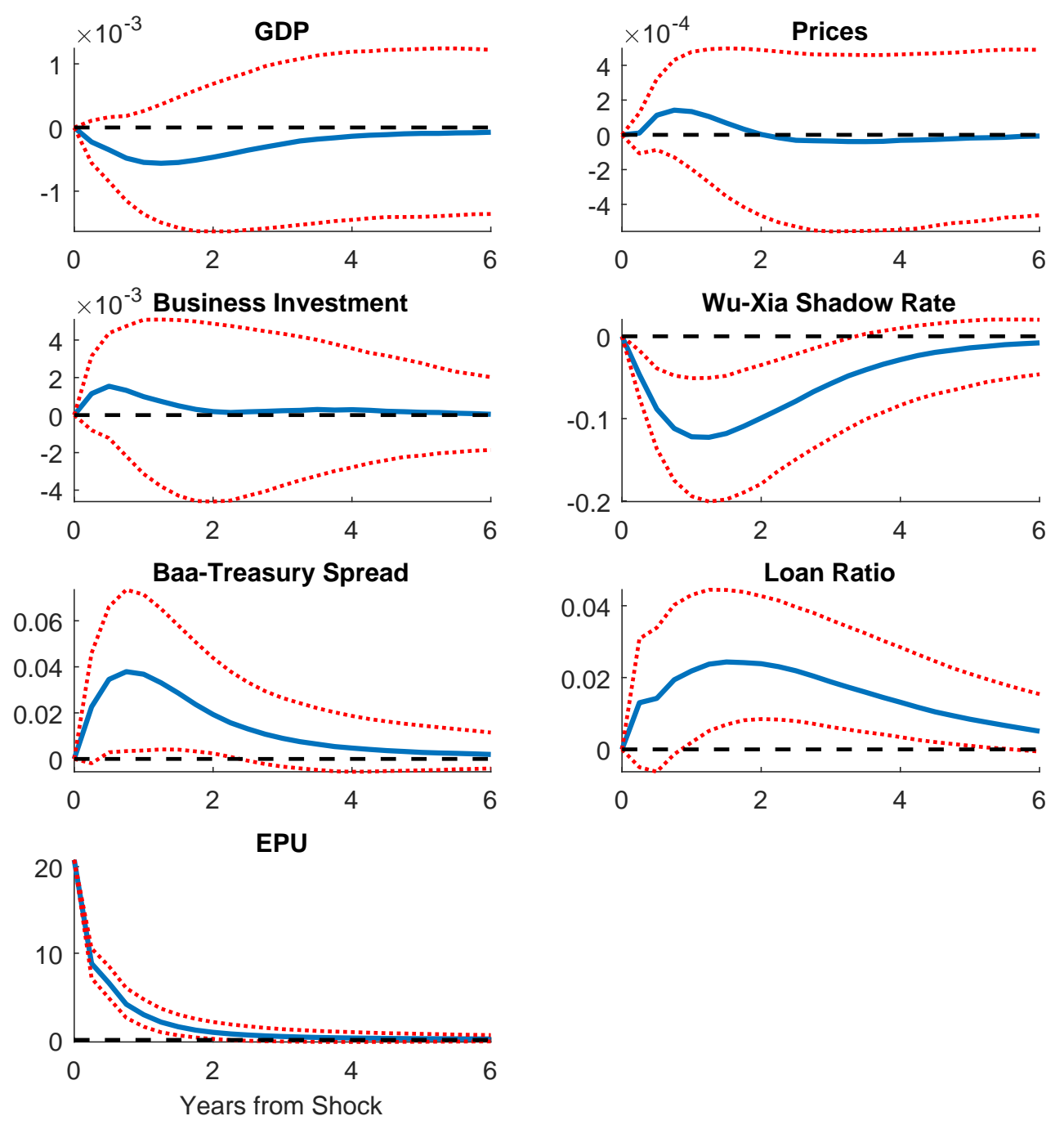

Figure A9: EPU and the Response of the Ratio of Loans Extended under Commitment to Spot Loans Extended by Large Banks from STBL, EPU Last in the Recursive Ordering, 1985:Q1-2017:Q1. Orthogonalized responses to a one-standard-deviation structural innovation of EPU. The model includes the log of real GDP, the log of the GDP deflator, the log of real gross business investment, the $\mathrm{Wu}-\mathrm{Xia}$ shadow rate, the ratio of loans extended under commitment to spot loans extended by large domestic banks, and the baseline overall EPU index. $\operatorname{VAR}(2)$. Years from the shock on the $\mathrm{x}$-axis. 

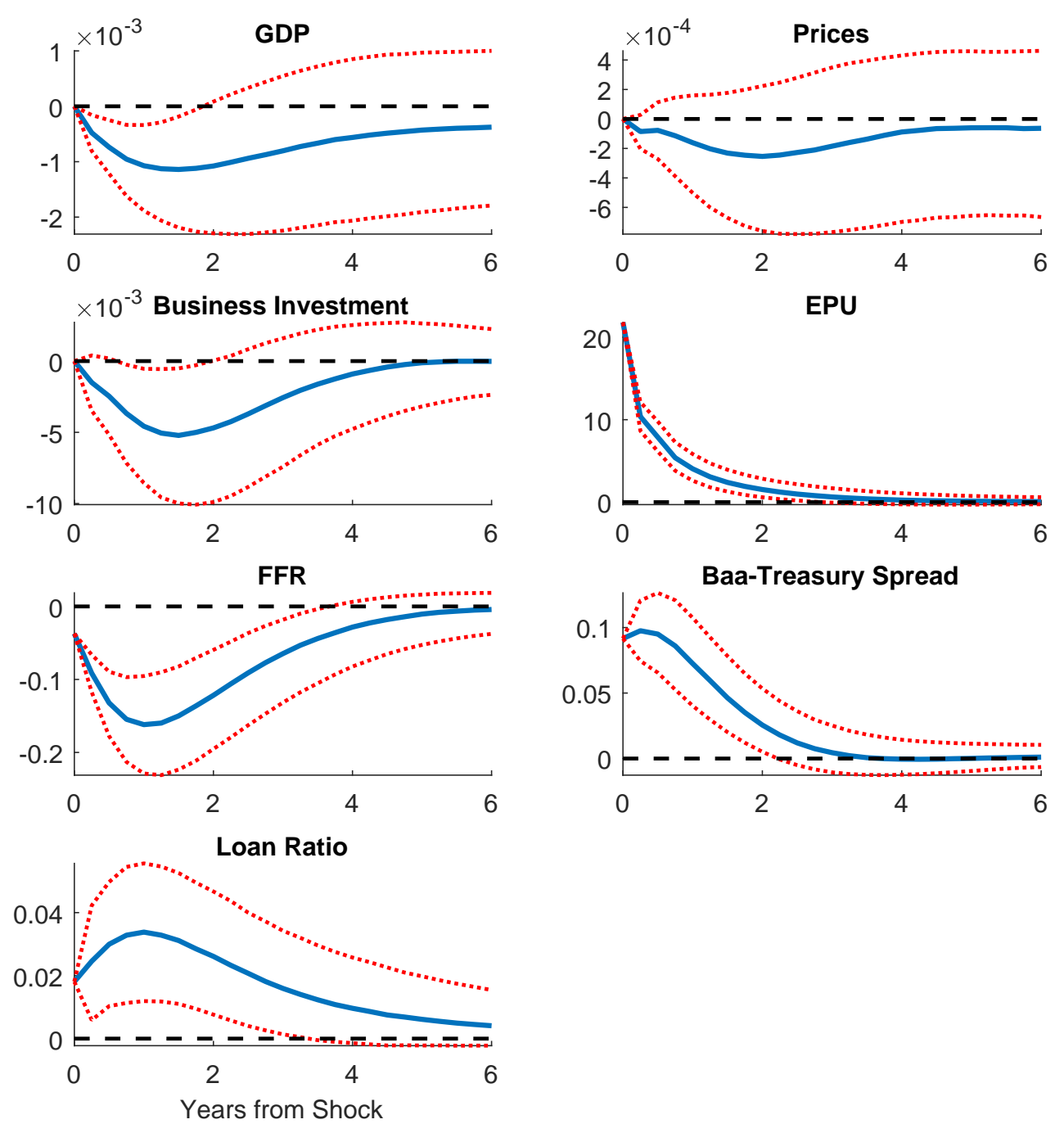

Figure A10: EPU and the Response of the Ratio of Loans Extended under Commitment to Spot Loans Extended by Large Banks from STBL, where Federal Funds Rate replaces the Wu-Xia Shadow Rate, 1985:Q1-2017:Q1. Orthogonalized responses to a one-standarddeviation structural innovation of EPU. The model includes the log of real GDP, the log of the GDP deflator, the log of real gross business investment, the baseline overall EPU index, the Federal Funds rate, the 10-year Baa-Treasury credit spread, and the ratio of loans extended under commitment to spot loans by large domestic banks. VAR(2). Years from the shock on the $\mathrm{x}$-axis. 


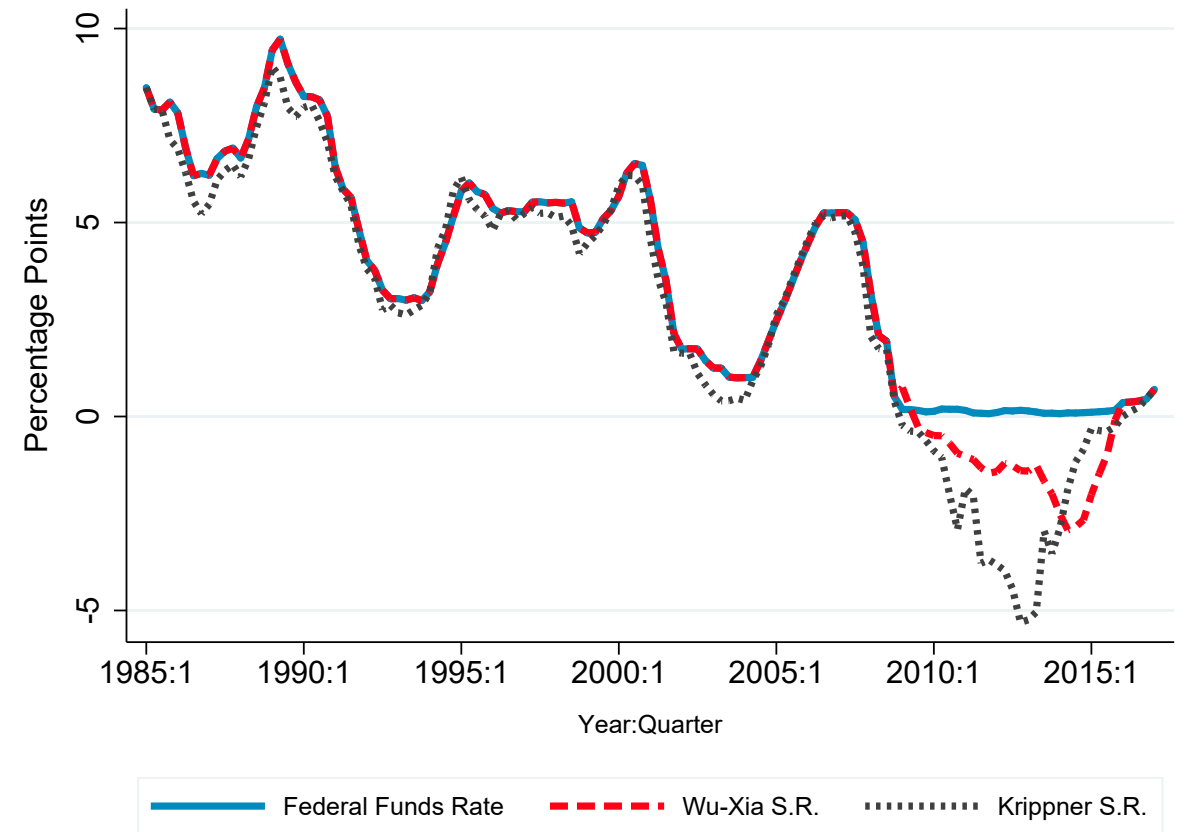

Figure A11: Monetary Policy Rates: Federal Funds Rate, Wu-Xia Shadow Rate, Krippner Shadow Rate. 

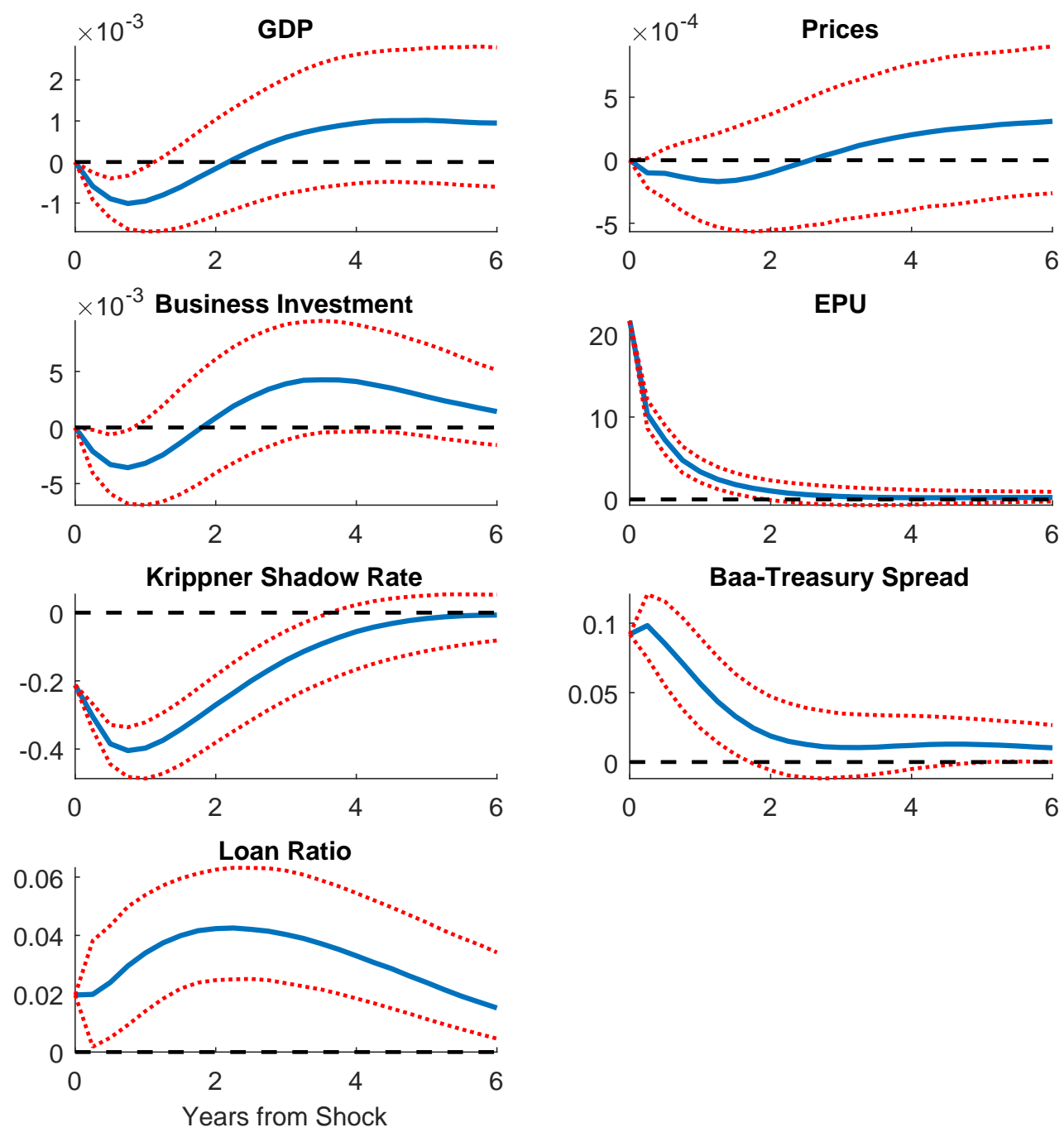

Figure A12: EPU and the Response of the Ratio of Loans Extended under Commitment to Spot Loans Extended by Large Banks from STBL, where the Krippner Shadow Rate replaces the Wu-Xia Shadow Rate, 1985:Q1-2017:Q1. Orthogonalized responses to a one-standarddeviation structural innovation of EPU. The model includes the log of real GDP, the log of the GDP deflator, the log of real gross business investment, the baseline overall EPU index, the Krippner shadow rate, the 10-year Baa-Treasury credit spread, and the ratio of loans extended under commitment to spot loans extended by large domestic banks. VAR(2). Years from the shock on the $\mathrm{x}$-axis. 

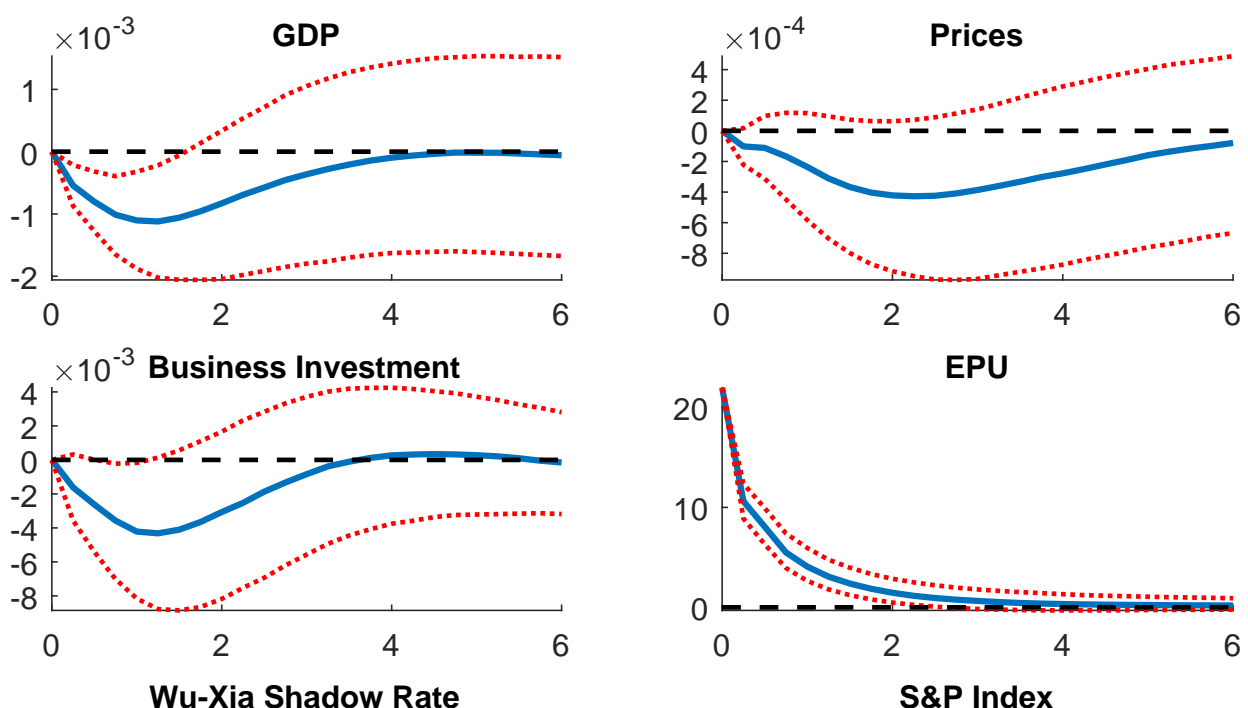

Wu-Xia Shadow Rate
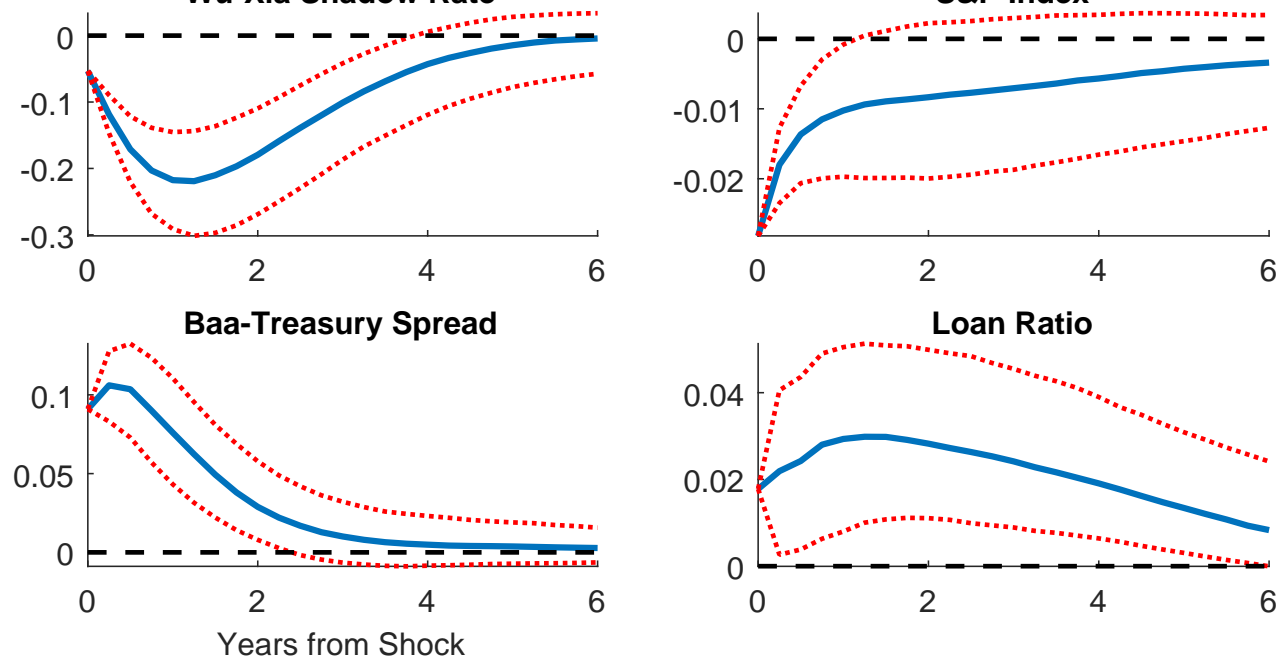

Figure A13: EPU and the Response of the Ratio of Loans Extended under Commitment to Spot Loans Extended by Large Banks from STBL, including the S\&PP Index, 1985:Q12017:Q1. Orthogonalized responses to a one-standard-deviation structural innovation of EPU. The model includes the log of real GDP, the log of the GDP deflator, the log of real gross business investment, the baseline overall EPU index, the Wu-Xia shadow rate, the log of the S\&P index, the 10-year Baa-Treasury credit spread, and the ratio of loans extended under commitment to spot loans extended by large domestic banks. VAR(2). Years from the shock on the $\mathrm{x}$-axis. 

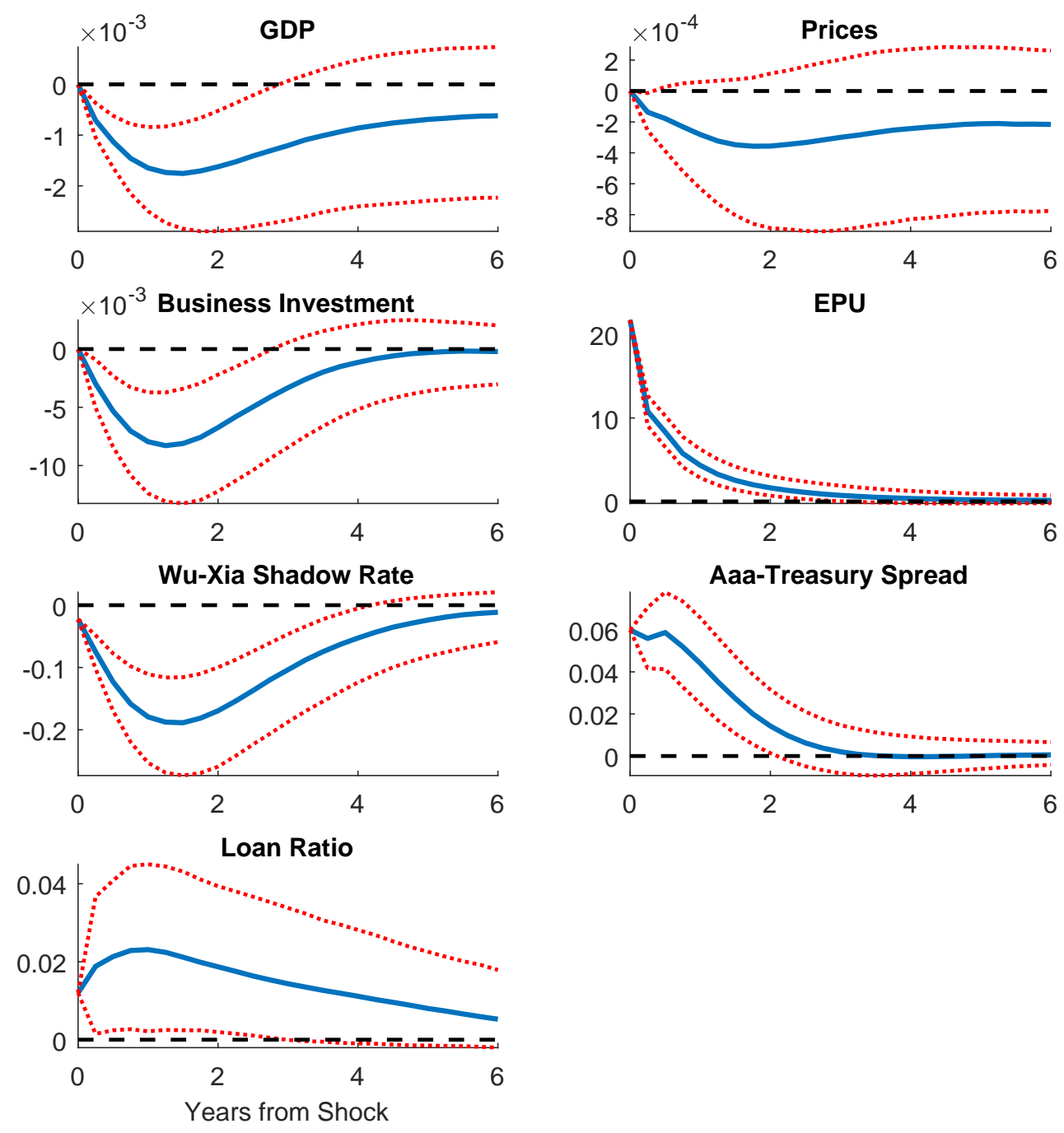

Figure A14: EPU and the Response of the Ratio of Loans Extended under Commitment to Spot Loans Extended by Large Banks from STBL, where the 10-year Aaa-Treasury Credit Spread replaces the 10-year Baa-Treasury Credit Spread, 1985:Q1-2017:Q1. Orthogonalized responses to a one-standard-deviation structural innovation of EPU. The model includes the log of real GDP, the log of the GDP deflator, the log of real gross business investment, the baseline overall EPU index, the Wu-Xia shadow rate, the 10-year Aaa-Treasury credit spread, and the ratio of loans extended under commitment to spot loans. VAR(2). Years from the shock on the x-axis. 

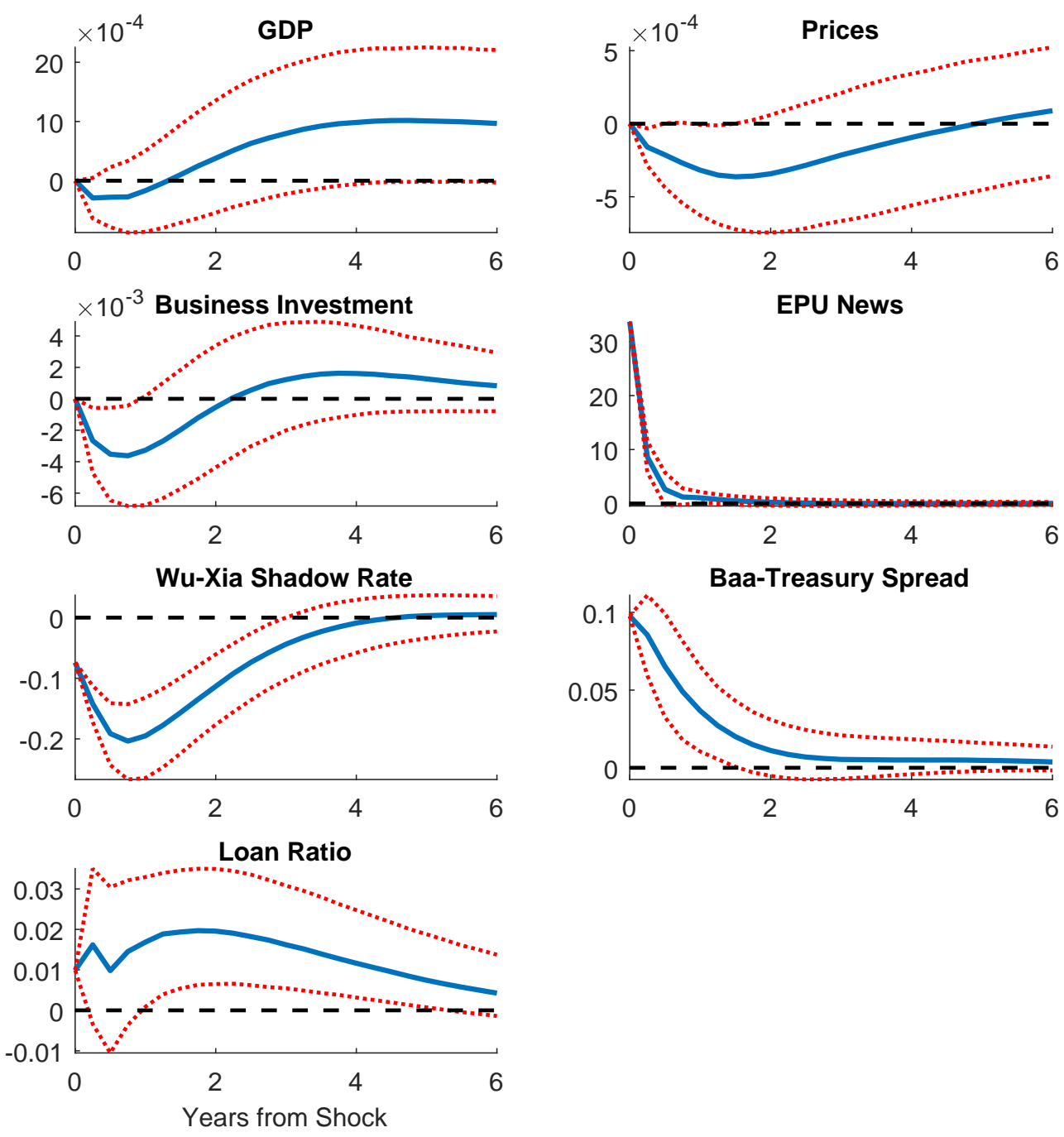

Figure A15: EPU News and the Response of the Ratio of Loans Extended under Commitment to Spot Loans Extended by Large Banks from STBL, 1985:Q1-2017:Q1. Orthogonalized responses to a one-standard-deviation structural innovation of EPU. The model includes the log of real GDP, the log of the GDP deflator, the log of real gross business investment, the EPU News index, the Wu-Xia shadow rate, the 10-year Baa-Treasury credit spread, and the ratio of loans extended under commitment to spot loans extended by large domestic banks. VAR(2). Years from the shock on the x-axis. 

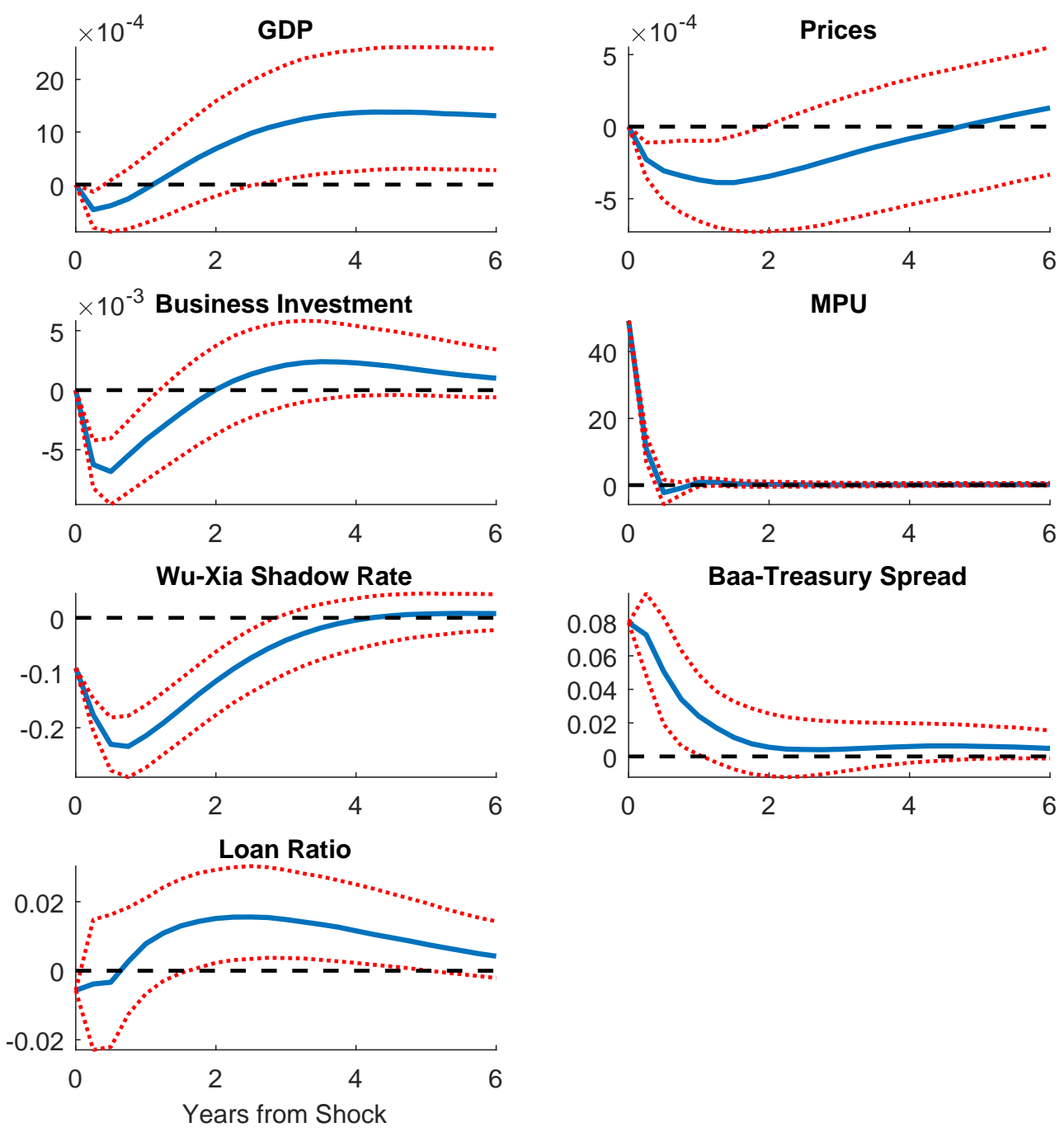

Figure A16: Monetary Policy Uncertainty and the Response of the Ratio of Loans Extended under Commitment to Spot Loans Extended by Large Banks from STBL, 1985:Q1-2017:Q1. Orthogonalized responses to a one-standard-deviation structural innovation of MPU. The model includes the $\log$ of real GDP, the $\log$ of the GDP deflator, the log of real gross business investment, Monetary Policy Uncertainty, the Wu-Xia shadow rate, the 10-year Baa-Treasury credit spread, and the ratio of loans extended under commitment to spot loans extended by large domestic banks. VAR(2). Years from the shock on the x-axis. 

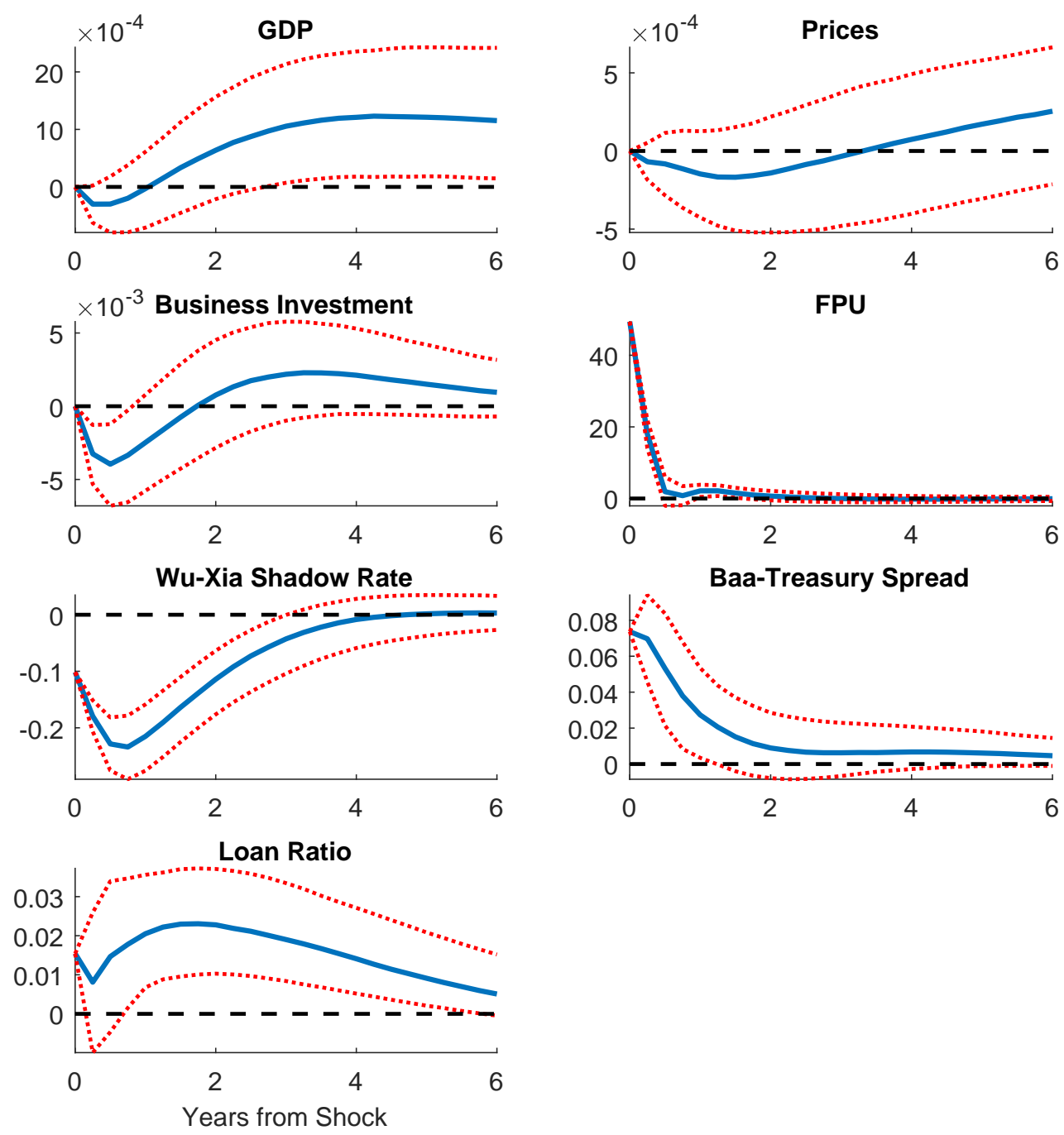

Figure A17: Fiscal Policy Uncertainty and the Response of the Ratio of Loans Extended under Commitment to Spot Loans Extended by Large Banks from STBL, 1985:Q1-2017:Q1. Orthogonalized responses to a one-standard-deviation structural innovation of FPU. The model includes the log of real GDP, the log of the GDP deflator, the log of real gross business investment, Fiscal Policy Uncertainty, the Wu-Xia shadow rate, the 10-year Baa-Treasury credit spread, and the ratio of loans extended under commitment to spot loans extended by large domestic banks. VAR(2). Years from the shock on the x-axis. 

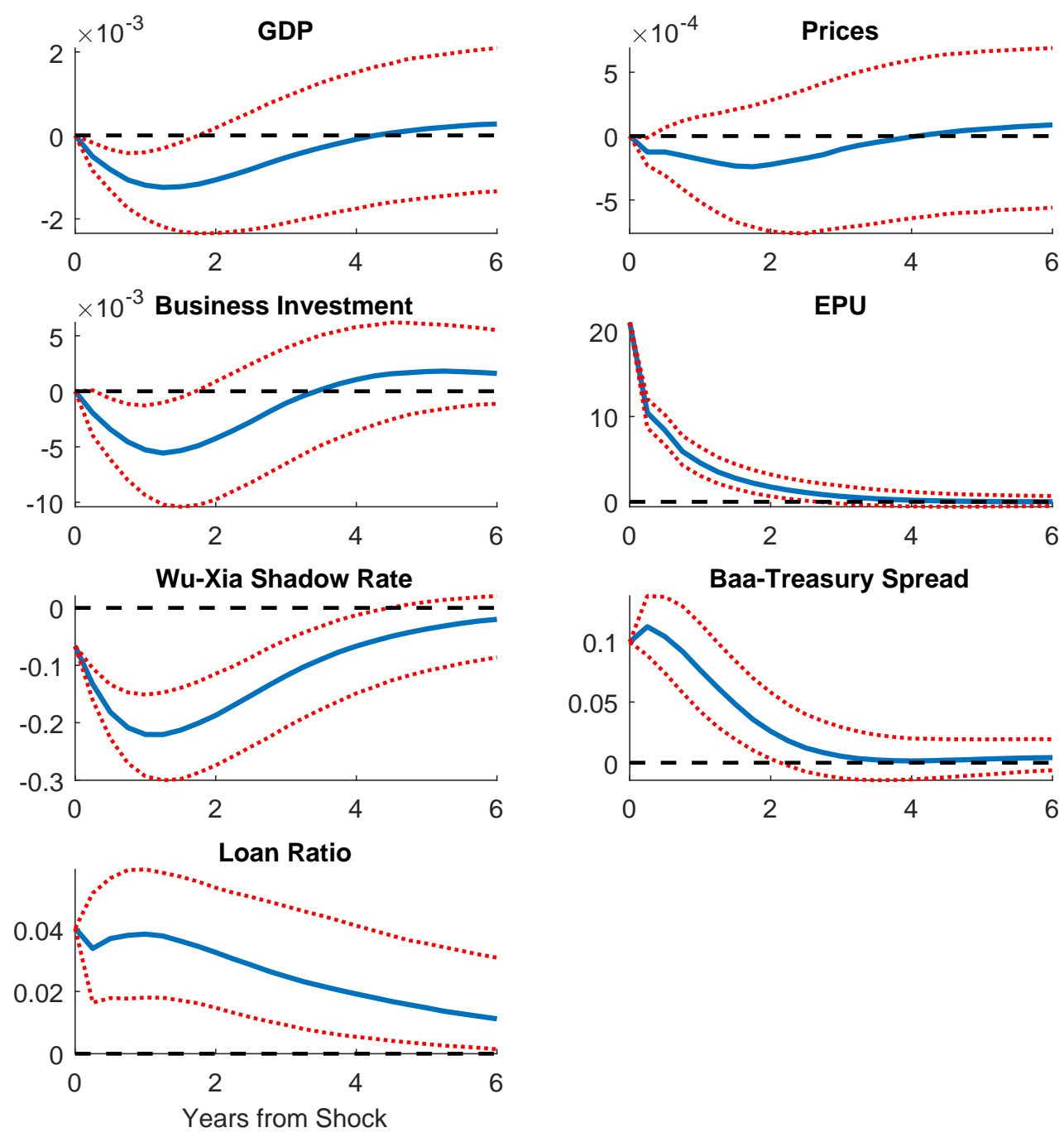

Figure A18: EPU and the Response of the Ratio of Loans Extended under Commitment to Spot Loans Extended by Large Banks from STBL, Baker, Bloom, and Davis (2016) Sample Period, 1985:Q1-2014:Q4. Orthogonalized responses to a one-standard-deviation structural innovation of EPU. The model includes the log of real GDP, the log of the GDP deflator, the log of real gross business investment, the baseline overall EPU index, the WuXia shadow rate, the 10-year Baa-Treasury credit spread, and the ratio of loans extended under commitment to spot loans extended by large domestic banks. VAR(2). Years from the shock on the $\mathrm{x}$-axis. 

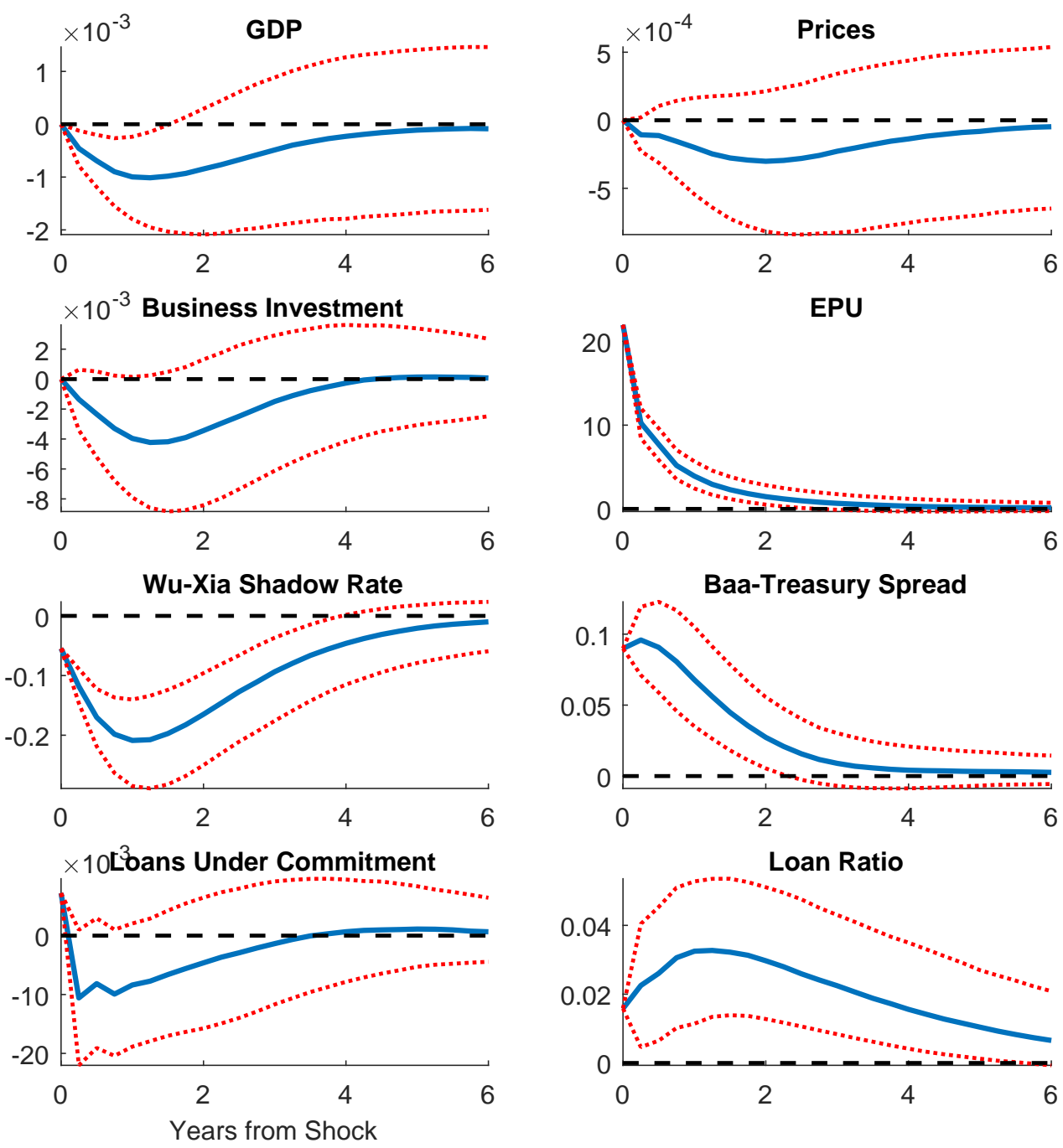

Figure A19: EPU and the Response of the Ratio of Loans Extended under Commitment to Spot Loans Extended by Large Banks from STBL, adding Loans extended under Commitment, 1985:Q1-2017:Q1. Orthogonalized responses to a one-standard-deviation structural innovation of EPU. The model includes the log of real GDP, the log of the GDP deflator, the log of real gross business investment, the baseline overall EPU index, the Wu-Xia shadow rate, the 10-year Baa-Treasury credit spread, the log of loans extended under commitment, and the ratio of loans extended under commitment to spot loans extended by large domestic banks. $\operatorname{VAR}(2)$. Years from the shock on the x-axis. 

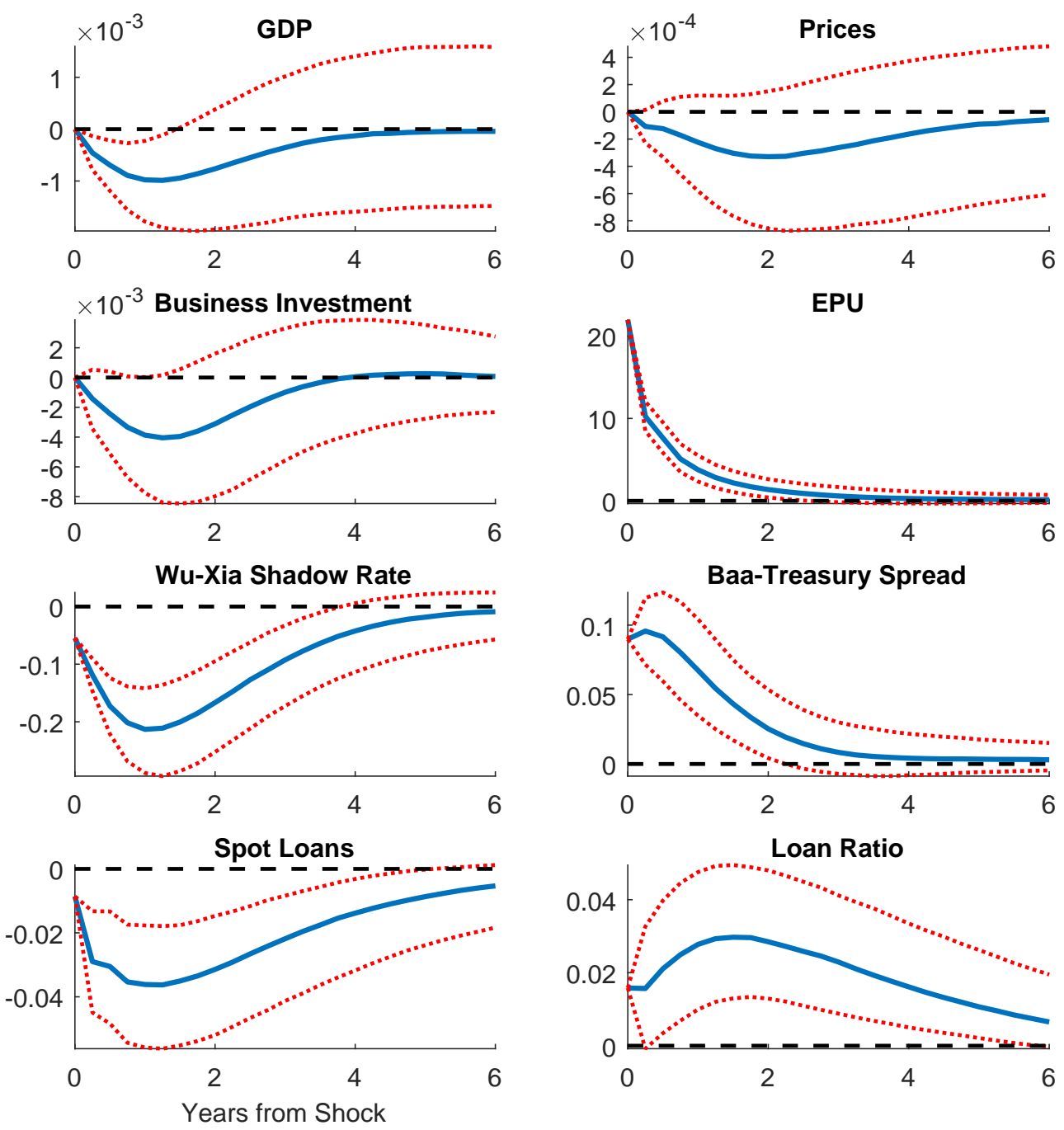

Figure A20: EPU and the Response of the Ratio of Loans Extended under Commitment to Spot Loans Extended by Large Banks from STBL, adding Spot Loans, 1985:Q1-2017:Q1. Orthogonalized responses to a one-standard-deviation structural innovation of EPU. The model includes the log of real GDP, the log of the GDP deflator, the log of real gross business investment, the baseline overall EPU index, the $\mathrm{Wu}$-Xia shadow rate, the 10-year Baa-Treasury credit spread, the log of spot loans, and the ratio of loans extended under commitment to spot loans. $\operatorname{VAR}(2)$. Years from the shock on the x-axis. 